\title{
SERI Biomass Program FY 1983 Annual Report
}

Robert E. Corder

Andrew M. Hill

Hilde Lindsey

Michael Z. Lowenstein

Robins P. McIntosh

Prepared under Task No. 1357.01

Solar Energy Research Institute

A Division of Midwest Research Institute

1617 Cole Boulevard

Golden, Colorado 80401

Prepared for the

U.S. Department of Energy

Contract No. DE-AC02-83CH10093 
Printed in the United States of America

Available from:

National Technical Information Service

U.S. Department of Commerce

5285 Port Royal Road

Springfield, VA 22161

Price:

Microfiche A01

Printed Copy A06

\section{NOTICE}

This report was prepared as an account of work sponsored by the United States Government. Neither the United States nor the United States Department of Energy, nor any of their employees, nor any of their contractors, subcontractors, or their employees, makes any warranty, express or implied, or assumes any legal liability or responsibility for the accuracy, completeness or usefulness of any information, apparatus, product or process disclosed, or represents that its use would not infringe privately owned rights. 


\section{PREFACE}

This report summarizes the progress and research accomplishments of the SERI Biomass Program during FY 1983. The SERI Biomass Program consists of three elements: Aquatic Species, Anaerobic Digestion, and Photo/ Biological Hydrogen. The program is funded through the Biomass Energy Technology Division of the Department of Energy (Beverly J. Berger, Director).

SERI has adopted several strategies to ensure that the data developed by the Biomass Program is transferred to other researchers and to the private sector. Involvement of industry in the early stages of research and development will help direct the program toward the development of operational systems as well as promote the transfer of the technical data base to private industry. Publication of data in peer-reviewed journals, in SERI publications, and proceedings of regular contractor review meetings will make SERI-sponsored research available to the scientific community in the public and private sectors.

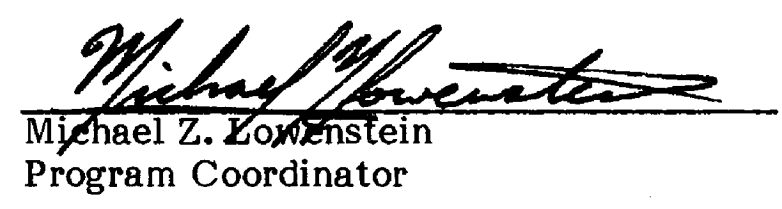

Approved for

SOLAR ENERGY RESEARCH INSTITUTE

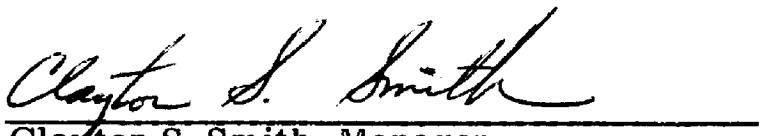

Clay ton S. Smith, Manager

Solar Fuels Research Division 


\section{SUMMARY}

\section{Objective}

To summarize the progress and research accomplishments of the SERI Biomass Program during FY 1983.

\section{Discussion}

Most products derived from petroleum and natural gas can be produced directly from biomass. The "biomass" with which this report is concerned includes aquatic plants, which can be converted into liquid fuels; organic wastes (crop residues as well as animal and municipal wastes), from which biogas can be produced via anaerobic digestion; and organic or inorganic waste streams, from which hydrogen can be produced by photobiological processes. The challenge is to develop technologies that will enable the production of fuels using nonrenewable resources and will be competitive with existing processes. The Biomass Program Office supports research in three areas which, although distinct, all use living organisms to create the desired products. The Aquatic Species Program (ASP) sponsors research on organisms that are themselves processed into the final products, while the Anaerobic Digestion (ADP) and Photo/Biological Hydrogen Program (P/BHP) deals with organisms that transform waste streams into energy products. The P/BHP also supports investigation of systems using water as a feedstock and cell-free systems which do not utilize living organisms. 


\section{TABLE OF CONTENTS}

$\underline{\text { Page }}$

1.0 Introduction $\ldots \ldots \ldots \ldots \ldots \ldots \ldots \ldots \ldots \ldots \ldots \ldots \ldots \ldots \ldots \ldots \ldots \ldots \ldots \ldots$

2.0 Program Element: Aquatic Species........................ 3

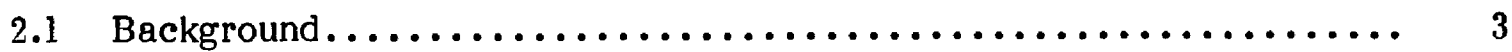

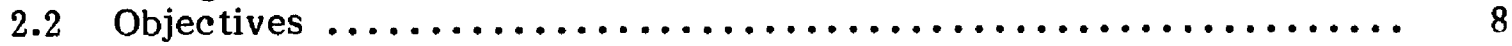

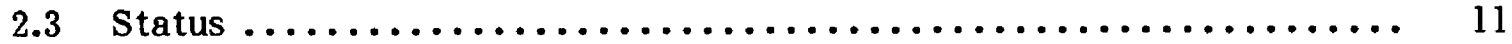

2.3.1 Biological Research ........................ 11

2.3.2 Engineering Research and Development $\ldots \ldots \ldots \ldots \ldots \ldots \ldots \ldots \quad 30$

2.3.3 Technology Analysis ........................ 37

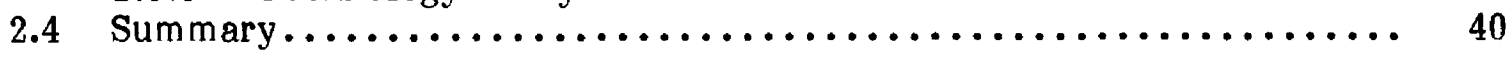

3.0 Anaerobic Digestion Subprogram $\ldots \ldots \ldots \ldots \ldots \ldots \ldots \ldots \ldots \ldots \ldots \ldots$

$3.1 \quad$ Background...................................... 43

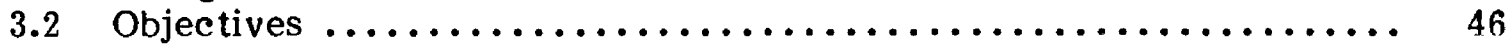

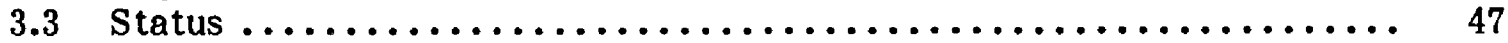

3.3.1 Pretreatment................................. 47

3.3.2 Biological Processes ............................. 58

3.3.3 Engineering Parameters ....................... 63

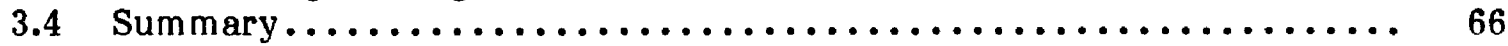

3.5 References........................................ 67

$4.0 \quad$ Photo/Biological Hydrogen Subprogram ..................... 68

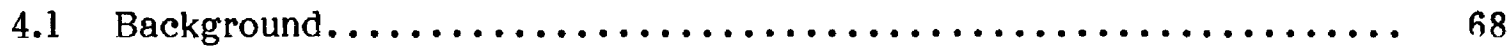

4.1.1 Whole-Cell Hydrogen Technologies ................. 68

4.1.2 Cell-Free Hydrogen Technologies.................. 70

4.1.3 Biochemical Engineering Research................ 70

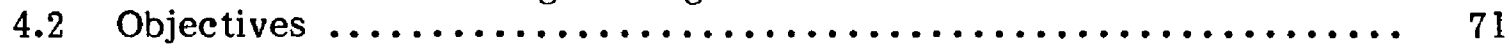

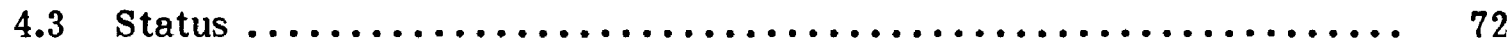

4.3.1 Whole-Cell Research ........................ 72

4.3.2 Cell-Free Research......................... 81

4.3.3 Biochemical Engineering Research................ 85

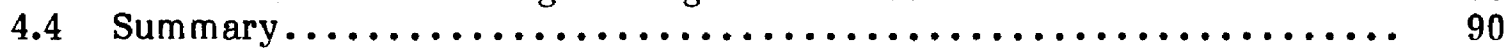

5.0 Publications $\ldots \ldots \ldots \ldots \ldots \ldots \ldots \ldots \ldots \ldots \ldots \ldots \ldots \ldots \ldots \ldots \ldots \ldots \ldots \ldots \ldots$

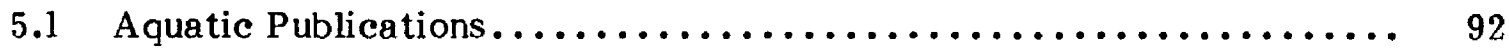

5.2 Anaerobic Digestion Publications ..................... 93

5.3 Photo/Biological Hydrogen Publications .................. 98

6.0 Meetings and Presentations $\ldots \ldots \ldots \ldots \ldots \ldots \ldots \ldots \ldots \ldots \ldots \ldots \ldots \ldots \ldots \ldots$

$6.1 \quad$ Aquatic Species Program $\ldots \ldots \ldots \ldots \ldots \ldots \ldots \ldots \ldots \ldots \ldots \ldots \ldots \ldots \ldots$

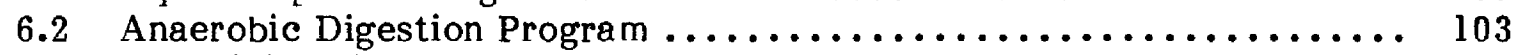

6.3 Photo/Biological Hydrogen Program $\ldots \ldots \ldots \ldots \ldots \ldots \ldots \ldots \ldots \ldots \ldots \ldots$ 


\section{LIST OF FIGURES}

Page

2-1a Cells of the Microalga Chlorella That Have Been Stained

for Oils $(50 \%$ of dry weight $) \ldots \ldots \ldots \ldots \ldots \ldots \ldots \ldots \ldots \ldots \ldots \ldots \ldots \ldots$

2-1b Oils from Microalgae Fractions into 5 Classes: Hydrocarbons

Isoprenoids, Triglycerides, Glycolipids, and Phosopholipids ............ 4

2-2a Shallow Raceway System Operated in Hawaii $\ldots \ldots \ldots \ldots \ldots \ldots \ldots \ldots \ldots$

2-2b Deeper Pond System Operated in California................... 7

2-3a Locations of Saline Groundwater Reservoirs in the Southwest

United States .................................. 9

2-3b Typical Southwest Desert Area........................ 9

2-4 Modified Burial Vaults at Harbor Branch Are Ideal for Screening

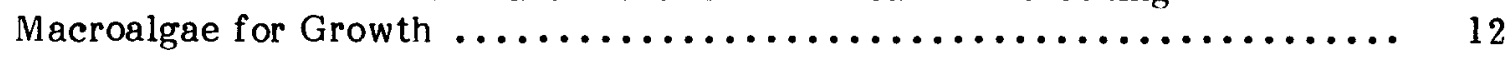

2-5 Relative Oxygen Production vs. $\mathrm{pH}(\mathrm{TIC} \approx 0.5 \mathrm{~m} \mathrm{M}) \ldots \ldots \ldots \ldots \ldots \ldots$

2-6 Schematic of Strategy for Comprehensive Screening of

Microalgae Strains ................................ 17

2-7a Collection of Microalgae from Saline Desert Regions.............. 18

2-7b Growth Studies of Selected Species Using Chemostats ............ 18

2-7c Studies of the Lipid Fractions Produced by the Microalgae .......... 19

2-8 General Locations of Areas Sampled in the Desert of Eastern

California and Western Nevada........................... 20

2-9a Ankistrodesmus falcatus Isolated from Pyramid Lake............. 24

2-9b Increases in Optical Density of Pyramid Lake Ankistrodesmus

Cultures Grown on Nitrate and Urea $\ldots \ldots \ldots \ldots \ldots \ldots \ldots \ldots \ldots \ldots \ldots \ldots \ldots$

2-10 Growth Curve of Ankistrodesmus to Salinity and Temperature ......... 25

2-11 Physiological Responses of Chlorella Nitrogen-Limitation............ 29

2-12 Changes in Cell Volume as a Result of Nitrogen Deprivation............ 29

2-13 Cost of Production Versus Market Volume $\ldots \ldots \ldots \ldots \ldots \ldots \ldots \ldots \ldots \ldots \ldots$

2-14 Algal Production Flume, Including Location of Heat Exchanger,

Lift Box, Drain Box, and Airlift System .................. 33 


\section{LIST OF FIGURES (Continued)}

Page

2-15 Pond System Operated by Microbial Products Co. $\ldots \ldots \ldots \ldots \ldots \ldots \ldots \ldots . \ldots 33$

2-16a Systematic Mixing Resulting from Foils Inserted in the Shallow

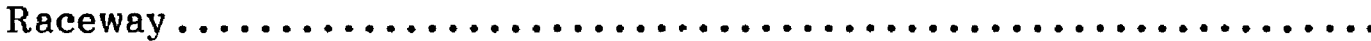

2-16b Ratio of Growth Rate under Ideal Flashing Light Regime to Growth Rate in Absence of Flashing Light Effect as a Function of Incident

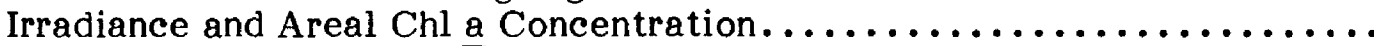

2-17 Production in Experimental Flumes as a Function of $\mathrm{pH}$ and Dilution Rate

2-18a Resource Data Mapping from Baseline Parameter Maps through Intermediate Composite Maps to the Final Composite Stratification

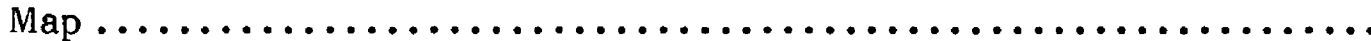

2-18b Computer-Generated Map of Overall Suitability for Microalgae

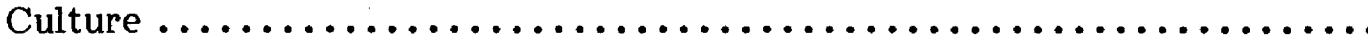

3-1 Effect of $\mathrm{pH}$ and Temperature on the First-Order Rate Constant

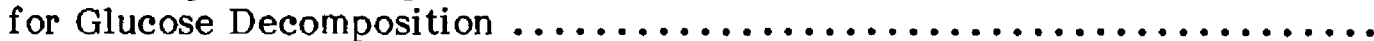

3-2 Effects on $\mathrm{pH}$ on the Products Formed from Glucose Decomposition with Thermochemical Treatment at Different Temperatures and Times

3-3 Overall Experimental Scheme for Manure/Residue Digestion $\ldots \ldots \ldots \ldots$

3-4 pH Stat Schematic Diagram $\ldots \ldots \ldots \ldots \ldots \ldots \ldots \ldots \ldots \ldots \ldots \ldots \ldots \ldots \ldots$

3-5 The $110-m^{3}$ Dry Fermentation Shown Loaded with Straw Prior to

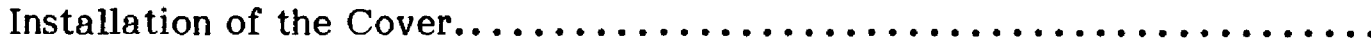

4-1 Z-Scheme of Photosynthesis Showing the Flow of Electrons from Water to Hydrogen Evolution or Carbon Fixation under the Influence of Light

4-2 Akira Mitsui Examines Strains Isolated from Tropical Marine Environments

4-3 Reconstitution of Nitrogenase Activity by Periplasmic Fraction

4-4 Apparatus for Simultaneous Measurement of Hydrogen and Oxygen Evolution in Algae.................................... 76

4-5 Phase-Contrast Photomicrographs $\ldots \ldots \ldots \ldots \ldots \ldots \ldots \ldots \ldots \ldots \ldots \ldots$ 


\section{LIST OF FIGURES (Concluded)}

4-6 Restriction Maps (partial) for Recombinant Plasmids Containing

Page

Hydrogenase/Hydrogen Uptake Genes .......................

4-7 Restriction Map of E. Coli Recombinant Plasmid pSE-22 and the Subclones Derived from Plasmid pSE-22. .................. 80

4-8 An Electrostatic Model for Hydrogenase-Mediator Interaction .......... 83

4-9 Mike Seibert Adjusts Apparatus for Measuring Oxygen Evolution from Photosystem II Preparations ......................... 84

4-10 Flash Yield Sequences of an Oxygen-Evolving Preparation ........... 85

4-11 Flash-Sequence Patterns of Oxygen Evolution in Photosystem II Preparations Resulting from Sequential Removal of 3 Proteins (18, 23 , and $33 \mathrm{kDa}$ ) from the Oxygen-Evolving Complex.............. 86

4-12 Field Test Reactor Unit $\ldots \ldots \ldots \ldots \ldots \ldots \ldots \ldots \ldots \ldots \ldots \ldots \ldots \ldots \ldots \ldots$

4-13 Thermal Network in SOLBUG $\ldots \ldots \ldots \ldots \ldots \ldots \ldots \ldots \ldots \ldots \ldots \ldots \ldots \ldots$ 


\section{LIST OF TABLES}

Page

2-1 Composition of Microalgae, Macroalgae, and Emergent Plants as

Found in Natural Stands and, in the Case of Microalgae, after

Laboratory Manipulation

2-2 Aquatic Species Program Tasks, Subtasks, Projects, and Principal

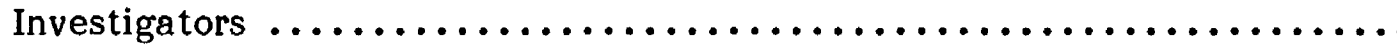

2-3 Lipid Composition of Selected Macrophytes ................... 15

2-4 Cultures of Desert Algae Isolated and Maintained by the Scripps

Project in FY 1983

2-5 Yields and Proximate Cellular Chemistry of Selected Desert

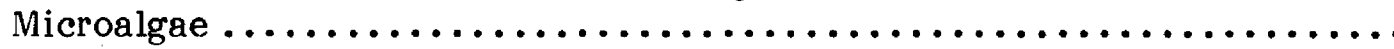

2-6 Responses of Some Saline Desert Algae to Temperature and

Salinity

2-7 Proximate Cellular Composition of Unicellular Algae Grown Under

Optimal, Nitrate-Deficient, or Salt Stress Conditions .............. 26

2-8 Fractionation of Algal Lipids on Unisil Columns $\ldots \ldots \ldots \ldots \ldots \ldots \ldots \ldots \ldots$

2-9 Comparison of Growth Responses and Lipid Content of Six Strains

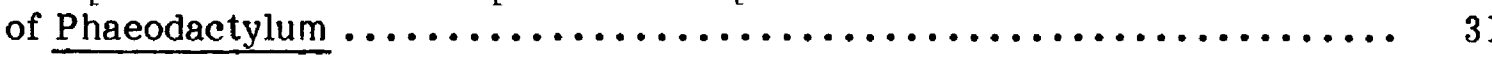

2-10 Performance Data from Raceway and Pond Systems $\ldots \ldots \ldots \ldots \ldots \ldots \ldots$

2-11 Chemical Characteristics of Water from California and Nevada

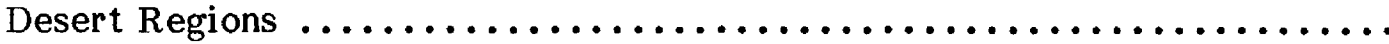

2-12 World Oil Price Projections for High, Middle, and Low World Oil

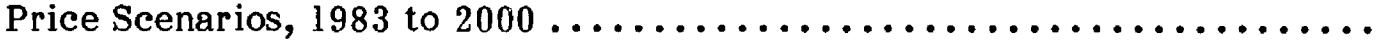

3-1 Anaerobic Digestion Program Tasks and Projects ................ 46

3-2 The Cyclic Voltammetry of Sugars Using a Glassy Carbon Electrode....... 55

3-3 Results of Electrolytic Experiments Using Levoglucosan $\ldots \ldots \ldots \ldots \ldots \ldots \ldots$

3-4 Pretreatment Process Variables Tested..................... 57

3-5 Effect of Alkaline Pretreatment of Straw on Methane Yield.......... 58

4-1 Photo/Biological Hydrogen Program Tasks, Subtasks, and Projects ....... 71

4-2 Light-Saturated Rates of $\mathrm{H}_{2}$ and $\mathrm{O}_{2}$ Photoproduction in

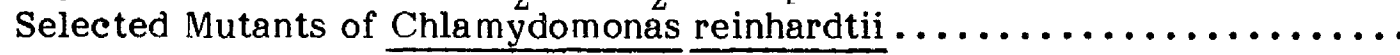




\section{LIST OF TABLES (Concluded)}

$\underline{\text { Page }}$

4-3 Results of Materials Analysis for Photosynthetic Bacterial

Reactors ..................................... 87

4-4 Possible Polymer Covers for Photosynthetic Bacterial

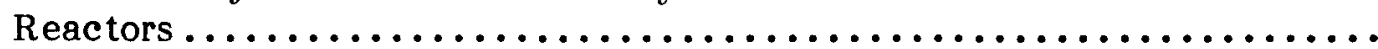

4-5 Comparison of Gas Permeation Rates Measured at SERI with Those Obtained from Manufacturer for Two Candidate Cover Materials 


\section{SECTION 1.0}

\section{INTRODUCTION}

Most products derived from petroleum and natural gas can be produced directly from biomass. The "biomass" with which this report is concerned includes aquatic plants, which can be converted into liquid fuels; organic wastes (crop residues as well as animal and municipal wastes), from which biogas can be produced via anaerobic digestion; and organic waste streams or water, from which hydrogen can be produced by photobiological processes. The challenge is to develop technologies that will enable the production of fuels using nonrenewable resources and will be competitive with existing processes. This challenge provides important opportunities for research in biomass production and conversion technologies.

The Biomass Program Office sponsors research in three areas which, although distinct, all use living organisms to create the desired products. The Aquatic Species Program (ASP) supports research on organisms that are themselves processed into the final products, while the Anaerobic Digestion (ADP) and Photo/Biological Hydrogen Programs (P/BHP) deal with organisms that transform waste streams into energy products. The $\mathrm{P} / \mathrm{BHP}$ also supports investigation of systems using water as a feedstock and cell-free systems which do not utilize living organisms.

The aquatic species program addresses the development of processes that utilize aquatic plants in the renewable production of fuels and chemicals. Emphasis is placed on salttolerant species for cultivation on poorly utilized, low-value lands where conventional agriculture is not economical. Candidate species include microalgae-unicellular plants capable of converting sunlight into high quality oils; macroalgae-large, chemically unique plants that can be easily fermented to methane or alcohols; and emergents-plants that grow rooted in waterways and bogs, but are partially exposed above water, which can also be converted to methane or alcohols.

The anaerobic digestion process has been used for years to obtain a useful energy product (methane gas) from very wet or otherwise low-quality biomass resources. Relatively unsophisticated, low-cost processes are possible, and anaerobic fermenters based on manure or other sewage feedstocks are well addressed outside the DOE program. Less well developed are fermenters utilizing crop residues and other cellulosic materials as feedstock, and these are, therefore, the main thrusts of the ADP. The bacteriological processes functioning within these systems are multistep and complex and are only now being delineated and understood. Since the development of low-cost manure fermenters is relatively far along in the commercialization stage, the primary research opportunity lies in the investigation, understanding, and biological control of the anaerobic digestion process with a view toward greater digester efficiency, better crop residue utilization, and possible energy product selectivity.

The photobiological hydrogen program address the understanding of processes that can produce hydrogen either from organic waste streams or by direct splitting of water. Emphasis is placed on understanding the organisms, both unicellular plants (algae) and photosynthetic bacteria, that can accomplish hydrogen production, and in determining the mechanisms of photosynthesis that are utilized by these organisms. 
The remainder of this report is organized into five sections: Section 2.0 discusses the Aquatic Species Program: Section 3.0 concerns the Anaerobic Digestion Program; Section 4.0 outlines the Photo/Biological Hydrogen Program; and Sections 5.0 and 6.0 lists the year's publications and meetings, respectively. 


\section{SECTION 2.0}

\section{PROGRAM ELEMENT: AQUATIC SPECIES}

\subsection{BACKGROUND}

The worldwide energy shortage and Arab oil embargo of the early 1970s encouraged many nations to look for new sources of oil, electricity, and gas. Renewable resources such as biomass were often highlighted as a long-term solution to the energy problem, due to their nondepletable, renewable nature. While the first biomass sources considered were the readily available ones such as corn or wood, it was apparent that new biomass sources should also be developed, among them aquatic plant species. Aquatic plant species may be divided into three distinct groups: macroalgae, emergent plants, and microalgae. Macroalgae range in size and morphology from small simple filamentous plants to very large, complex seaweeds, such as Macrocystis (giant kelp). Macroalgae may grow attached (Macrocystis) or free floating (Sargassum, Gracilaria). The predominant storage product of macroalgae is carbohydrate, which can be harvested for fermentation to methane or alcohol. Emergent plants are vascular plants common to bogs, and fresh or salt marshes, rooted in the substratum. Familiar genera with potential for energy production include Typha (cattail), Scripus (rush), and Phragmites (reed). The emphasis of the Aquatic Species program has been on the production of microalgae (Figure 2-1). Microalgae are unicellular plants that range in size from 1 to $10 \mu \mathrm{m}$.

The production of microalgal biomass has been studied for about 4 decades. Its potential to provide food, feed, and energy for mankind has been the reason for increasing interest in these organisms. Microalgae was also contain high amounts of fats and oils (lipids). They are produced by direct use of the sun's energy via photosynthesis. In principle, lipids from microalgae are suitable for refining into conventional liquid fuels. Indeed, in the past, biological oils have been refined to fuels during shortages in petroleum supply. In 1980, Aaronson and Dubinsky proposed using saline water resources and arid land to produce microalgae for oils. They also projected that these microalgal oils could be used as a source of fuel.

The chemical composition of these microalgae includes three classes of organic compounds--proteins, carbohydrates, and lipids-and inorganic minerals, generally referred to as ash. Proteins are either enzymatic or structural. Enzymes act as catalysts in the metabolism of the cell. It is the high protein content (up to 60\%) that makes the microalgae metabolic factories. Carbohydrates are used by the cell for energy storage (sugars, and starch) or have a structural function (cellulose). Macroalgae and emergent plants are extremely high in carbohydrates (up to $85 \%$ of the organic weight). Lipids are compounds that, like carbohydrates, may be used for energy storage (triglycerides) or have structural functions (phospholipids in the membrane). Lipids have the highest energy content per unit weight of the three classes of compounds (lipid, $9.2 \mathrm{kcal} / \mathrm{g}$; carbohydrate, $3.7 \mathrm{kcal} / \mathrm{g}$; protein, $5.7 \mathrm{kcal} / \mathrm{g}$ ). They may be utilized directly as liquid fuel replacement products, and thus are of great interest as a renewable energy source. Certain microalgae, such as diatoms, synthesize large quantities of lipids.

The metabolic states of photosynthetic organisms may be changed as well as the cellular chemical compositions, by culture manipulation. Thus potential exists for manipulating plants to produce large quantities of the desired energy products. Table 2-1 presents data on the plant composition found in nature and, for microalgae, the composition after culture manipulation. As indicated lipid composition is highly variable and can be drastically increased through culture manipulation. 


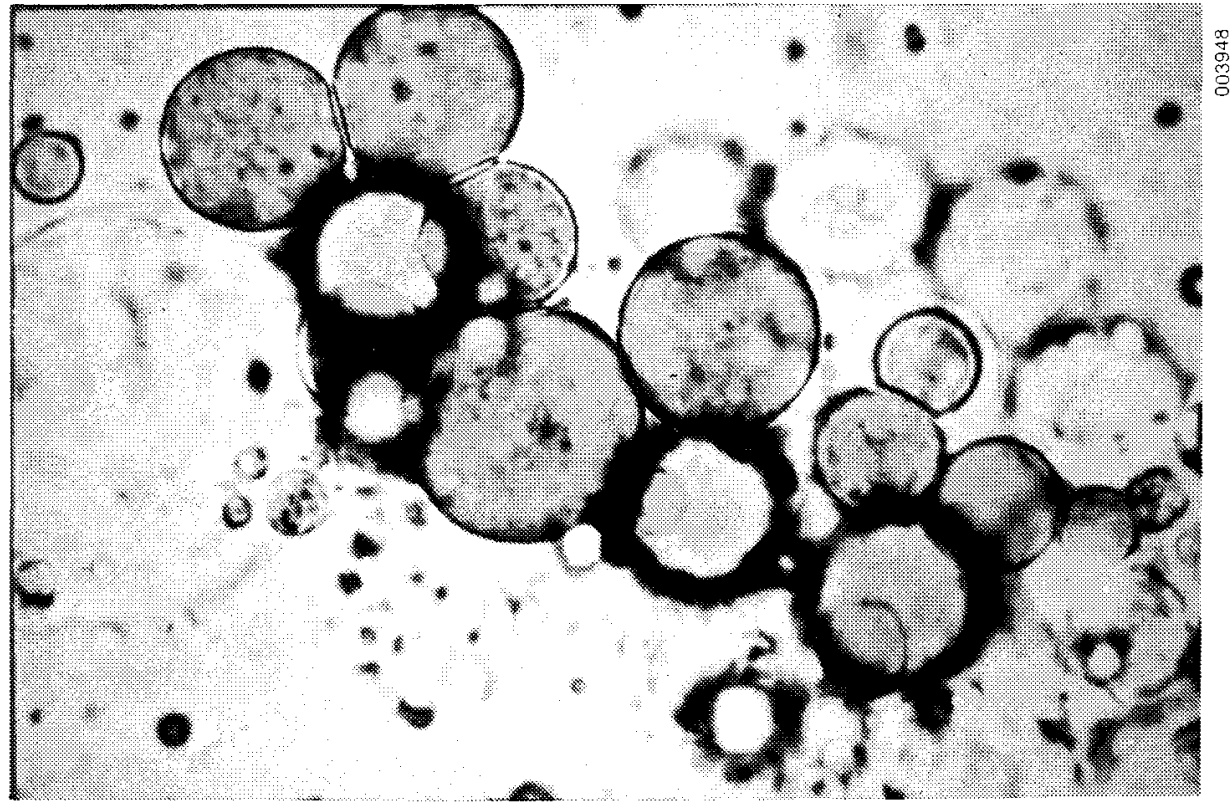

Figure 2-1a. Cells of the Microalga Chlorella That Have Been Stained for Oils (50\% of dry weight)

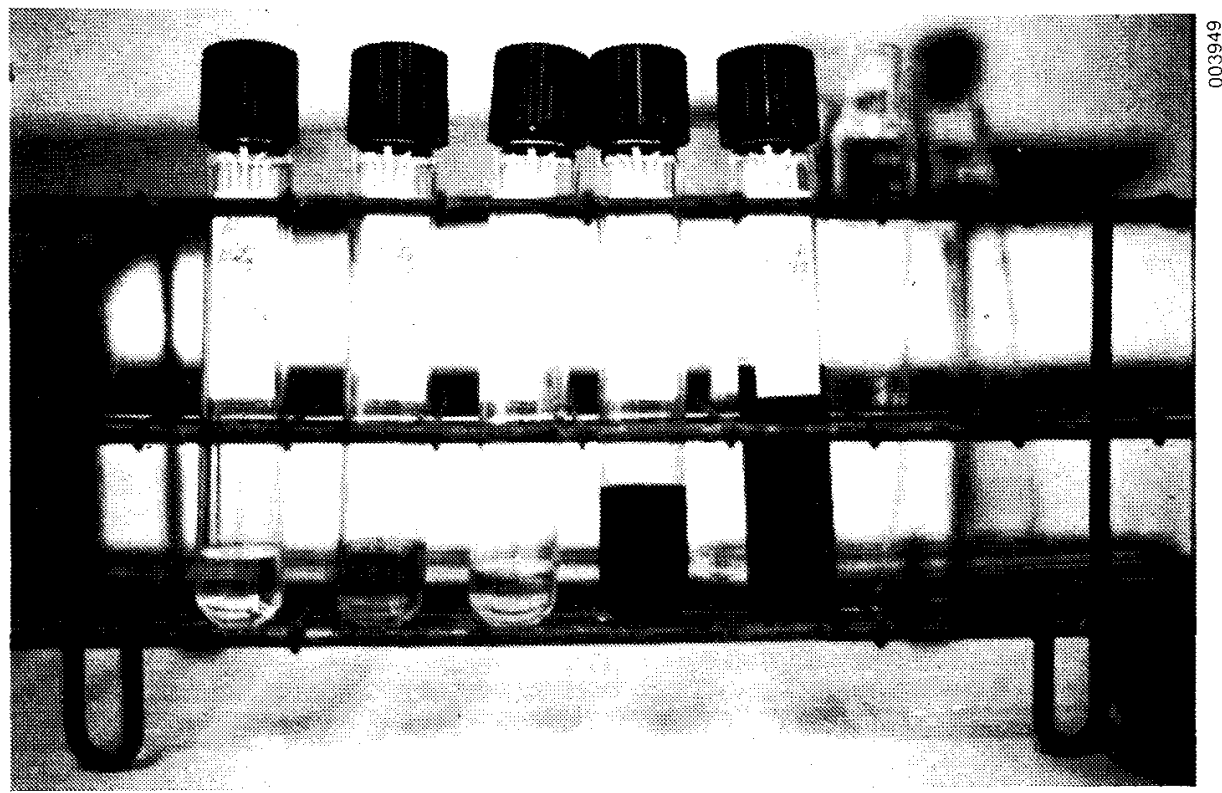

Figure 2-1b. Oils from Microalgae Fractionated into 5 Classes: Hydrocarbons, Isoprenoids, Triglycerides, Glycolipids, and Phosopholipids 
Table 2-1. Composition of Microalgae, Macroalgae, and Emergent Plants as Found in Natural Stands and, in the Case of Microalgae, after Laboratory Manipulation

\begin{tabular}{lcccc}
\hline & \multicolumn{2}{c}{ Microalgae } & $\begin{array}{c}\text { Natural } \\
\text { Macroalgae }\end{array}$ & $\begin{array}{c}\text { Natural } \\
\text { Emergents }\end{array}$ \\
\cline { 2 - 4 } & Natural & Manipulated & $73-85$ & $70-85$ \\
\hline Carbohydrate (\%) $^{\mathrm{a}}$ & $20-30$ & $5-90$ & $12-20$ & $4-10$ \\
Protein (\%) $^{\mathrm{a}}$ & $50-60$ & $10-60$ & $3-7$ & $2-7$ \\
Lipid (\%) & $7-25$ & $7-70$ & $25-49$ & $3-8$ \\
Ash (\%) & $8-36$ & $8-36$ & $88-92$ & $60-70$ \\
Moisture (\%) & $88-92$ & $88-92$ & & \\
\hline a Percentage of dry, ash-free weight. & & & \\
b Percentage of total weight.
\end{tabular}

Since 1982 the emphasis of the Aquatic Species subprogram has been to develop a technology for the mass culture of microalage utilizing saline resources in arid areas of the American Southwest. The primary productivity of these areas has been measured at 0$0.7 \mathrm{~g} \mathrm{~m}^{-2}$ day $^{-1}$. Primary productivity is limited by a lack of suitable water. It is estimated that by using brackish water resources, microalgal production could exceed $50 \mathrm{~g} \mathrm{~m}^{-2}$ day $^{-1}$. The research supported by this program is organized into three tasks: Biological Research, Engineering Research, and Technology Analysis.

The focus of the biological research is on increasing the oil yield from cultured microalgae. To do this, researchers are selecting the most promising species, domesticating these species through genetic manipulation and classical agronomic practices, developing culture techniques that maximize biomass production, and learning to manipulate cellular metabolism so that the sun's energy is converted into the most desirable fuel products (i.e., lipids, oils).

In selecting the most promising microalgae, researchers are conducting a comprehensive survey of microalgae. Microalgae with the following characteristics will be considered the best species for fuel production:

- Rapid growth rate at high cell density

- High energy content (lipids and hydrocarbons)

- Wide environmental tolerance range (temperature, salinity)

- Minimal requirements for media supplementation (addition of vitamins, trace minerals)

- Sustainable monoculture in outdoor culture.

Once the best species are selected, genetic manipulations may be used to domesticate the microalgae to produce the greatest yields in mass culture. This will be very similar to the process used in modern agriculture to improve yields. Techniques similar to those used in agronomics to improve wheat and corn yields will be used. Selection of strains 
that are highly productive and have large portions of carbon being allocated to oils will be given priority. Techniques will be developed to genetically cross strains to develop superior strains of microalgae for oil production. Presently the program is involved in assembling and characterizing a genetic pool for such efforts.

Work is being performed to define the best culture conditions for the most promising species. To optimize microalgal culture, light, nutrient (nitrogen, phosphorus, trace metals), carbon $\left(\mathrm{CO}_{2}, \mathrm{HCO}_{3}^{-}\right), \mathrm{pH}$, temperature, and salinity requirements must be defined and understood in terms of yield-cost trade-offs.

Finally, as mentioned previously, manipulation of the culture can alter cellular metabolism so that the cell synthesizes desirable fuel products. "Hitting the lipid trigger" is a phrase of ten used to express this phenomenon; that is, switching cellular metabolism from a growth phase, characterized by rapid cell division, to a lipid accumulation phase. This has been accomplished by imposing stresses on the cells, such as an osmotic shock or nitrogen deprivation. Basic lipid metabolism is being studied, so that in the future the cell' metabolic machinery can be manipulated to permit the cell to synthesize the most desired lipids in terms of fuel utilization. An example would be to switch the cell from synthesizing structural polar lipids to natural storage lipids.

The purpose of engineering research is to integrate biological concepts with engineering principles to develop a cost-effective microalgal culture technology. An example of this is developing culture systems that most efficiently utilize the flashing light effect. Algal productivity has been demonstrated to be increased by exposing cells to regular flashes of light. This may be accomplished by mixing cells so that they move from the dark areas within the culture to the surface at regular intervals.

The most critical microalgal production design considerations are the depth of the culture, the mixing strategy, and the enclosure configuration. The choices involve tradeoffs in algal productivity, environmental control, system capital, and operating costs. The subprogram is supporting the operation of two systems of differing depth and channel configuration. A shallow raceway system (10 cm depth) (Figure 2-2a) is being operated in Hawaii. Shallow systems have the advantage of developing higher cell concentrations, well above $1 \mathrm{~g} / \mathrm{L}$. This minimizes the volume that must be handled by the harvesting process, makes more efficient use of added nutrients, and increases the capacity for manipulation of the chemical composition of the cultured alga. Also, the flow characteristics of shallow systems are more easily manipulated. Foils placed in the Hawaiian system cause regular patterns of induced turbulence, which allows the culture to utilize a flashing light effect. The addition of foils has doubled productivity.

Microbial Products, Inc., is operating a deeper pond system $(20 \mathrm{~cm}$ ) (Figure 2-2b) in California. Deep systems have the advantage of natural temperature control, but the greater light limitation results in reduced cell concentrations. The reduced cell concentration increases the cost of harvesting the algae.

Microalgal cultures must be mixed to prevent cell settling or flotation, to prevent thermal stratification, and to ensure adequate contact between the algae and its nutrients. Mixing costs are the highest of the various power costs of these systems. Since the power required is proportional to the cube of the velocity for a given volumetric flow, it is important to minimize culture velocity while maintaining adequate mixing. 


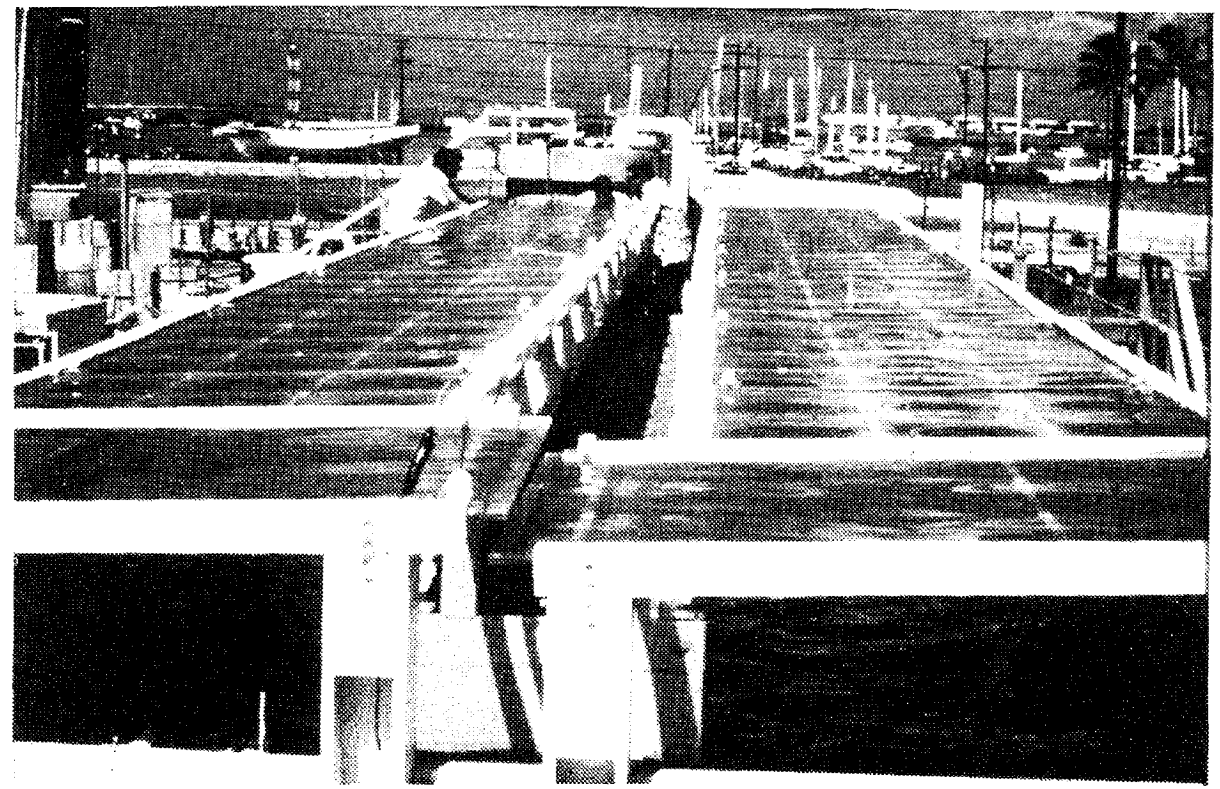

Figure 2-2a. Shallow Raceway System Operated in Hawaii

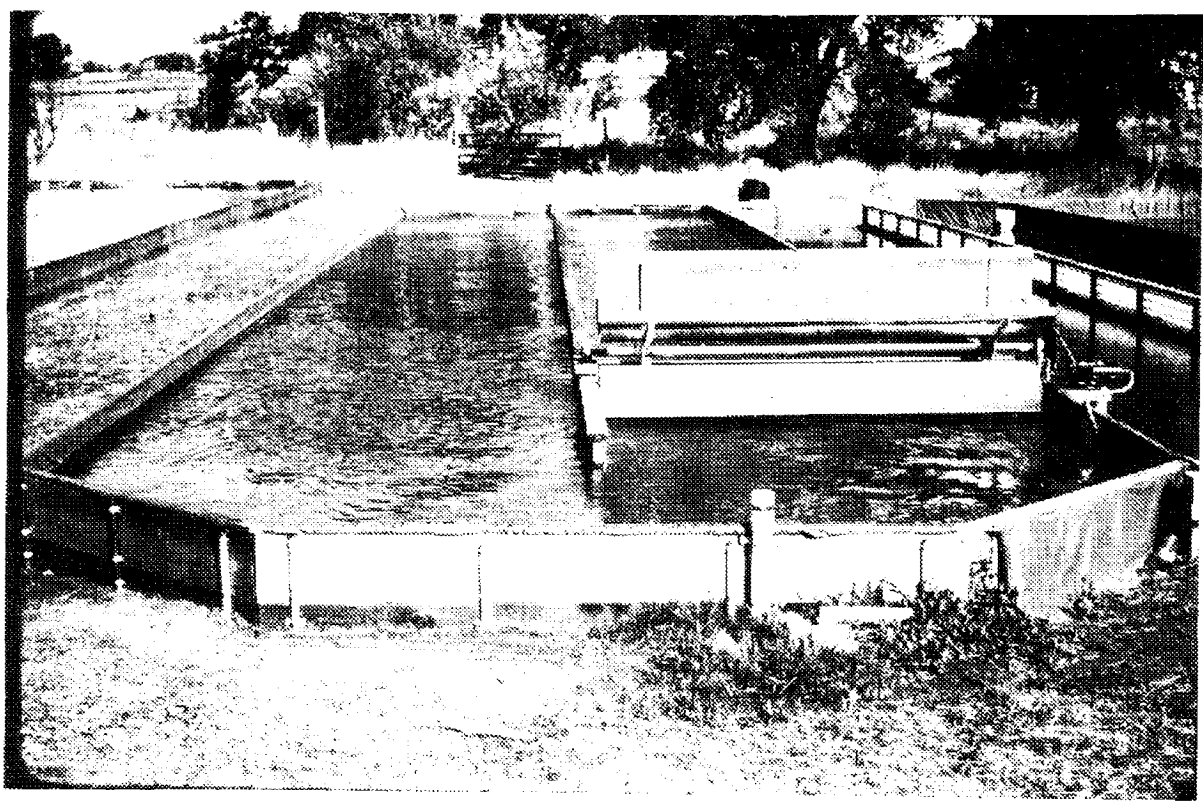

Figure 2-2b. Deeper Pond System Operated in California 
The development of culture management techniques is another area of engineering research. Culture management alternatives are needed that lead to higher sustained yields of energy products. Two culture strategies are common: batch and continuous. In batch culture a pond is innoculated, and the microalgae are allowed to grow to a point at which all algae in the pond are harvested. In continuous culture a portion is harvested daily and makeup water added to the culture.

To determine which type of design-the shallower raceway or deeper ponds-is more cost-effective, it is necessary to project the costs of building and operating each system at the time the technology is scheduled for commercialization (10 to 15 years hence for microalgae). To do this, the supply and demand of the required inputs (water, carbon, nutrients, and energy) must be calculated, as must the market potential for the intended products. This task is the objective of the third area of research in the Aquatic Species subprogram-technology analysis. There are two subtasks in analysis: resource assessment and economic analysis. The resource assessment subtask is concerned with detailing the availability of required resources, and the economic evaluation subtask with determining cost/benefit ratios and ultimate marketability analyses.

Sunlight, land, and water are the most basic required resources. Careful study has shown the American Southwest to be best suited to fulfill these requirements. It is an area with high insolation, a large amount of land with few competitive uses, and a vast supply of saline water available in underground aquifers (see Figure 2-3).

Carbon, nitrogen, and phosphorus are the resources needed in the next greatest quantities. Potential carbon sources in the form of $\mathrm{CO}_{2}$ include commercial $\mathrm{CO}_{2} ; \mathrm{CO}_{2}$ trapped in geologic formations in the Southwest; and $\mathrm{CO}_{2}$ from mining and processing of calcium carbonate in the Southwest, from power plant stack gases, from synthetic fuel plant waste streams, and from biogas produced by anaerobic digestion of organic byproducts or waste streams from algal facilities. Bicarbonate is an alternative source of carbon for some microalgae species. Initially nitrogen and phosphorus must be added to cultures, but researchers expect that $90 \%$ of the nitrogen removed with the algal biomass at harvest will be recycled back to the culture.

In summary, the Aquatic Species subprogram supports research on the development of microalgae, macroalgae, and emergent plants as a source of renewable fuels. It is the objective of biological research to identify, culture, evaluate, and manipulate aquatic species to produce sustained yields of high-value energy products. The engineering research is concerned with design, evaluation, construction, and testing of the components and processes that will be required to produce these yields. The technology analysis efforts identify the resources required and available and evaluate the economics of a mass-production system.

\subsection{OBJECTIVES}

The overall objective of the Aguatic Species subprogram is to define and improve the productivity, conversion to fuels, and cost efficiency of aquatic plant species cultivated for energy. Table 2-2 lists the tasks, subtasks, and projects of the AS subprogram. 


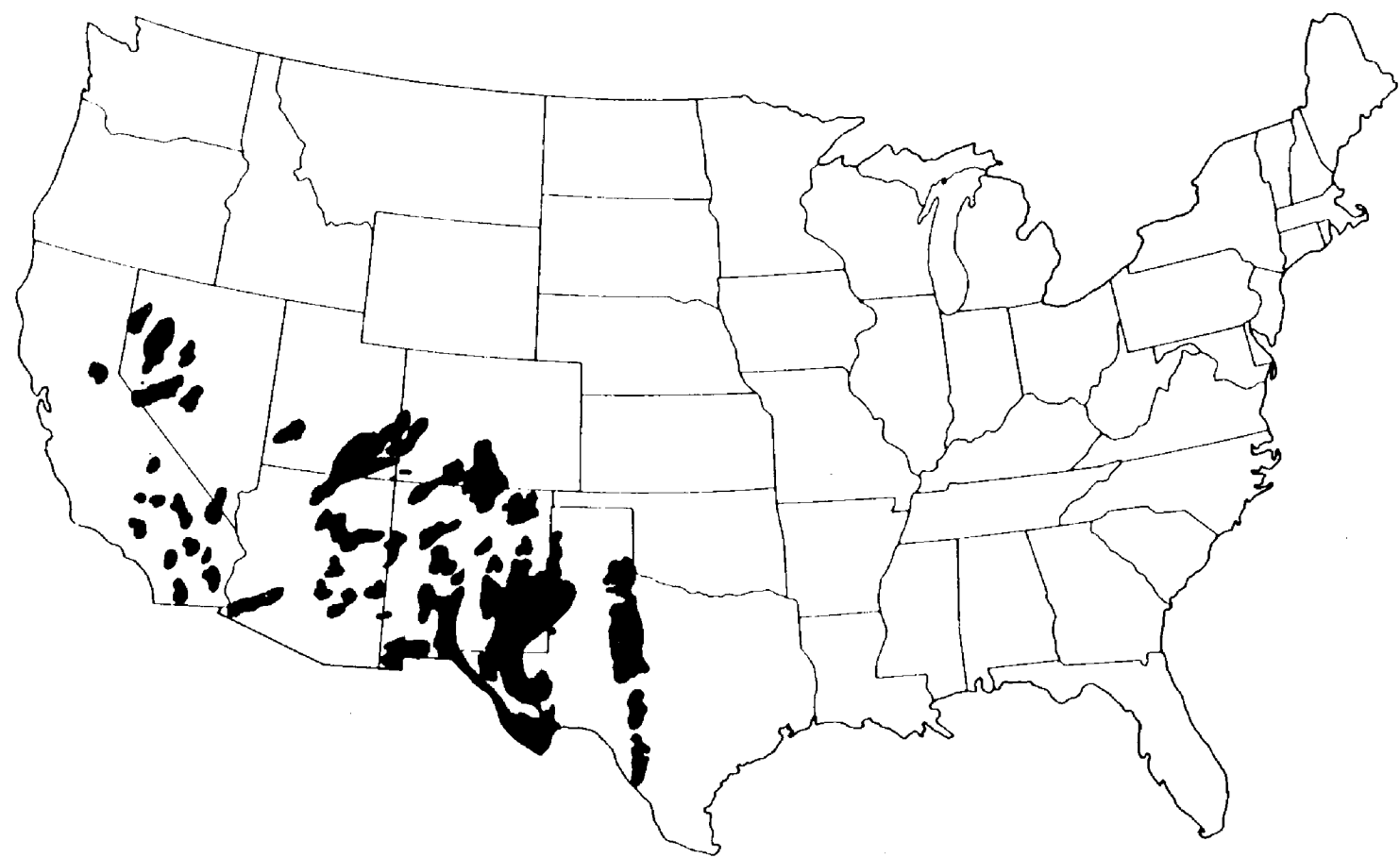

Figure 2-3a. Locations of Saline Groundwater Reservoirs in the Southwest United States

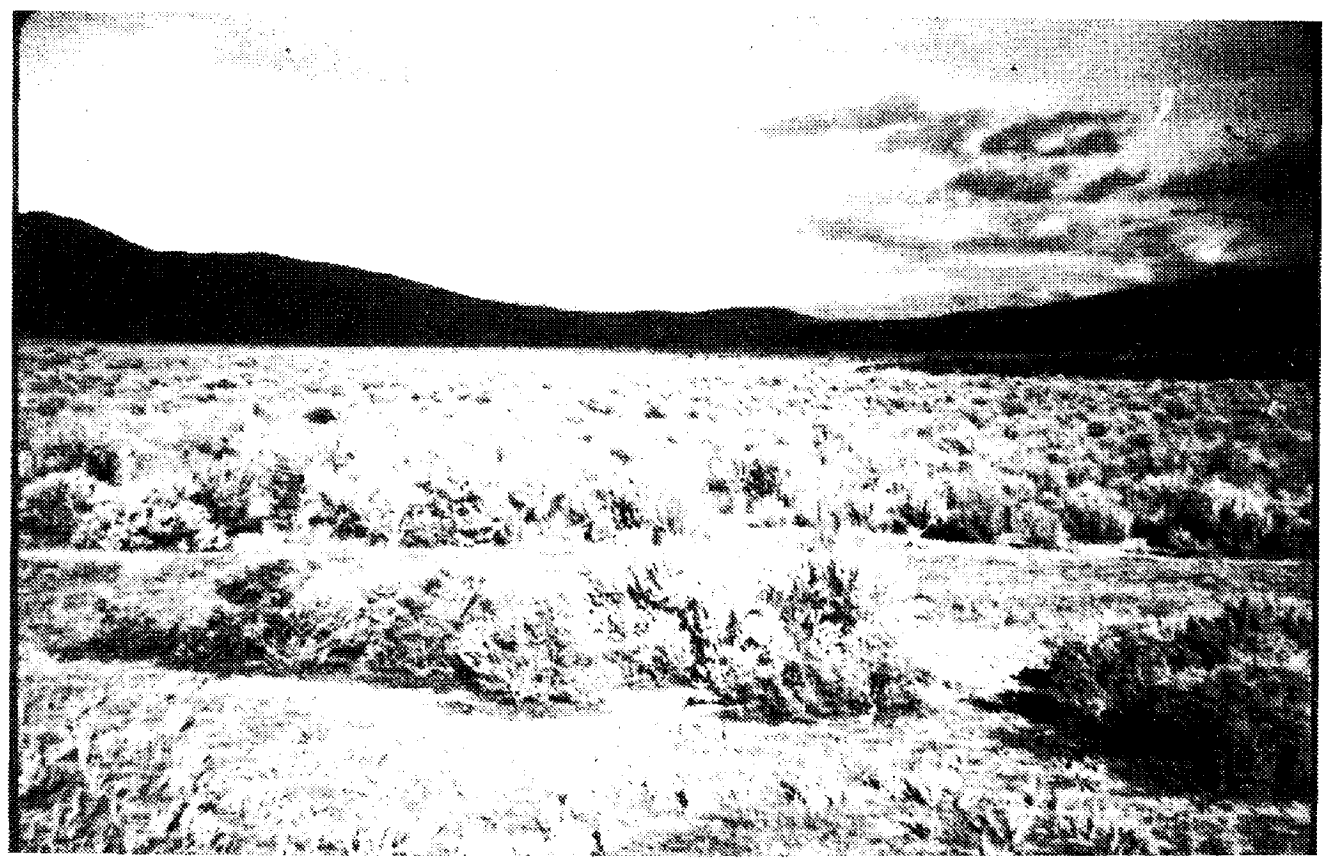

Figure 2-3b. Typical Southwest Desert Area 
Table 2-2. Aquatic Species Program Tasks, Subtasks, Projects, and Principal Investigators

Task I: Biological Research

A. Species Screening and Culture

Emergents

University of Minnesota - Wetland Biomass Production-Douglas Pratt

Macroalgae

Harbor Branch Institute-Cultivation and Conversion of Marine Macroalgae-John Ryther

Microalgae

Scripps Institution of Oceanography-Collection and Selection of Oil-Producing Microalgae-William Thomas

Georgia Institute of Technology-Chemical Profiles of Microalgae-Thomas Tornabene

Solar Energy Research Institute-Microalgae Oils Technology-Lawrence Raymond

Ben Gurion University-Development of Outdoor Raceway Capable of Culturing Oil-Rich Halotolerant Microalgae-Shoshana Arad

B. Species Improvement

Solar Energy Research Institute-Algal Oils R\&D-Steve Lein

Solar Energy Research Institute-Photophysics and Photochemistry of Algal and Bacterial Pigments-John Connolly

Task II: Engineering Research

A. Design Coordination

Jaycor-Biological and Engineering Parameters of Algal Mass Culture-Les Levine

Science Applications, Inc.-Microalgal Systems Simulation-William Hubka

B. Component Development

No subcontracts

C. Experimental Facilities

University of Hawaii-Sustaining Yield Performance of Shallow Algal CulturesEdward Laws

Microbial Products, Inc.-Production of Liquid Fuels and Chemicals from Microalgae-John Benemann and Joel Weismann

Task III: Technology Analysis

Solar Energy Research Institute--Resource Assessment for Aquatic Biomass ProductionEugene Maxwell

Solar Energy Research Institute-Cost Budgeting of Microalgal Facilities-Andrew Hill 


\subsection{STATUS}

\subsubsection{Biological Research}

Aquatic microorganisms such as algae represent a major potential source of photosynthetically produced biomass. Their inherent rapid growth characteristics, combined with diverse chemical compositions, represent a significant resource for the production of fuels and other chemicals.

Because of their high yields and efficiencies of light utilization compared to higher plants, microalgae are attractive potential sources of biomass for energy and protein production. Program emphasis is being placed on aquatic species that produce lipids, which may be used as fuel or petrochemical replacements and may be grown in the saline or brackish waters of the American Southwest desert.

Biological research is divided into two subtasks: species screening and culture, and species improvement. Species screening and culture is concerned with selecting the best species and developing cost-effective methods of culturing those species. Species improvement is concerned with enhancing the performance characteristics of the best species through culture manipulation, metabolic regulation, and genetic techniques. The program has been involved in the screening and culture of macroalgae, emergents, and microalgae. Emphasis has been placed on improving macroalgae species.

\subsubsection{Species Screening and Culture}

Macroalgae. The original concept of an energy farm based on the production of macroscopic algae was the open-ocean farm, a suspended framework structure, buoyed and moored at depths of $700 \mathrm{~m}$ or more in the open ocean, to which plants like the giant kelp (Macrocystis pyrifera) would be attached. Nutrient-rich bottom water would be pumped through a pipe to the surface and through the kelp plants as their source of nourishment. Costs of pumping the deep water to the surface and other aspects of the system associated with its deep sea and open ocean location caused initial doubts about its economic feasibility and cost-effectiveness. A small test module was anchored off the coast of California in 1978 and was, from the start, beset with numerous technical problems; it sank to the ocean bottom before any useful data was obtained.

An alternative concept was a land-based energy production system utilizing saline waters from underground aquifers or enclosed coastal areas. Work on this concept was begun in 1979 and transferred to the Harbor Branch Institute, where the work was carried out in FY 1983. Research began with a screening program designed to evaluate growth and biomass production of all macroscopic algal species that could be obtained in adequate quantity in the central Florida area. A total of 42 species were grown in specially adapted burial vaults (Figure 2-4). These included 16 green algae (Chlorophyta), 2 brown algae (Phaeophyta), and 18 red algae (Rhodophyta). Of these, the most successful and suitable species were a strain of Gracilaria (a red seaweed) and Ulva (a green seaweed). These two species have a high carbohydrate content that may be anaerobically digested to methane gas. The demonstrated energy yields of Gracilaria and Ulva are $2.5 \times 10^{6}$ and $3.0 \times 10^{6} \mathrm{~J} / \mathrm{m}^{2}$ day, respectively.

Gracilaria may be grown in channels or raceways on land or in shallow coastal waters in tropical to semitropical latitudes. At an offshore site, the seaweed would presumably be 


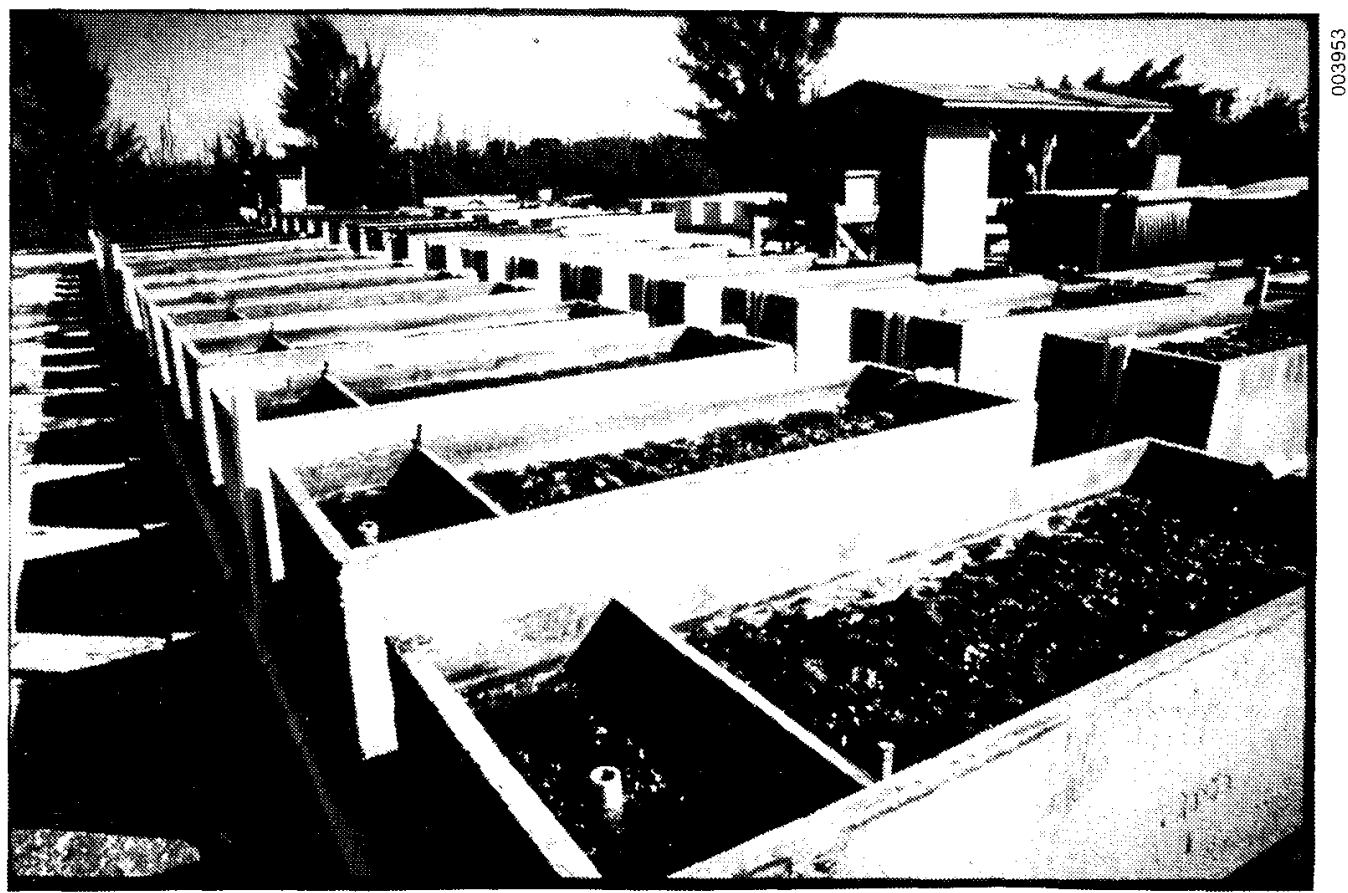

Figure 2-4. Modified Burial Vaults at Harbor Branch Are Ideal for Sereening Macroalgae for Growth

confined by a fence or other barrier. Within the enclosure, the culture is maintained at a density of approximately two kilograms wet weight per square meter. At this density, the algae is compacted such that normal wind and tidal action will not cause the algal mass to drift and accumulate unevenly. At brief intervals during the day, the culture is mixed and rotated by compressed $\mathrm{CO}_{2}$ from pipes distributed throughout the culture systems.

Well-nourished Gracilaria exposed to full sunlight at such latitudes will double its biomass in 1 to 4 weeks, depending on the season, water flow, and other variables. After its biomass has doubled (i.e., from 2 to $4 \mathrm{~kg} / \mathrm{m}^{2}$ ) the incremental grow th is harvested to return the crop to a starting density that will ensure continued optimal yield. The doubling of biomass will be accompanied by the utilization of all stored nutrients and a reduction of elemental nutrients in the plant tissues to roughly half the initial concentrations. Enrichment of the new starting crop following harvest could conceivably be accomplished onsite at the seaweed farm, but the rapid uptake and storage of nutrients by depleted seaweeds makes possible a simpler, more efficient enrichment process, known as pulse fertilization.

During the past year research has focused on reducing energy inputs to the culture system. In particular, aeration frequency, water turnover rates, and carbon utilization have been investigated. To determine the trade-off between operating costs and yield, researchers are assessing $\mathrm{CO}_{2}$ addition and frequency of aeration. A series of gas diffusion experiments was conducted to determine the relative mass transfer rates for $\mathrm{CO}_{2}$ and $\mathrm{O}_{2}$ in waters of various types. These experiments were also designed to confirm the theoretical relationship of $\mathrm{CO}_{2} / \mathrm{O}_{2}$. A nonlinear curve-fitting program is being used to reduce the data, but the analysis is not yet complete. Preliminary results indicate a noticeable decrease in the gas transfer rates of actively growing Gracilaria cultures. This is probably due to surface-active polysaccharides which are exuded by the plants. 
One benefit of aeration in seaweed culture tanks may be the elimination of diffusion barriers, which reportedly can develop around the macroalga held under stagnant conditions. Because the absorption of nutrients may be hindered by this phenomenon, the use of aeration may be critical when the seaweed is being pulse-fed. An experiment was conducted in which nitrogen uptake by nitrogen-starved Gracilaria was examined under various aeration regimes. The seaweed was soaked for 24 hours in seawater containing either high levels of nitrogen (no water exchange) or low levels of nitrogen (10 exchanges of seawater/day, ambient nitrogen at a level of $0.1 \mathrm{mg} / \mathrm{L}$ ). The high levels are similar to the nitrogen concentrations used during pulse feeding, and the low levels simulate the nitrogen concentrations to which the seaweed is exposed during its growth period.

As expected, it was found that nitrogen uptake (as determined by changes in plant nitrogen content) increases with increased aeration time. In addition, nitrogen uptake under all aeration regimes was greater in the high-nitrogen seawater than in the low-nitrogen seawater, indicating that water motion or agitation of the thallus is essential for the uptake of nutrients present in low concentrations. Whether aeration was provided in the day or night did not seem to affect nitrogen uptake by Gracilaria.

These data indicate that the goal of pulse-fertilization (increasing total plant nitrogen content) can be achieved most rapidly by utilizing high seawater nitrogen concentrations and continuous aeration. In addition, the poor nitrogen uptake under low-nitrogen stagnant conditions indicates that Gracilaria may be susceptible to a nutrient limitation during a nonaerated growth period, especially if "luxury consumption" of the particular nutrient does not occur during fertilization.

Trade-offs between pumping costs, the cost of carbon addition, and the frequency and duration of aeration were also made. A preliminary analysis of pumping seawater to supply carbon naturally resulted in energy-fixed/energy-expended ratios of 11.2 for Gracilaria and 21.6 for Ulva.

An evaluation of the effect of $\mathrm{CO}_{2}$ enrichment on Ulva and Gracilaria yields was completed during the past year. Oxygen production by Ulva was determined to be a function of alkalinity (carbon concentration) and $\mathrm{pH}$. Photosynthesis remains relatively constant within the range of $\mathrm{pH}$ tested (7.5-9.5) but increases significantly with increasing alkalinity. Oxygen production by Gracilaria was determined to be a function of $\mathrm{pH}, \mathrm{CO}_{2}$, and the total alkalinity. At a constant $\mathrm{CO}_{2}$ concentration, photosynthesis increases uniformly as the $\mathrm{pH}$ is increased. This suggests that Gracilaria photosynthesis correlates poorly with $\mathrm{CO}_{2}$ concentration and may indeed correlate with biocarbonate or total carbon concentration. The conclusion is that Gracilaria is more adversely affected by low alkalinity than Ulva. Gracilaria photosynthesis also declines more precipitously at high $\mathrm{pH}$ than does Ulva photosynthesis (see Figure 2-5). Higher photosynthetic rates at higher $\mathrm{pH}$ levels and lower alkalinities would be of significant advantage in the culture of macroalgae. It is advantageous to grow macroalgae which flourish at higher pH levels and lower alkalinities.

A screening activity was undertaken to examine macroalgae as a potential source of petroleum replacement products. Initial results indicate that macroalgae produce very low quantities of lipids, ranging from $1 \%$ to $5 \%$ of the total organic weight. The majority are polar, membrane-bound lipids (Table 2-3), which are less valuable as fuels.

Emergents. Research on emergent aquatics was begun by SERI in 1980, when a subcontract was let to the University of Minnesota to investigate the use of wetlands to 


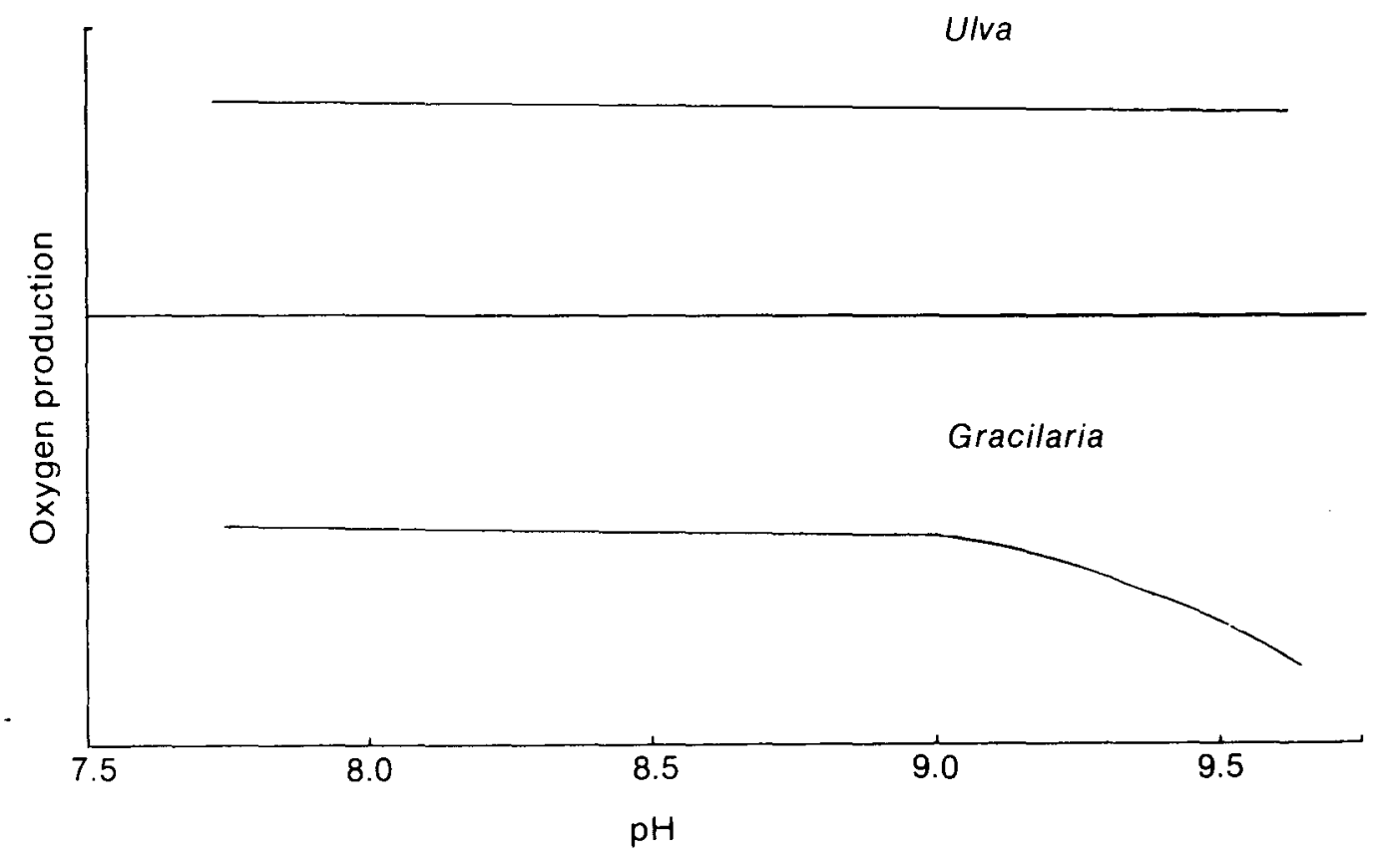

Figure 2-5. Relative Oxygen Production vs. $\mathrm{pH}(\mathrm{TIC}=0.5 \mathrm{mM}$ )

produce biomass energy crops. Wetlands dominated by Typha (cattails) and other emergent vegetation, such as Phragmites (reeds) and Scripus (rushes), are among the most productive systems in the temperate zone. Minnesota, with over 2 million hectares of available peatland and 1.4 million additional hectares of available wet mineral soils, appears to have considerable potential for wetland crop production. Among the attractive features of this system is the fact that wetland crops would not compete with traditional crops for prime agricultural land. The use of peatlands for the production of a renewable resource also offers an attractive alternative to peat mining.

The Minnesota research effort has demonstrated that total annual biomass yields between 20 and 30 dry tons/hectare are possible in planted stands. This compares with yields of total plant material between 9 and 16 dry tons/hectare in a typical Minnesota corn field. At least $50 \%$ of the Typha plant is composed of a below-ground rhizome system containing $40 \%$ starch and sugar, making rhizomes an attractive feedstock for alcohol production.

The major activity during 1983 was to conduct field trials to compare the effects of fertilization rates, planting densities, water management, and age of the establishment on yields of Typha. Biomass production was always superior in the second-year stands. In July 1982, the total biomass was $5 \mathrm{~g} / \mathrm{m}^{2}$; in July 1983 , the biomass was $652 \mathrm{~g} / \mathrm{m}^{2}$.

Nutrient levels were monitored to indicate which nutrients were limiting. Analysis of harvest data and tissue nutrient concentrations from field fertilization studies showed a large yield increase of $188 \%$, while tissue nitrogen increased by only $7 \%$ and tissue phosphorus by only 39\%. This supports the general conclusion from first-year results (when fertilizer was used) that nutrients were not the limiting growth factor in that year. No fertilizer was used in the second year. 
Table 2-3. Lipid Composition of Selected Macrophytes

\begin{tabular}{|c|c|c|c|c|c|c|}
\hline \multirow{2}{*}{ Species } & \multicolumn{6}{|c|}{$\begin{array}{l}\text { Lipid Fraction } \\
(\%)\end{array}$} \\
\hline & $\begin{array}{c}\text { Lipid } \\
(\% \text { dry } w t)\end{array}$ & Hydrocarbons & Isoprenoids & Triglycerides & Glycolipids & Phospholipids \\
\hline \multicolumn{7}{|l|}{ Gracilaria } \\
\hline $\begin{array}{l}\text { Nitrogen } \\
\text { enriched }\end{array}$ & 1.8 & 0.8 & 1.3 & 18.3 & 46.0 & 33.5 \\
\hline $\begin{array}{l}\text { Nitrogen } \\
\text { starved }\end{array}$ & 0.8 & 0.3 & 1.9 & 4.8 & 62.3 & 30.8 \\
\hline Ascophyllum & 4.5 & 0.3 & 15.7 & 15.4 & 50.0 & 19.5 \\
\hline Sargassum & 4.6 & 0.4 & 1.5 & 1.0 & 74.3 & 22.8 \\
\hline Caulerpa & 5.2 & 0.1 & - & - & - & - \\
\hline
\end{tabular}


Ash content has also been determined for tissue samples from all field experiments, because it is an important factor in biomass conversion. Typha grown on mineral soils exhibited mean ash contents of $6.5 \%$ to $7.4 \%$, while Typha grown on organic soils had a mean ash content of $5.2 \%$. Potassium is one of the more prevalent nutrients in Typha samples; the level of applied potassium fertilizer was found to significantly affect the ash content of the plant tissue. The variability in ash content resulting from soil types and nutrient application may significantly affect plant growth and development, as well as biomass conversion.

Analysis of plant material from the nutrient uptake studies showed that, on the average, $65 \%$ of the plant potassium and $76 \%$ of the plant phosphorus were located in the belowground tissue by late October. This trend-translocation of nutrients from above to below ground (as the season progresses)-is similar to that observed for tissue nitrogen. It could have significant impact on production scenarios, including aspects such as the time of harvest, amount of below-ground harvest, and long-term fertilization requirements. At the very least, the simultaneous maximum uptakes of the three macronutrients suggests the possibility of a single, timed fertilizer application. Also, two-year yield and nutrient usage studies show that Typha stands utilize nutrients more efficiently af ter the establishment year, a promising trend for efficient biomass production.

Microalgae. The objective of this activity is to conduct a comprehensive screening activity that will identify the best microalgae strains for energy production. The strategy for this activity is illustrated in Figure 2-6 and 2-7. As a first level activity, microalgae species are collected and characterized for growth. The most rapidly growing species are then characterized for lipid content. As a final test for first level screening they are grown in outdoor culture. Species that have the best characteristics are passed to the second level of testing for detailed characterization and species improvement. Emphasis has been on collecting species from the California and Nevada deserts. (See Figure 2-8 for map of locations sampled.)

The collection, isolation, and analysis of individual algae species found in the desert was conducted from a mobile field laboratory. This laboratory allowed for the collection and preliminary growth estimations of various algae from numerous desert locations. Isolation of algal species into monocultures allowed detailed analysis of the yields, efficiencies, and proximate composition of each species. In addition, water samples were analyzed to identify major inorganic chemical constituents. These studies provided basic information on marine and desert algae and on the aquatic environment in the desert which can be applied to any installation in which saline water may be used.

During 1983, 58 microalgae were isolated from California and Nevada desert areas and grown in unialgal cultures (Table 2-4). Determination of the best nitrogen source and estimation of rough yields and efficiencies were made for some of desert the isolates. Yields and chemical composition were determined for five species or strains of desert microalgae (see Table 2-5).

Of importance in determining the suitability of a species for culture is its growth response to environmental variation. Responses to temperature and salinity variation of selected desert microalgae, as determined by salinity-temperature gradient analysis, is given in Table 2-6.

Of the species collected and characterized, the Ankistrodesmus falcatus from Pyramid Lake in Nevada has seemed most promising and is now being fully characterized for lipids and growth in outdoor facilities. Growth of the species is exceptional over a wide range 


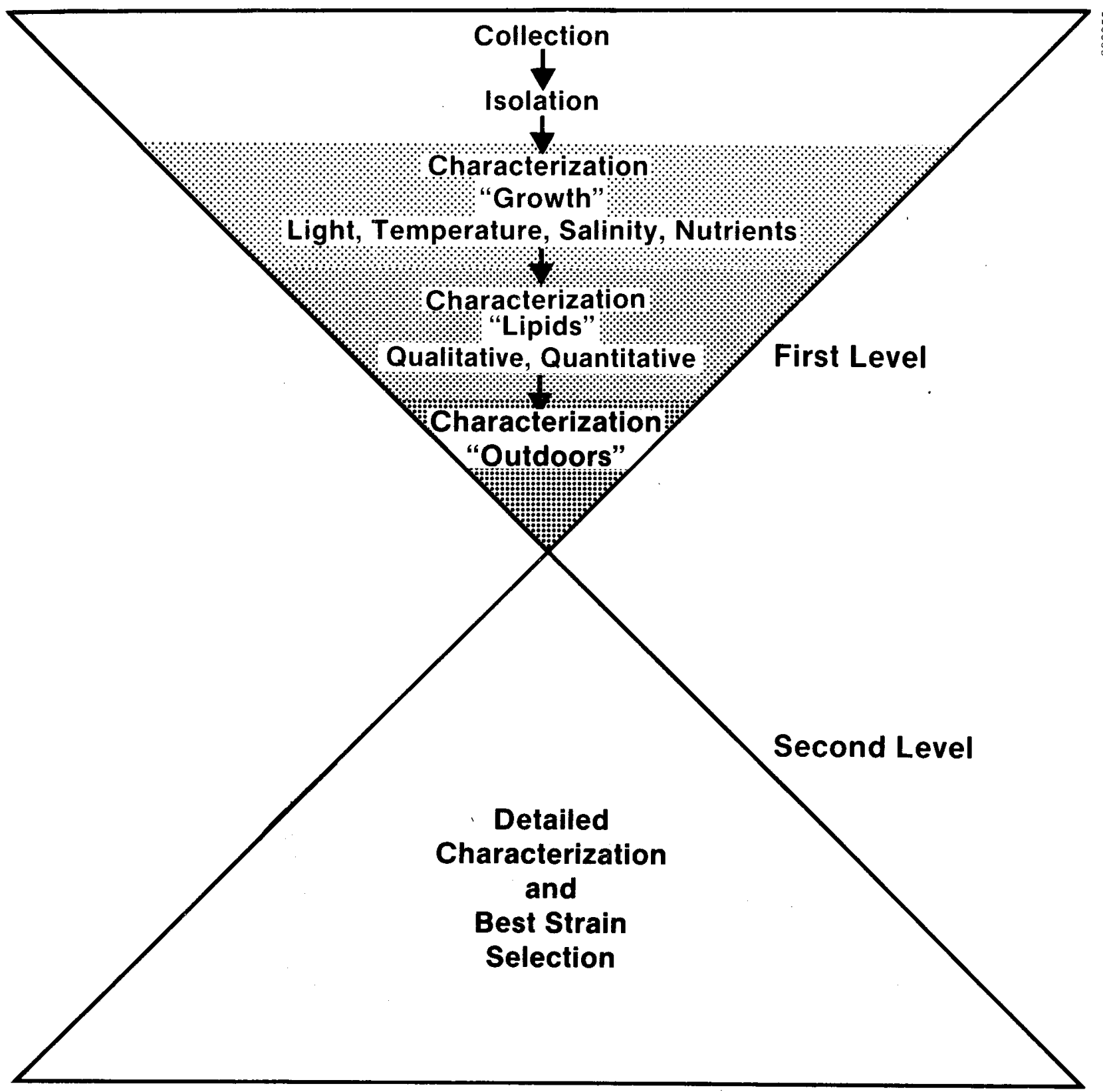

Figure 2-6. Schematic of Strategy for Comprehensive Sereening of Microalgae Strains 


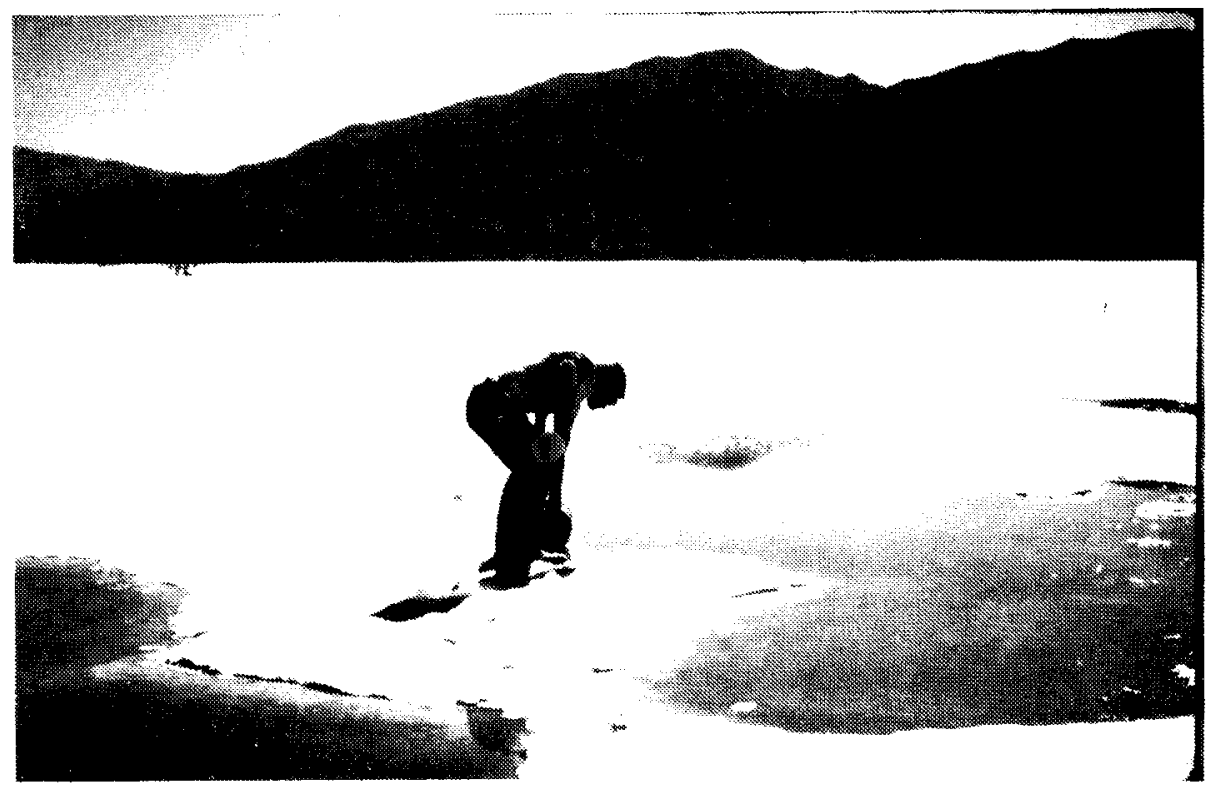

Figure 2-7a. Collection of Microalgae from Saline Desert Regions

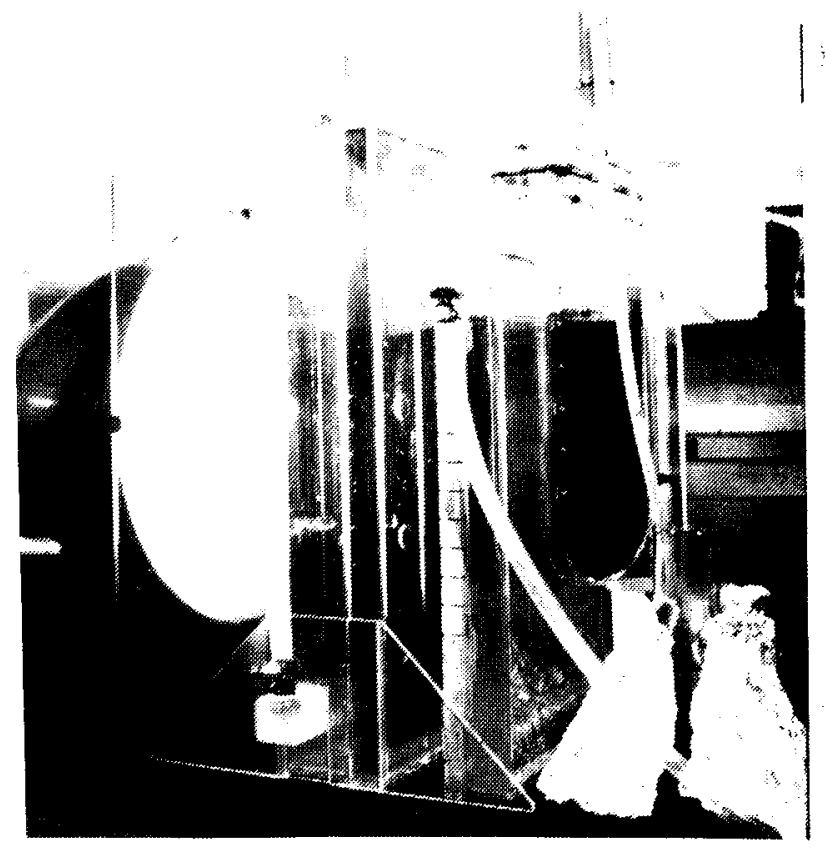

Figure 2-7b. Growth Studies of Selected Species Using Chemostats 


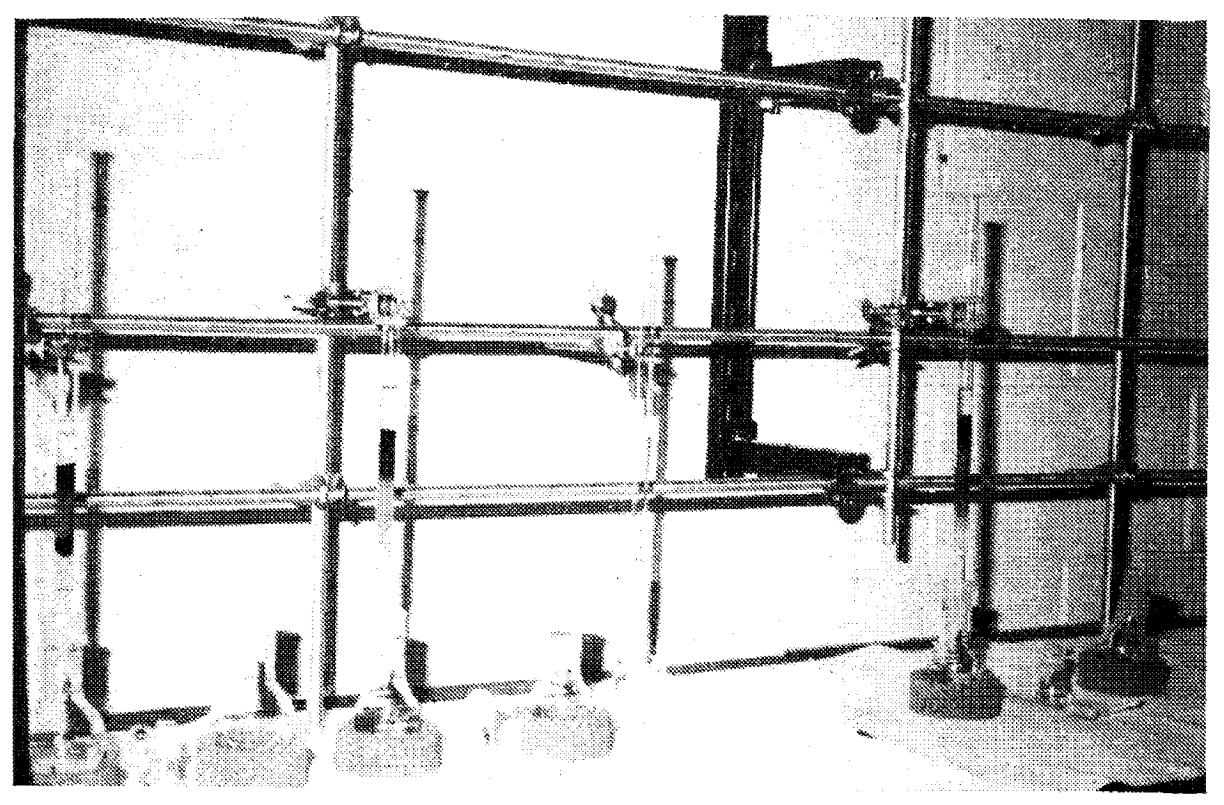

Figure 2-7c. Studies of the Lipid Fractions Produced by the Microalgae

of salinities, temperatures, and nutrients (see Figures 2-9 and 2-10). From the response curve it is evident that best growth occurrs between $5-7 \mathrm{~g} / \mathrm{L}$ and $16-26^{\circ} \mathrm{C}$. It grows well at a high biomass density and has a high lipid content.

The second step in screening is the determination and quantification of the chemical composition of selected microalgae grown under different conditions. This analysis is an important aspect of the screening process. This activity is primarily carried out at the Georgia Institute of Technology. Chemical analyses are carried out in accordance with a standard procedure set up by the program.

Microalgal lipids are typically esters of glycerol and fatty acids having carbon numbers in the range of $\mathrm{C}_{12}-\mathrm{C}_{20^{\circ}}$. Lipids can be subdivided according to their polarity, which depends on the nonpolar (lipophilic) carbon chains (fatty acids, long-chain alcohols) and on the polar (hydrophilic) moieties, such as phosphate and carboxylic groups, alcohols, sugar, or bases in each lipid. Nonpolar lipids (neutral lipids) are triglycerides, free fatty acids, hydrocarbons, and wax esters (only a few algae). The polar lipids are acyl lipids and mainly consist of phospholipids and glycolipids. The main phospholipids of algae are phosphatidyl choline (PC), phosphatidyl glycerol (PG), phosphatidic acid (PA), and diphosphatidyl glycerol (cardiolipin, DPG). The major algal glycolipids are monogalactosyl diglyceride (MGDG), digalactosyl diglyceride (DGDG), and sulphoquinovosyl diglyceride (sulpholipid, SL). A novel class of algal lipids are chlorosulpholipids which are derivatives of $\mathrm{N}$-docosane-1,14-diol and of N-tetracosane1,15-diol disulphates and which have been found in Chrysophyceae, and Cyanophyceae. 


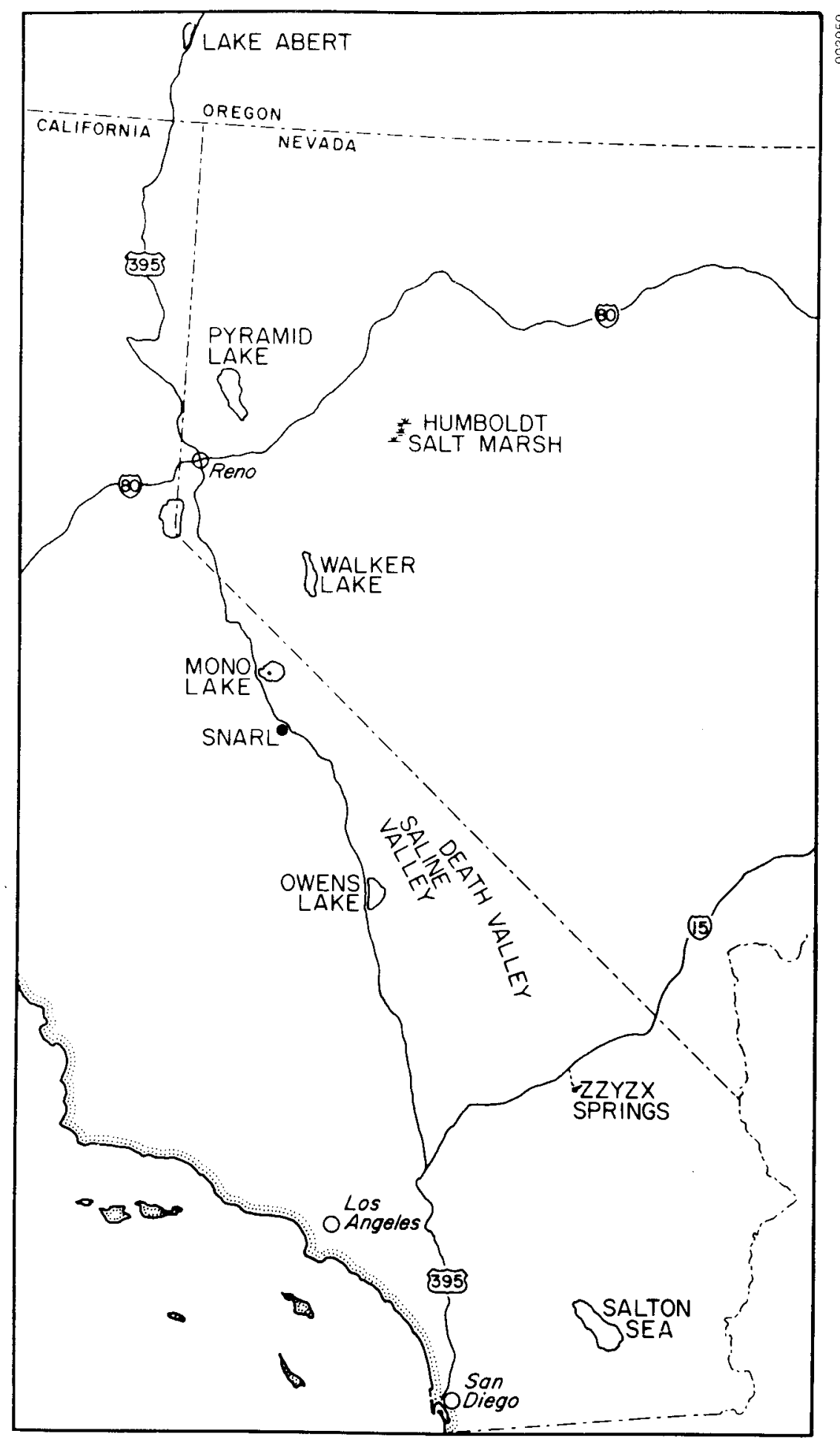

Figure 2-8. General Locations of Areas Sampled in the Desert of Eastern California and Western Nevada 
Table 2-4. Cultures of Desert Algae Isolated and Maintained by the Scripps Project in FY 1983

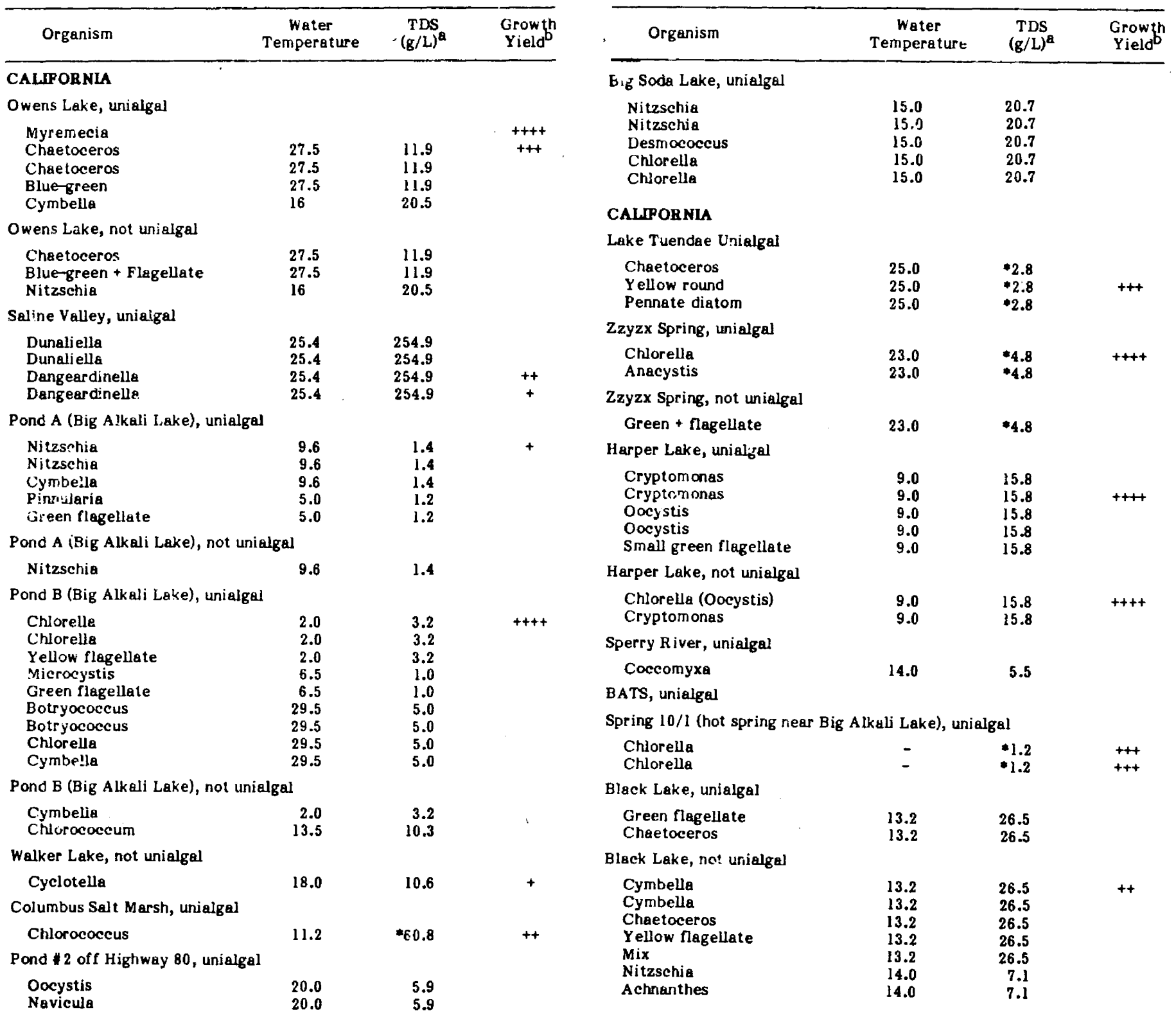


Table 2-4. Cultures of Desert Algae Isolated and Maintained by the Seripps Project in FY 1983 (Concluded)

\begin{tabular}{|c|c|c|c|}
\hline Organism & $\begin{array}{c}\text { Water } \\
\text { Temperature }\end{array}$ & $\underset{(\mathrm{g} / \mathrm{L})^{\mathrm{a}}}{\operatorname{TDS}}$ & $\begin{array}{l}\text { Growth } \\
\text { Yield }\end{array}$ \\
\hline \multicolumn{4}{|l|}{ NEVADA } \\
\hline \multicolumn{4}{|l|}{ Pyramid Lake, unialgal } \\
\hline $\begin{array}{l}\text { Anacystis } \\
\text { Nannochloris } \\
\text { Ankistrodesmus Falcatus } \\
\text { Synechococcus } \\
\text { Nitzschia } \\
\text { Green flagellate } \\
\text { Green ovoid }\end{array}$ & $\begin{array}{l}17.4 \\
17.4 \\
17.4 \\
15.0 \\
15.0 \\
15.0 \\
15.0\end{array}$ & $\begin{array}{l}4.9 \\
4.9 \\
4.9 \\
4.7 \\
4.7 \\
4.7 \\
4.7\end{array}$ & $\begin{array}{c}++++ \\
+++\end{array}$ \\
\hline \multicolumn{4}{|l|}{ Pyramid Lake, not unialgal } \\
\hline $\begin{array}{l}\text { Nannochloris } \\
\text { Nannochloris } \\
\text { Yellow round } \\
\text { Green round } \\
\text { Coccoid green }\end{array}$ & $\begin{array}{l}17.4 \\
17.4 \\
17.4 \\
15.0 \\
15.0\end{array}$ & $\begin{array}{l}4.9 \\
4.9 \\
4.9 \\
4.7 \\
4.7\end{array}$ & $\begin{array}{c}++++ \\
+\end{array}$ \\
\hline \multicolumn{4}{|l|}{ Walker Lake, unialgal } \\
\hline $\begin{array}{l}\text { Cyclotella } \\
\text { Anacystis } \\
\text { Oocystis } \\
\text { Nannochloris } \\
\text { Nannochloris } \\
\text { Yellow-green flagellate } \\
\text { Yellow-green flagellate } \\
\text { Green ovoid } \\
\text { Green flagellate } \\
\text { Nitzschia } \\
\text { Nannochloris } \\
\text { Desmococeus } \\
\text { Cyclotella } \\
\text { Chlorella } \\
\text { Cosmarium } \\
\text { Anacystis }\end{array}$ & $\begin{array}{l}18.0 \\
18.0 \\
18.0 \\
18.0 \\
18.0 \\
18.0 \\
18.0 \\
13.5 \\
13.5 \\
13.5 \\
13.5 \\
13.5 \\
13.5 \\
13.5 \\
24.0 \\
24.0\end{array}$ & $\begin{array}{l}10.6 \\
10.6 \\
10.6 \\
10.6 \\
10.6 \\
10.6 \\
10.6 \\
10.3 \\
10.3 \\
10.3 \\
10.3 \\
10.3 \\
10.3 \\
10.3 \\
* 4.7 \\
* 4.7\end{array}$ & $\begin{array}{c}++ \\
++++ \\
+++ \\
++++ \\
++++ \\
++ \\
++\end{array}$ \\
\hline \multicolumn{4}{|l|}{ BATS, not unialgla } \\
\hline Chaetoceros & 24.0 & $* 4.7$ & \\
\hline \multicolumn{4}{|l|}{ Armagosa River, unialgla } \\
\hline $\begin{array}{l}\text { Green flagellate } \\
\text { Nitzschia sigmoida } \\
\text { Nitzschia }\end{array}$ & $\begin{array}{r}8.4 \\
24.0 \\
24.0\end{array}$ & $\begin{array}{l}8.4 \\
2.2 \\
2.2\end{array}$ & \\
\hline \multicolumn{4}{|c|}{ MISCELLANEOUS CALIFORNIA CULTURES } \\
\hline \multicolumn{4}{|l|}{ Salton Sea, unialgal } \\
\hline $\begin{array}{l}\text { Chaetoceros } \\
\text { Dunaliella } \\
\text { Nitzschia } \\
\text { Flagellate (agar) } \\
\text { Pennate (agar) } \\
\text { Flagellate }\end{array}$ & $\begin{array}{l}20.7 \\
20.7 \\
20.7 \\
20.7 \\
20.7 \\
20.7\end{array}$ & $\begin{array}{l}39.0 \\
39.0 \\
39.0 \\
39.0 \\
39.0 \\
39.0\end{array}$ & $\begin{array}{l}+++ \\
+++\end{array}$ \\
\hline \multicolumn{4}{|l|}{ Salton Sea, not unialgal } \\
\hline $\begin{array}{l}\text { Navicula + green alga } \\
\text { Green colony }\end{array}$ & $\begin{array}{l}20.7 \\
20.7\end{array}$ & $\begin{array}{l}39.0 \\
39.0\end{array}$ & \\
\hline \multicolumn{4}{|l|}{ Mono Lake, unialgal } \\
\hline $\begin{array}{l}\text { Nitzschia } \\
\text { Coccomyxa }\end{array}$ & & $\begin{array}{r}++++ \\
+++\end{array}$ & \\
\hline
\end{tabular}

a Total dissolved solids (TDS) calculated from conductivity measurements.

${ }^{b}$ Growth yield estimated visually by one person for all cultures. 
Table 2-5. Yields and Proximate Cellular Chemistry of Selected Desert Microalgae

\begin{tabular}{lcccc}
\hline \multicolumn{1}{c}{ Isolate and Origin } & $\begin{array}{c}\text { Yield } \\
\left(\mathrm{g} / \mathrm{m}^{2} \text { day) }\right.\end{array}$ & $\begin{array}{c}\text { Lipid } \\
(\%)\end{array}$ & $\begin{array}{c}\text { Carbohydrate } \\
(\%)\end{array}$ & $\begin{array}{c}\text { Protein } \\
(\%)\end{array}$ \\
\hline Ankistrodesmus (Pyramid Lake) & 11.5 & 31 & 24 & 36 \\
Nitzschia (Mono Lake) & 21.6 & 22 & 14 & 36 \\
Oocystis (Walker Lake) & $40^{\mathrm{a}}$ & 10.5 & 37 & 39 \\
Chlorella (Pond B) & 13.9 & 18 & - & 68 \\
Chlorella (Zzyzx) & 13.2 & 21 & 24 & 55 \\
\hline
\end{tabular}

${ }^{a}$ This yield experiment is being repeated.

Table 2-6. Responses of Some Saline Desert Algae to Temperature and Salinity

\begin{tabular}{|c|c|c|c|c|c|c|}
\hline \multirow[b]{2}{*}{$\begin{array}{c}\text { Isolate } \\
\text { (and Origin) }\end{array}$} & \multicolumn{3}{|c|}{ Temperature $\left({ }^{\circ} \mathrm{C}\right)$} & \multicolumn{3}{|c|}{ Salinity (g/L) } \\
\hline & $\begin{array}{l}\text { For Best } \\
\text { Growth }\end{array}$ & $\begin{array}{l}\text { Range } \\
\text { for Some } \\
\text { Growth }\end{array}$ & $\begin{array}{l}\text { Little } \\
\text { or No } \\
\text { Growth }\end{array}$ & $\begin{array}{l}\text { For Best } \\
\text { Growth }\end{array}$ & $\begin{array}{l}\text { Range } \\
\text { for Some } \\
\text { Growth }\end{array}$ & $\begin{array}{l}\text { Little } \\
\text { or No } \\
\text { Growth }\end{array}$ \\
\hline$\frac{\text { Nitzschia }}{\text { (Mono Lake) }}$ & $30-36$ & $15-36$ & $10,41-44$ & $50-70$ & $28-86$ & 9,120 \\
\hline$\frac{\text { Ankistrodesmus }}{\text { (Pyramid Lake) }}$ & 26 & $21-30$ & $11-16,35$ & 5.8 & $0.6-3$ & 8,11 \\
\hline$\frac{\text { Oocystis }}{\text { (Walker Lake) }}$ & $20-25$ & $16-33$ & 11 & 18 & $6.8-24$ & 1.2 \\
\hline$\frac{\text { Chlorella }}{\text { (Zzyzx) }}$ & 25 & $15-30$ & 9,34 & 12 & $3-12$ & - \\
\hline$\frac{\text { Cryptomonas }}{\text { (Harper Lake) }}$ & $16-30$ & $11-35$ & - & 36 & $2-36$ & - \\
\hline$\frac{\text { Dangeardinella }}{\text { (Saline Valley) }}$ & $30-35$ & $21-35$ & 10,16 & 266 & 206 & $27-146$ \\
\hline
\end{tabular}




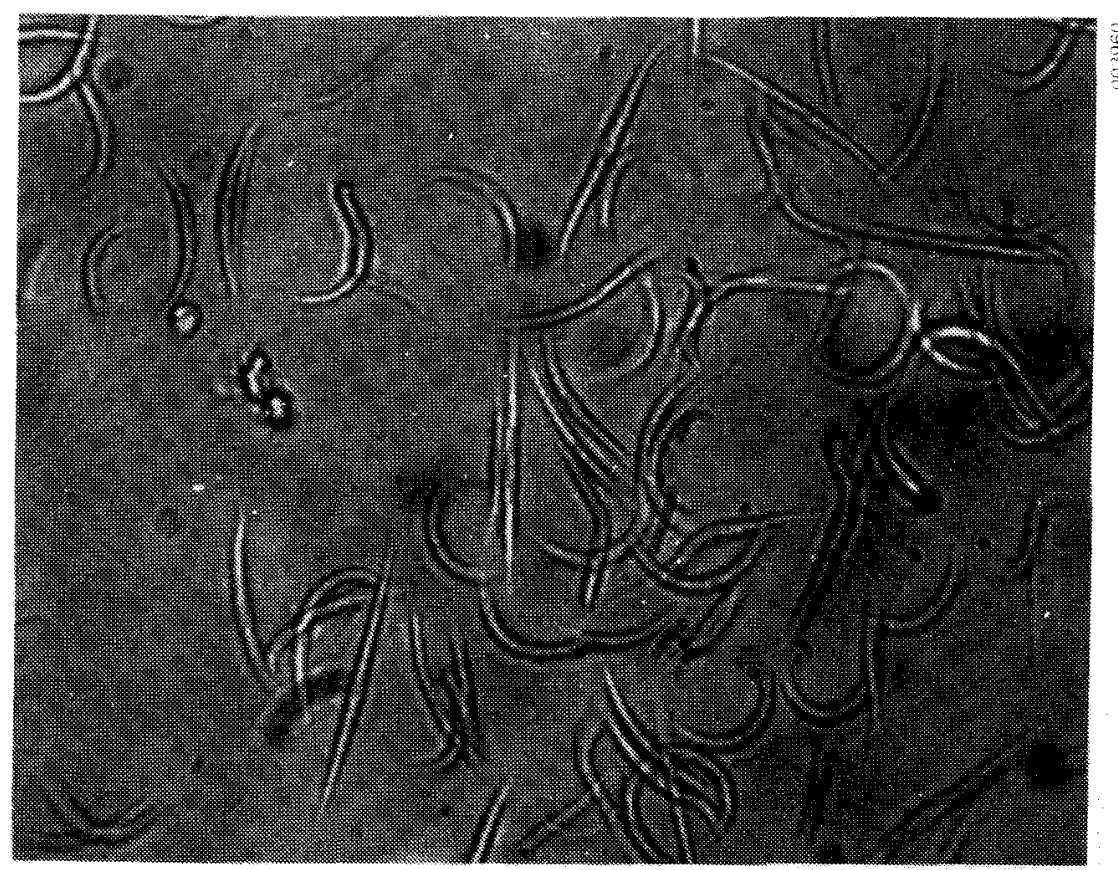

Figure 2-9a. Ankistrodesmus falcatus Isolated from Pyramid Lake

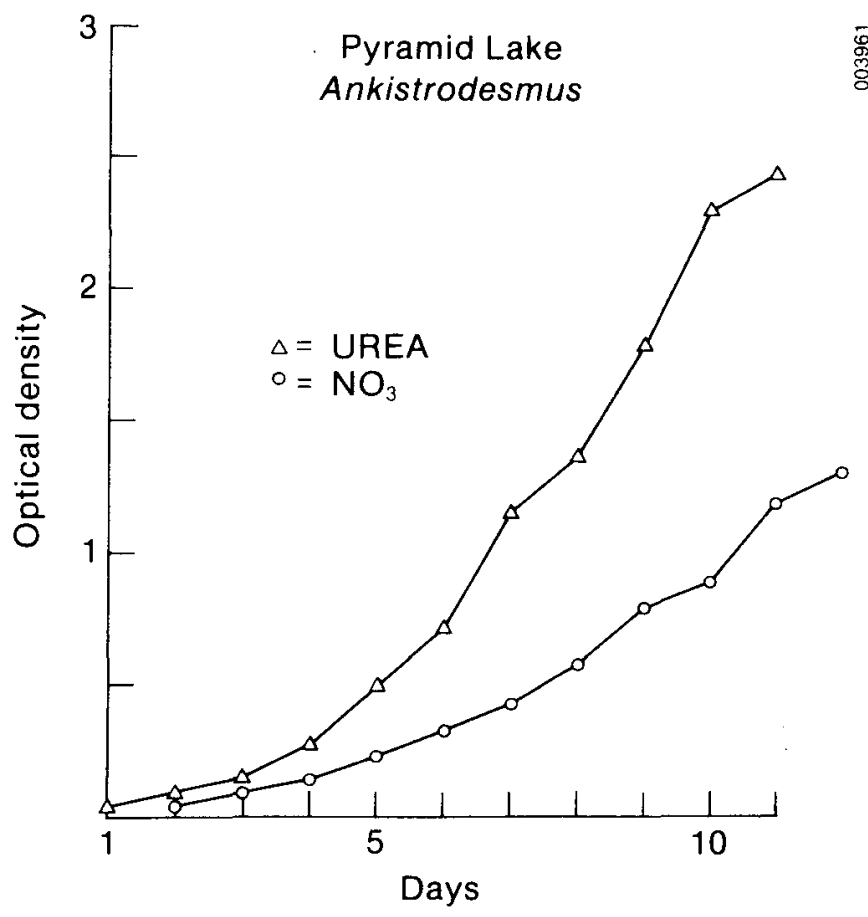

Figure 2-9b. Increases in Optical Density of Pyramid Lake Ankistrodesmus Cultures Grown on Nitrate and Urea 


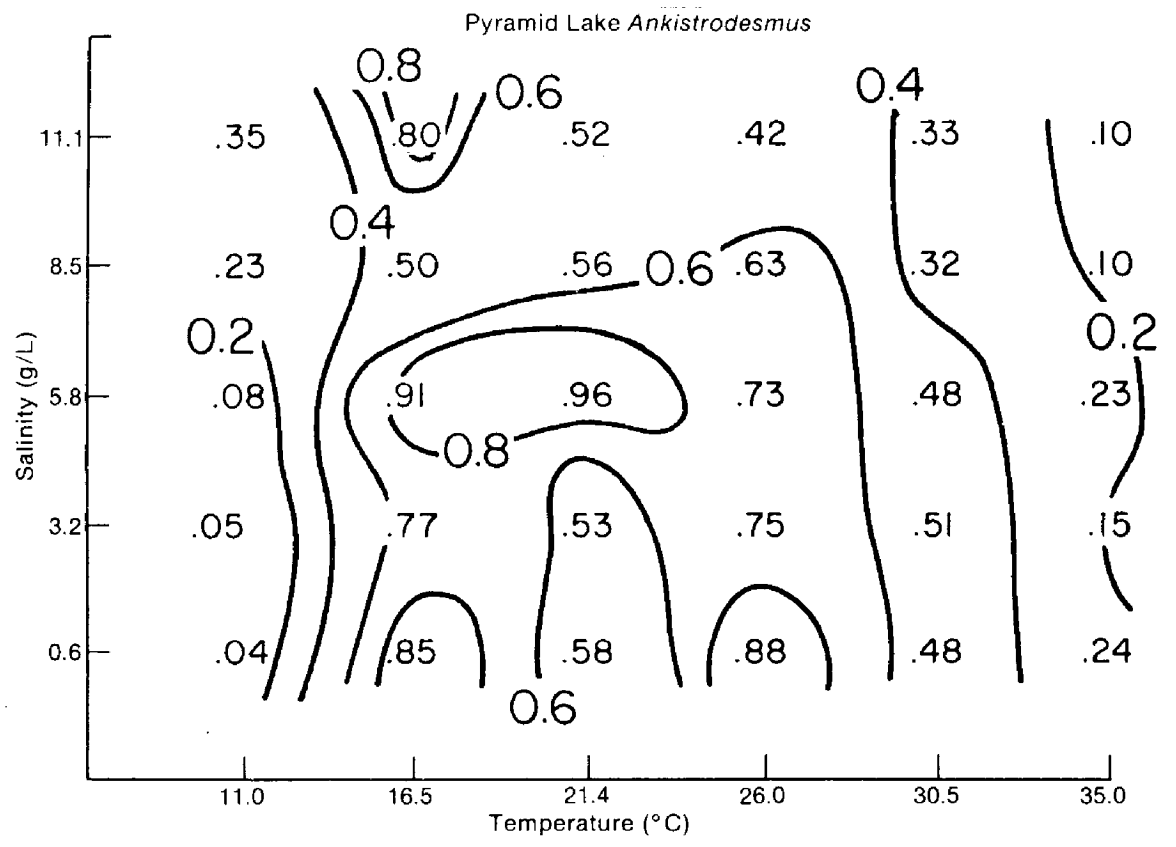

Figure 2-10. Growth Curve of Ankistrodesmus Showing Response to Salinity and Temperature

The proximate chemical composition of seven species of freshwaster, desert, and marine unicellular eukaryotic microalgae grown under controlled conditions was measured. Emphasis was placed on the analysis of lipids (Table 2-7). Ankistrodesmus, Dunaliella spp., Isochrysis, Nannochloris, and Nitzschia contained an average of $30 \%$ protein, $15 \%$ carbohydrate, and $25 \%$ lipid (the percentages are percentages of organic cell weight). Botryococcus braunii contained about $45 \%$ lipid. The effects of culture conditions on the proximate chemical composition of Botryococcus braunii, Dunaliella salina, and Isochrysis in nitrogen-deficient medium were a decrease in protein content and an increase in carbohydrate content; of Dunaliella salina, a decrease in lipids; and of Isochrysis, an increase in lipid content. Cultivation of Dunaliella salina in medium with an increased concentration of sodium chloride induced the accumulation of osmotic glycerol with minimal effect on the other constituents. In Botryococcus and Isochrysis, sodium stress was mainly expressed by reduced protein content.

Lipids may be divided into various classes of compounds, according to the polarity. Neutral lipids and triglycerides (fatty acids) are considered to have the most potential as fuels. Microalgae produce a variety of lipids, and the proportions of lipids change with growth conditions. (Table 2-8 shows the lipid concentrations for several species under different growth conditions.) The relative proportion of neutral lipids in Botryococcus braunii, Isochrysis sp., and a nitrogen-deficient culture Dunaliella bardawil was high, with multiply branched hydrocarbons predominating. The concentrations of the polar glycolipids and phospholipids in all species investigated were fairly typical of photosynthetic eukaryotic algae in general. The fatty acid compositions were species-specific with changes occurring in the relative frequencies of individual acid chains of cells cultivated under different conditions and growth phases. All species synthesized Cl4:0, Cl6:0, $\mathrm{C} 18: 1, \mathrm{Cl}$ 18:2, and $\mathrm{C} 18: 3$ fatty acids; Ankistrodesmus sp. synthesized $\mathrm{Cl6:4}$ and $\mathrm{C} 18: 4$; Isochrysis sp., C18:4 and C22:6; Nannochloris sp., C16:2, C16:3, and C20:5; and Nitzschia, $\overline{\mathrm{Cl}}$ 6:2, C16:3, and $\mathrm{C} 20: 5$. Nitrogen deficiency and salt stress induced the accumulation 
Table 2-7. Proximate Cellular Composition of Unicellular Algae Grown under Optimal, Nitrate-Deficient, or Salt Stress Conditions ${ }^{\mathbf{a}}$

\begin{tabular}{|c|c|c|c|c|c|c|c|}
\hline \multirow{2}{*}{ Species } & \multirow{2}{*}{$\begin{array}{l}\text { Growth } \\
\text { Conditions }\end{array}$} & \multirow{2}{*}{$\begin{array}{l}\text { \% Dry } \\
\text { Weight } \\
\text { Ash }\end{array}$} & \multicolumn{5}{|c|}{ \% Organic Weight } \\
\hline & & & Protein & Carbohydrate & Lipid & Glycerol & Unknown \\
\hline \multirow[t]{3}{*}{ Botryococcus braunii } & FW, NE & 5.6 & 22.0 & 14.1 & 44.5 & 0.1 & 19.3 \\
\hline & FW, ND & 7.8 & 20.6 & 14.3 & 54.2 & 0.1 & 10.8 \\
\hline & $0.5 \mathrm{M} \mathrm{NaCl}, \mathrm{NE}$ & 59.6 & 15.0 & 13.3 & 46.3 & 0.1 & 25.3 \\
\hline Dunaliella bardawil & $2 \mathrm{M} \mathrm{NaCl}, \mathrm{ND}$ & 14.7 & 9.7 & 40.4 & 10.4 & 16.4 & 23.1 \\
\hline \multirow[t]{3}{*}{ Dunaliella salina } & $0.5 \mathrm{M} \mathrm{NaCl}, \mathrm{NE}$ & 8.6 & 29.3 & 16.3 & 25.3 & 9.4 & 19.7 \\
\hline & $0.5 \mathrm{M} \mathrm{NaCl}, \mathrm{ND}$ & 7.7 & 12.5 & 55.5 & 9.2 & 4.7 & 18.1 \\
\hline & $2 \mathrm{M} \mathrm{NaCl}, \mathrm{NE}$ & 21.7 & 35.9 & 12.5 & 18.5 & 27.7 & 5.4 \\
\hline Ankistrodesmus sp. & $\mathrm{FW}, \mathrm{NE}$ & 4.5 & 31.1 & 10.8 & 24.5 & 0.1 & 33.5 \\
\hline \multirow[t]{3}{*}{ Isochrysis $\mathrm{sp}}$. & $0.5 \mathrm{M} \mathrm{NaCl}, \mathrm{NE}$ & 12.0 & 37.0 & 11.2 & 7.1 & 0.1 & 44.6 \\
\hline & $0.5 \mathrm{M} \mathrm{NaCl}, \mathrm{ND}$ & 52.0 & 23.3 & 20.5 & 26.0 & 0.1 & 30.1 \\
\hline & $1 \mathrm{M} \mathrm{NaCl}, \mathrm{NE}$ & 65.9 & 34.7 & 15.5 & 15.3 & 0.1 & 34.4 \\
\hline Nannochlor is $\mathrm{sp}$. & FW, NE & 13.6 & 33.1 & 13.2 & 20.8 & 0.1 & 32.8 \\
\hline Nitzschia sp. & $1.4 \mathrm{M} \mathrm{Na}^{+}, \mathrm{NE}$ & 20.4 & 16.8 & 9.2 & 12.1 & 0.1 & 61.8 \\
\hline
\end{tabular}

${ }^{a}$ Analyses of five different algal cultures of each species were conducted; statistical analysis showed no standard error greater than $10 \%$.

$\mathrm{b}_{\mathrm{FW}}=$ Freshwater, $\mathrm{NE}=$ Nutrient enriched, ND $=$ Nutrient deficient. 
Table 2-8. Fractionation of Algal Lipids on Unisil Columns ${ }^{2}$

\begin{tabular}{|c|c|c|c|c|c|c|}
\hline \multirow{2}{*}{ Species } & \multirow{2}{*}{$\begin{array}{l}\text { Growth } \\
\text { Conditions }\end{array}$} & \multicolumn{5}{|c|}{ \% Total Lipid Weight } \\
\hline & & Hydrocarbon & Isoprenoid & Triglyceride & Glycolipids & Phospholipids \\
\hline \multirow[t]{3}{*}{ Botryococcus braunii } & $\mathrm{FW}, \mathrm{NE}$ & 4.6 & 51.4 & 4.5 & 30.0 & 9.4 \\
\hline & FW, ND & 14.9 & 52.7 & 3.4 & 21.6 & 7.4 \\
\hline & $0.5 \mathrm{M} \mathrm{NaCl}, \mathrm{NE}$ & 5.2 & 46.0 & 28.5 & 9.3 & 9.7 \\
\hline Duna liella bardawil & $2 \mathrm{M} \mathrm{NaCl}, \mathrm{ND}$ & 0.1 & 49.9 & 14.8 & 24.1 & 10.8 \\
\hline \multirow[t]{3}{*}{ Dunaliella salina } & $0.5 \mathrm{M} \mathrm{NaCl}, \mathrm{NE}$ & 0.1 & 0.4 & 6.3 & 76.8 & 16.5 \\
\hline & $0.5 \mathrm{M} \mathrm{NaCl}, \mathrm{ND}$ & 0.1 & 24.8 & 20.6 & 31.7 & 22.8 \\
\hline & $2 \mathrm{M} \mathrm{NaCl}, \mathrm{NE}$ & 0.2 & 2.1 & 28.2 & 55.9 & 13.6 \\
\hline Ankistrodesmus sp. & FW, NE & 0.7 & 1.8 & 39.6 & 40.9 & 17.0 \\
\hline \multirow[t]{3}{*}{ Isochrysis $\mathrm{sp}}$. & $0.5 \mathrm{M} \mathrm{NaCl}, \mathrm{NE}$ & 1.4 & 27.4 & 32.1 & 26.3 & 12.6 \\
\hline & $0.5 \mathrm{M} \mathrm{NaCl}, \mathrm{ND}$ & 2.2 & 28.4 & 18.0 & 26.0 & 25.3 \\
\hline & $1 \mathrm{M} \mathrm{NaCl}, \mathrm{NE}$ & 1.4 & 23.6 & 13.6 & 43.0 & 18.4 \\
\hline Nannochlor is sp. & $\mathrm{FW}, \mathrm{NE}$ & 0.2 & 5.9 & 32.5 & 35.9 & 25.5 \\
\hline Nitzschia sp. & $1.4 \mathrm{M} \mathrm{Na}^{+}, \mathrm{NE}$ & 0.2 & 1.7 & 51.2 & 22.0 & 24.6 \\
\hline
\end{tabular}

${ }^{a}$ Proportions of lipid eluates were determined by gas-liquid chromatography for the hexane eluate and gravimetrically for the others.

${ }^{b_{F W}}=$ freshwater, $\mathrm{NE}=$ nutrient enriched, ND = nutrient deficient. 
of $\mathrm{C18:1}$ in all treated species and to some extent C20:5 in Botryococcus braunii. These data provide additional evidence for the concept of biochemical classification and its control by environmental factors. During 1984, additional species will be characterized chemically with an emphasis on understanding how environmental changes influence lipid composition.

In addition to screening activities at Scripps and Georgia Tech, species will be collected and characterized by researchers at Alabama A\&M (salt marsh species), the Solar Energy Research Institute (Colorado halophytic species), and Ben Gurion University in Israel (halotolerant species shown to be oil rich). A preliminary literature search provided the basis for selecting Isochrysis, Monallanthus, and Chlorella as species for further study. Culture conditions will be defined and sustainable outdoor yields will be determined.

Finally, in 1983, the need for a centralized microalgae culture collection was identified. During the next year a steering committee will select the most promising species for fuel production, and include the $m$ in a specialized culture collection. The purpose of this collection is to make a unique and specialized set of species and data available to all organizations wishing to research, develop, or apply the capabilities of oil-producing microalgae.

\subsubsection{Species Improvement: Microalgae}

Species improvement comprises three areas of research: (1) culture manipulation and (2) metabolic regulation to enhance lipid production, and (3) genetics to develop the most useful strains. The emphasis has been on establishing lipid triggers in various species of microalgae through culture manipulation. A lipid trigger is the mechanism by which the metabolism of a microalgal culture may be switched from a state of cell division to that of lipid accumulation or switched from synthesis of one lipid fraction to another. For example, preliminary results of culture manipulation of Isochrysis have shown a marginal shift to higher total lipid production and a dramatic shift (40\%) toward increased neutral lipid production. This result is significant because maximum production of higher-value products such as these neutral lipids is desirable.

Researchers at the Solar Energy Research Institute have investigated the photophysiological and metabolic response of a strain of Chlorella to nutrient deficiency. Their studies indicate that high rates of biomass production can be maintained for 5-7 days after severe nitrogen starvation, even though cell division stops during this period. Furthermore, during this stage of no reproductive growth, 80\%-90\% of the newly produced algal mass appears as intracellular storage oil and lipids (Figure 2-11). The algal cells are characterized by an increase in cell volume (Figure 2-12) and a great reduction in the complexity of their intracellular membrane structures. Isotope tracer studies indicated that the increase in lipids was due to a synthesis of triglycerides. During this switch in metabolism, the amount of carbon incorporated into the cell dropped $60 \%$.

New evidence suggests that nonlipoidal material is not converted to lipids during periods of darkness, as was previously believed. The apparent synthesis of lipid in the dark does not appear to be due to the conversion of nonlipoidal storage materials into lipid. Instead, respiration preferentially consumes nonlipoidal material, whereas lipids are nearly totally conserved. Net production of additional lipids can occur only under illumination. 


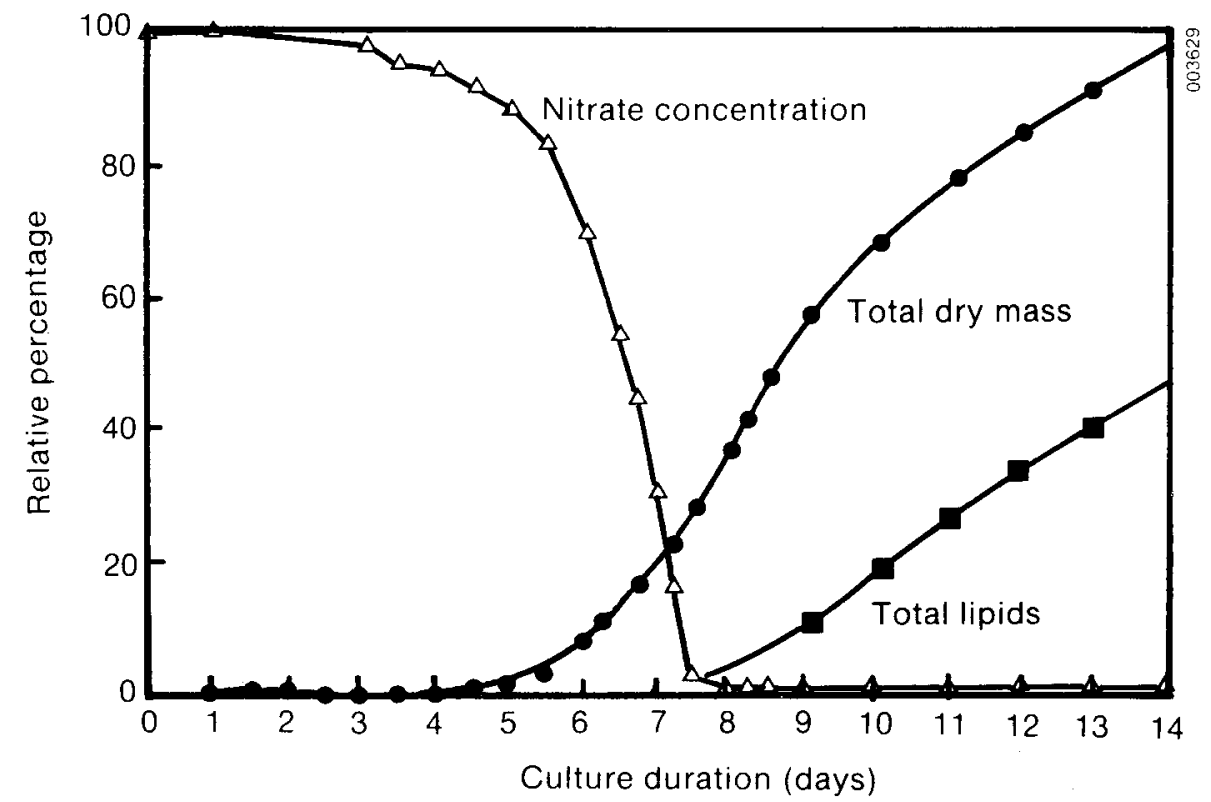

Figure 2-11. Physiological Responses of Chlorella Nitrogen-Limitation

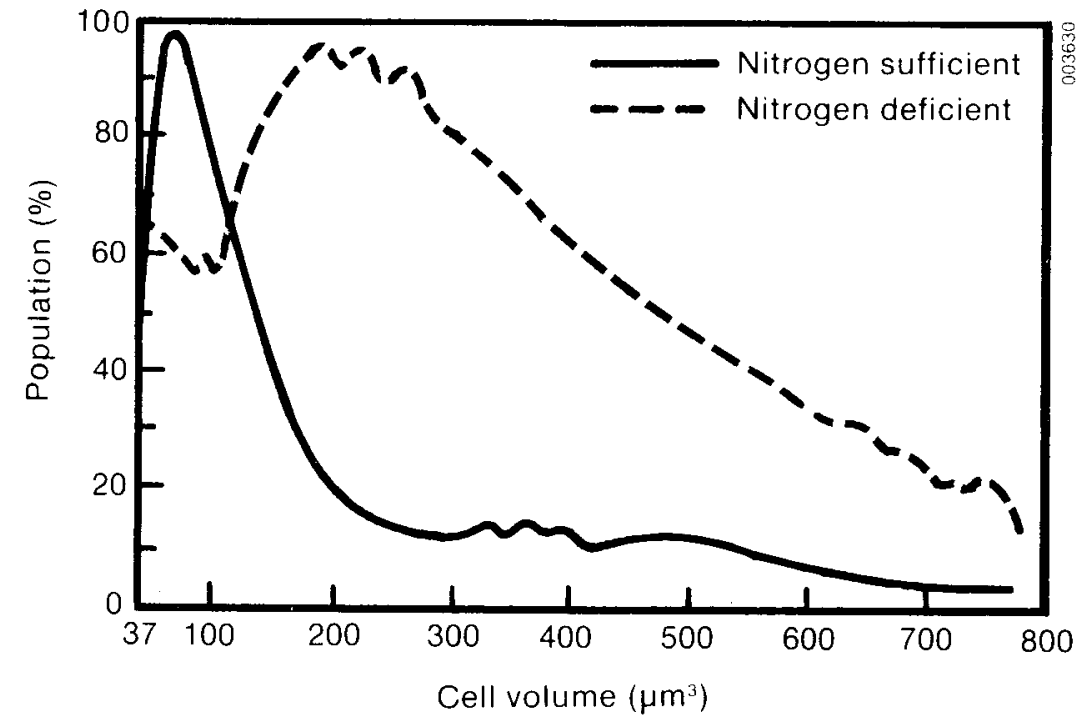

Figure 2-12. Changes in Cell Volume as a Result of Nitrogen Deprivation 
The Aquatic Species subprogram will continue to emphasize research on improving lipid yields through culture manipulation. Work is also being initiated to determine if, by the deregulation of various metabolic pathways, the yield of neutral lipids can be increased.

Researchers will also begin to isolate strains of species of microalgae that are promising. (Strains are genetic variants of the same species.) The physiological differences between strains of microalgae have been demonstrated to be as great as between species. At the University of Hawaii, strains of Phaeodactylum were tested for growth and lipid content. As shown in Table 2-9, different strains exhibited extreme differences in growth and lipid content response. Isolation of multiple strains of a promising species will allow development of a gene pool, which will be essential for future improvements through the application of genetics.

\subsubsection{Engineering Research and Development}

The objective of engineering research is to integrate biological concepts with engineering principles to develop a cost-effective microalgal culture technology. To accomplish this, engineering research is divided into three tasks: design coordination, component development, and experimental facilities.

\subsubsection{Design Coordination}

The objective of this subtask is to combine engineering criteria with biological perspectives to develop new approaches, novel systems, or design adaptations that stimulate research and development.

Jaycor, a subcontractor in the Aquatic Species subprogram is conducting systems analyses relating the complex interactions of a variety of physical, biological, and engineering variables, and comparing and evaluating system benefits and technical uncertainties. During the past year Jaycor reviewed the literature and summarized the existing microalgae technologies. This work led to the categorization of microalgal production designs into five basic concepts. The five basic concepts of production systems were organized according to the three most critical design factors: culture depth, mixing strategy, and enclosure configuration. The concepts are:

- Open bubbling systems

- Open pool circulation systems

- Deep open raceway cultivation systems

- Shallow open raceway cultivation systems

- Shallow closed raceway cultivation systems.

The extent of the diversity of design ideas has been documented in the publication Algal Mass Culture Technology Review of Patents. In addition, a technology review of microalgae harvesting technology was completed by Ben Gurion University.

A number of microalgal systems have been operated both commercially and experimentally during the past 30 years. Because of the variety of design approaches used in these systems, it is not possible to use one or two figures of merit (such as yield and 
Table 2-9. Comparison of Growth Responses and Lipid Content of Six Strains of Phaeodactylum

\begin{tabular}{lrrrrr}
\hline \multirow{2}{*}{ Strain } & \multicolumn{3}{c}{ Relative Growth } & \% Lipid \\
\cline { 2 - 4 } & $20^{\circ} \mathrm{C}$ & $25^{\circ} \mathrm{C}$ & $28^{\circ} \mathrm{C}$ & \\
\hline Scripps & 0.70 & 0.30 & death & 21 \\
Utex & 640 & - & 0.45 & 0.50 & - \\
& 642 & 0.75 & 0.40 & 0.35 & - \\
& 646 & 1.00 & 0.45 & 0.25 & 10 \\
& 2089 & 0.95 & 0.20 & 0.25 & 15 \\
\hline
\end{tabular}

product cost) for each system to determine which systems are best. None of the commercial systems were designed for low-cost production. Since they produce a high-value product--protein--few or no attempts have been made to minimize costs and maximize productivity. When producing fuels, costs must be minimized while maximizing productivity, if microalgal oils are to compete with petroleum products on the world market (Figure 2-13). It is possible to look at the operating characteristies along with the yields and costs for each system, observe the positive and negative aspects of each design, note problems common to all systems, and decide which systems or combinations of design factors are worth pursuing.

A mass culturing model was designed by Scientific Applications, Inc. (SAI), to provide an analytical tool for evaluating microalgal production systems, taking into account the effects of the complex interaction of the many biological, physical, chemical, and engineering factors involved in algae production, harvesting, and processing into final products. Essentially a process simulation model to describe the operations of a production facility, the model is designed with sufficient flexibility to describe and evaluate alternative cultivation designs and techniques. The production model has been coded and operated on the SERI computer system, and satisfactory correlations have been developed using the model to describe a thirty-day production cycle of the raceway at the University of Hawaii and production by the ponds operated by Microbial Products (see Section 2.3.2.2 for description of these systems).

\subsubsection{Experimental Facilities}

There are several reasons for establishing outdoor experimental mass culture facilities: (1) The performance of various systems can be compared. (2) Strategies for mass culture management can be developed. (3) Laboratory tests can be scaled up. (4) Laboratoryselected microalgae strains can be tested in outdoor mass culture. Presently SERI supports two experimental facilities: one is operated by the University of Hawaii, and the other by Microbial Products, Inc. (formerly EnBio, Inc.) in California. Figure 2-14 is a schematic of the raceway in Hawaii, and Figure 2-15 is a diagram of the pond system operated by Microbial Products. The two systems differ primarily in depth: the ponds are operated at $20 \mathrm{~cm}$ and the raceways at $10 \mathrm{~cm}$. The mixer types, harvesting methods, and media salinities also differ. 


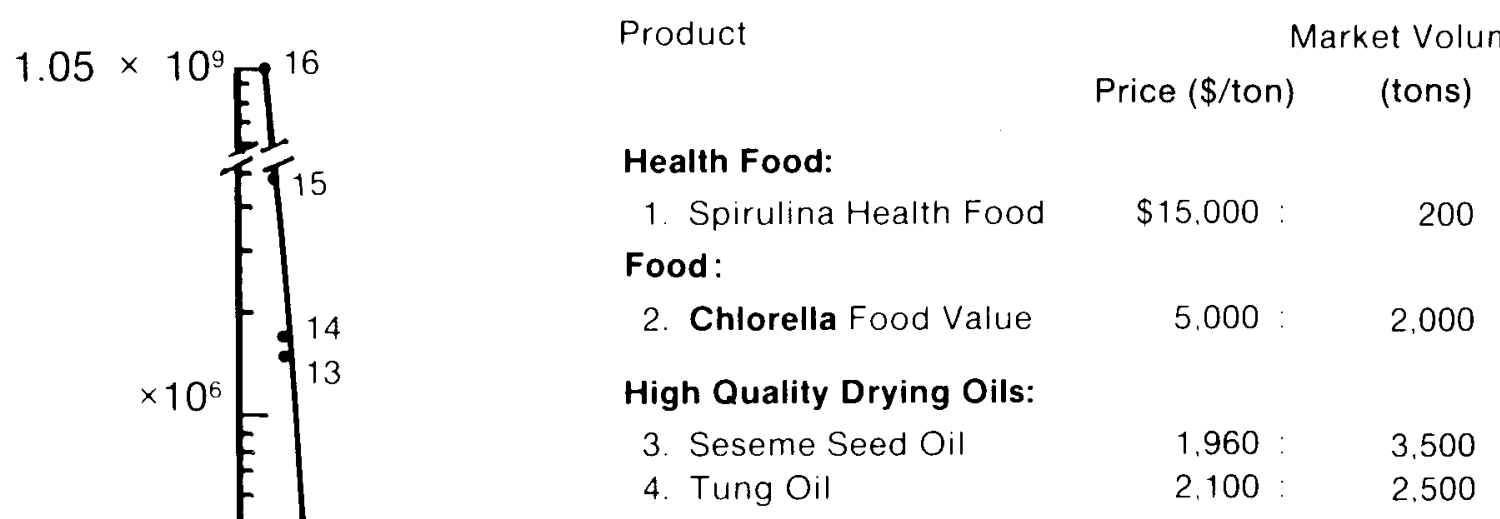

\section{General Drying Oils and Vegetable Oils:}

5. Safflower Oil $900: \quad 3,000$

6. Castor Oil $640: \quad 6,500$

7. Linseed Oil $680: \quad 15,000$

8. Peanut Oil 320: 17,500

9. Cotton Seed Oil 620: $\quad 35,000$

10. Corn Oil $680: 40,000$

11. Palm Oil $540: 45,000$

\section{Bulk Feeds:}

12. Peanut Meal

13. Linseed Meal

14. Cotton Seed Meal

15. Soybean Meal

$340: \quad 50,000$

$240: 1,500,000$

$220: 1,750,000$

$220: \quad 4,500,000$

Fuels:

16. Crude Petroleum $180: 1: 05 \times 10^{9}$

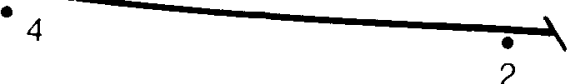

$\times 10^{3}$

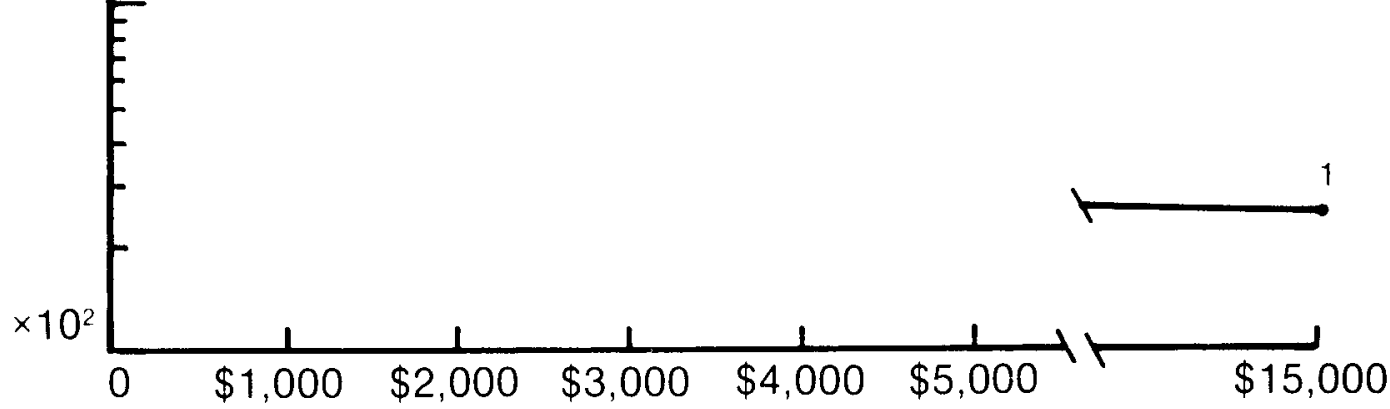

Price (1982 \$/ton) 


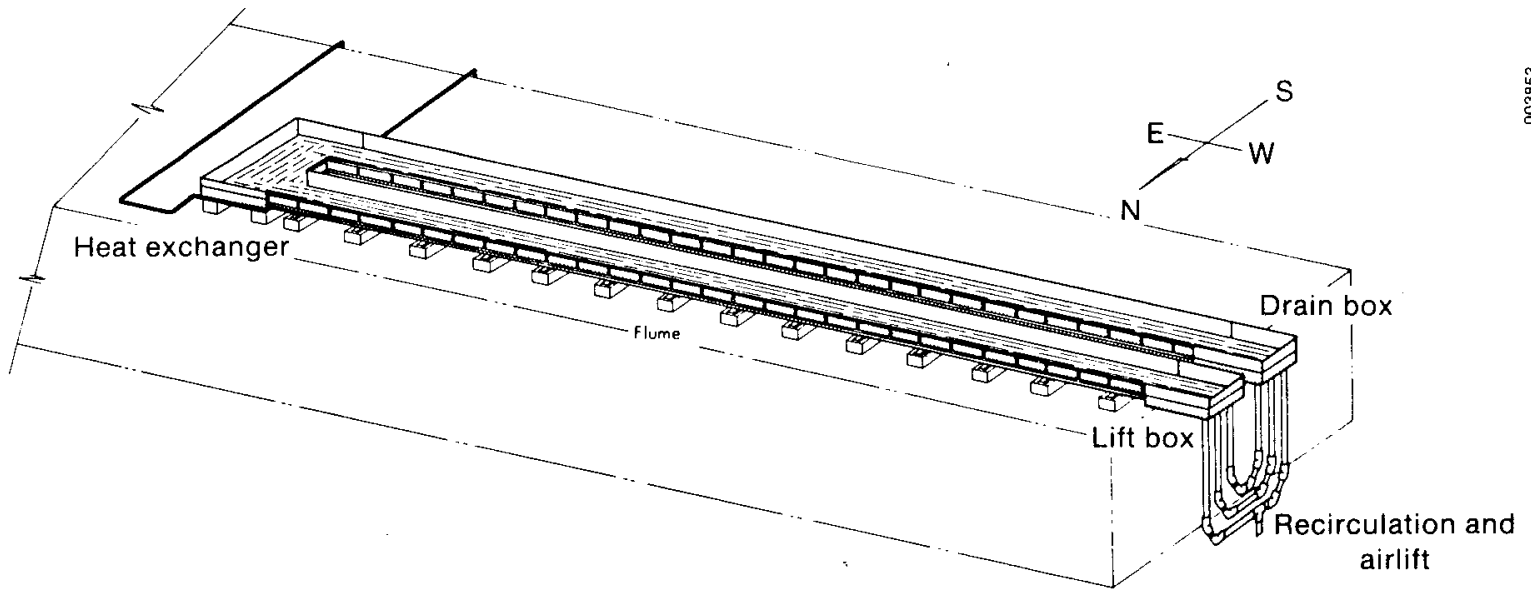

Figure 2-14. Algal Production Flume, Including Location of Heat Exchanger, Lift Box, Drain Box, and Airlift System

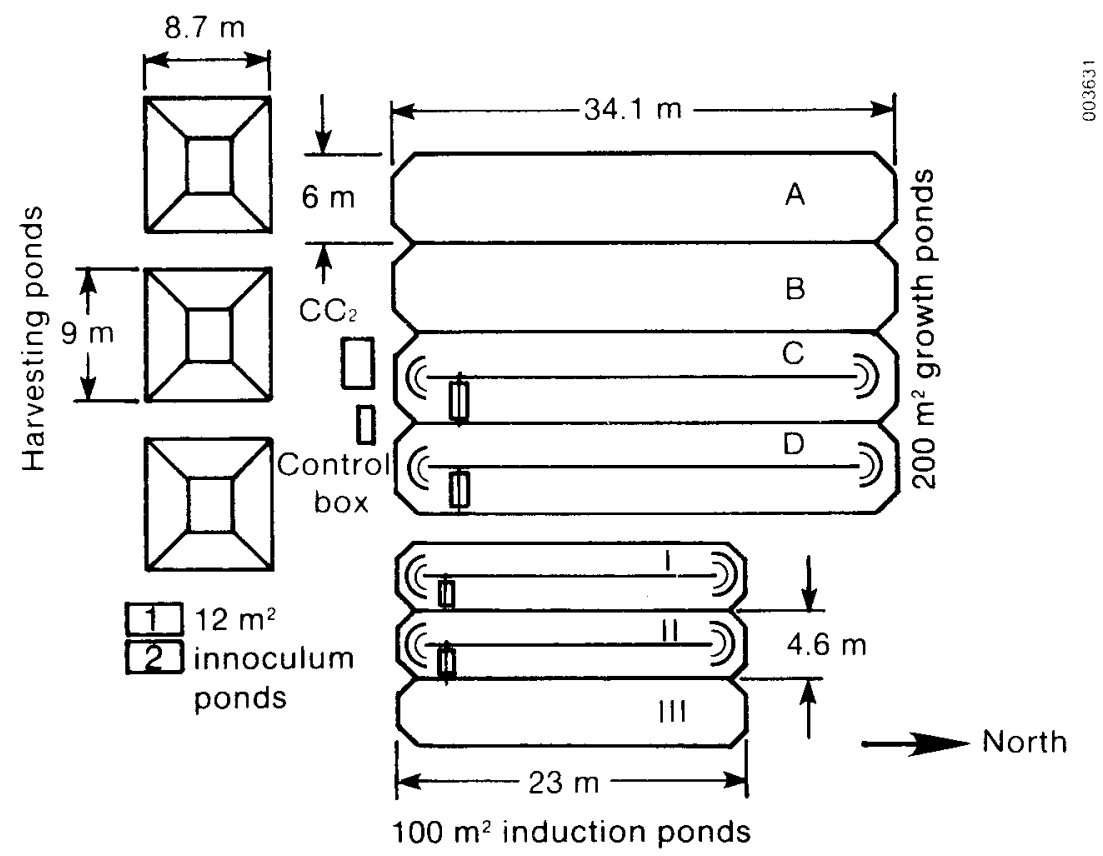

Figure 2-15. Pond System Operated by Microbial Products Co. 
The shallower raceway permits the use of foils, which effect systematic vertical mixing in the raceway. The foils are shaped like airplane wings, forcing the water flowing over them to spiral downward, creating a helical flow pattern downstream of the foil (Figure 2-16a). The optimum angle of attack is approximately 23 degrees at the flow rate and culture depth of the system, with the foil arrays placed $1.2 \mathrm{~m}$ apart. Biomass production after insertion of the foils increased $50 \%$. This enhancement is assumed to result from more efficient utilization of the flashing light effect. The flashing light effect is the increase in productivity that results from exposing microalgae to intermittent flashes of dark and light. A modeling effort to describe this flashing light effect was completed and the following points were observed: (1) At very low light intensity, there is no flashing light effect, (2) at very low cell densities there is no flashing light effect, and (3) the magnitude of enhancement from the flashing light effect increases with increased light intensity and increased cell density. The relationship between cell density, light intensity, and enhanced growth is shown in Figure 2-16b.

Performances of the two systems were established during the past year for a number of different species (see Table 2-10). Hawaii cultured the marine diatom Phaeodactylum and the marine flagellate Platymonas, while Microbial Products cultured two freshwater strains of Scenedesmus and a brackish water strain of Ankistrodesmus falcatus isolated from Pyramid Lake. Cultures were sustained for periods of one to three months. Cold and wet spring weather in California prevented Microbial Products from running the cultures for any extended period of time. Performance data from the two systems indicate species selection was most important. The shallower raceway established denser cultures but cultures of Phaeodactylum required cooling. The large amount of energy required to cool the raceway has caused the investigators in Hawaii to look for thermophilic strains of microalgae for culture. They found that Platymonas grows at much higher temperatures $\left(28^{\circ}-30^{\circ} \mathrm{C}\right)$ than Phaeodactylum, thus eliminating the cooling requirement. One of the better performing species cultured at Microbial Products was the laboratoryselected Ankistrodesmus. It consistently had the highest lipid content, averaging $28 \%$ of the organic weight. After investigators discovered that this species requires potassium, productivities with added potassium increased over those initially obtained. Researchers at Scripps found that maximum yields for this species occurred at light intensities equivalent to 50\%-60\% full California sunlight. In dense cultures they observed that the light was attenuated by five orders of magnitude in the first centimeter of culture thickness. This indicates the importance of culture mixing and hydrodynamic studies. Work will continue with Ankistrodesmus next year, when long-term productivity data will be obtained from both the raceways and ponds.

Cost analyses indicate that operational costs associated with the two systems represent approximately $70 \%$ of the total annualized costs. The major cost will be for nutrients, followed by utilities (pumping of water, operation of harvesting systems, and mixing requirements). Because the raceway has a much greater mixing velocity $(30 \mathrm{~cm} / \mathrm{s}$ versus $20 \mathrm{~cm} / \mathrm{s}$ ), associated mixing energy costs are 4 times greater than those for the pond. Pumping costs, however, are 4 times greater for the pond system because the volume of the system is larger.

An important aspect of the work at the University of Hawaii is to evaluate and optimize system parameters for selected species. During 1983, factorially designed experiments were conducted in four $8-\mathrm{m}^{2}$ raceways with Phaeodactylum to determine optimum system operating parameters. The factorial design allowed for efficient determination of effects of variable culture parameters; i.e., salinity, $\mathrm{pH}$, temperature, depth, mixing speed, and dilution rate. Researchers found that the most important factors to consider 


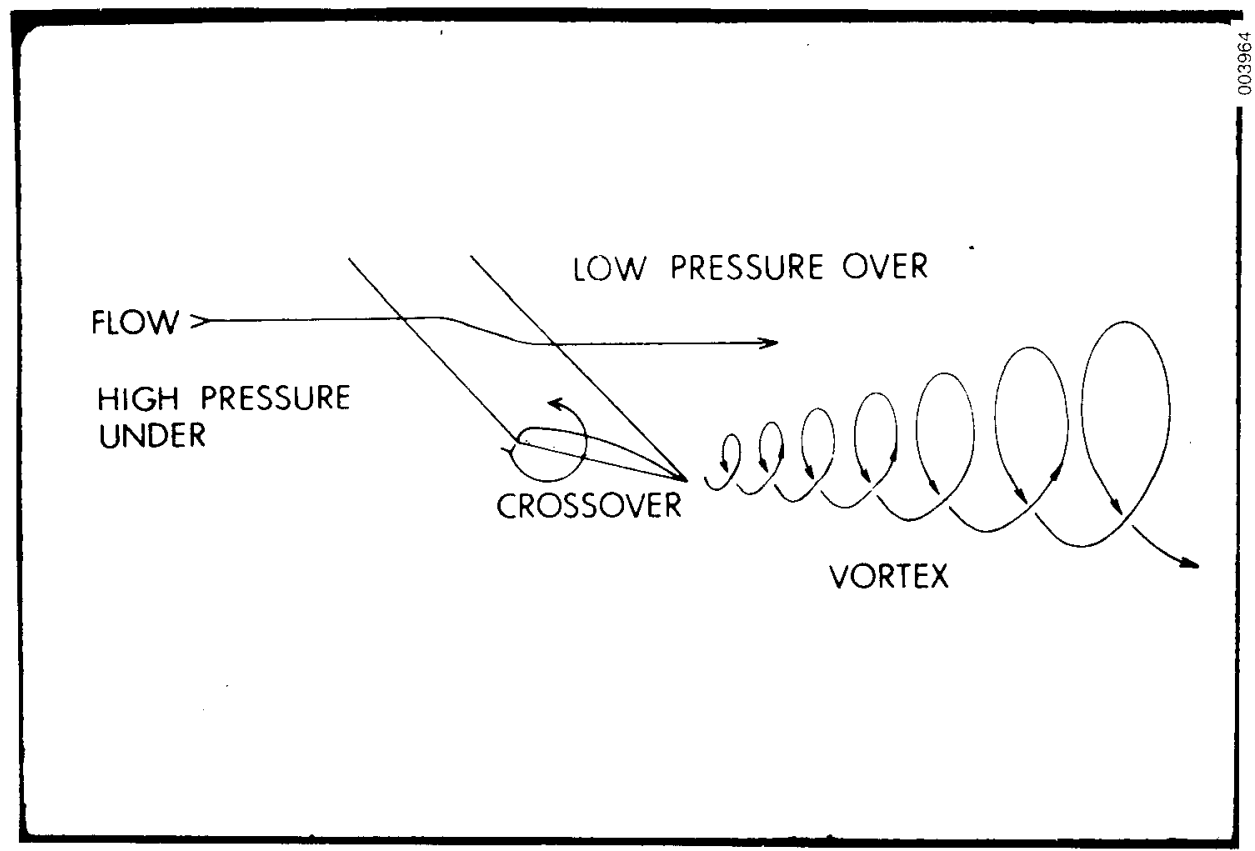

Figure 2-16a. Systematic Mixing Resulting from Foils Inserted in the Shallow Raceway

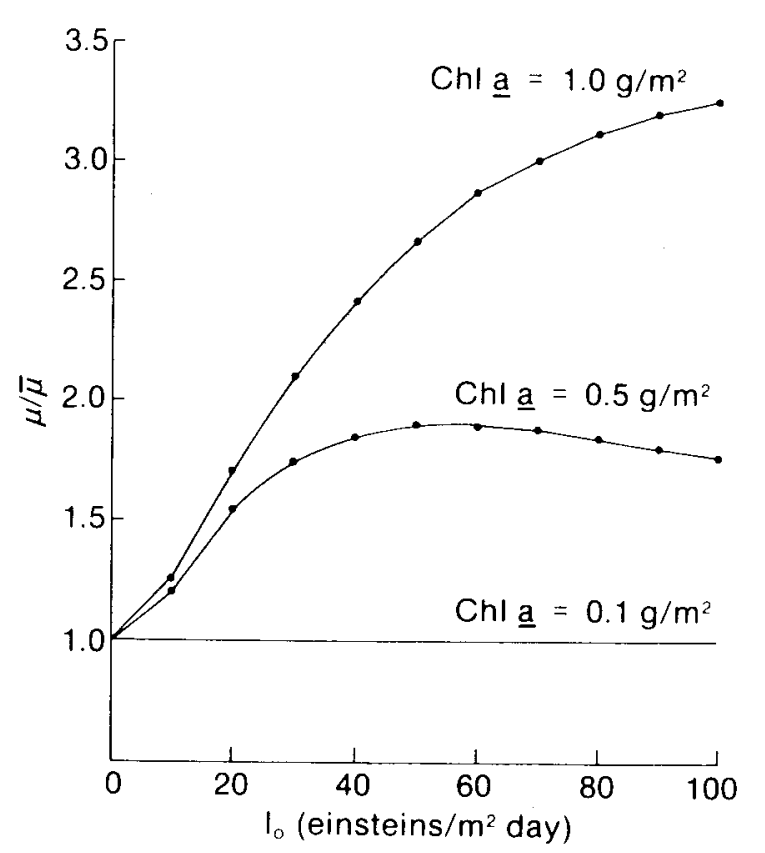

Figure 2-16b. Ratio of Growth Rate under Ideal Flashing Light Regime to Growth Rate in Absence of Flashing Light Effect as a Function of Incident Irradiance and Areal Chl a Concentration 
Table 2-10. Performance Data from Raceway and Pond Systems

\begin{tabular}{|c|c|c|c|c|}
\hline & \multicolumn{2}{|c|}{ Raceway } & \multicolumn{2}{|c|}{ Pond } \\
\hline & Phaeodactylum & Platymonas & Ankistrodesmus & Scenedesmus \\
\hline $\begin{array}{l}\text { Produc tivity } \\
\text { (g dry } w t / m^{2} \text { day) }\end{array}$ & 20 & 25 & 16 & 20 \\
\hline Lipid content (\%) & 22 & 20 & 28 & 20 \\
\hline $\begin{array}{l}\text { Culture density } \\
\text { (mg dry wt/L) }\end{array}$ & 800 & 900 & 300 & 250 \\
\hline
\end{tabular}

in the design and operation of the raceway are depth, dilution rate, $\mathrm{pH}$, and temperature. The following chart lists these factors in descending order of importance for production, lipid yield, and sustained monoculture. Optimal values are given in parentheses.

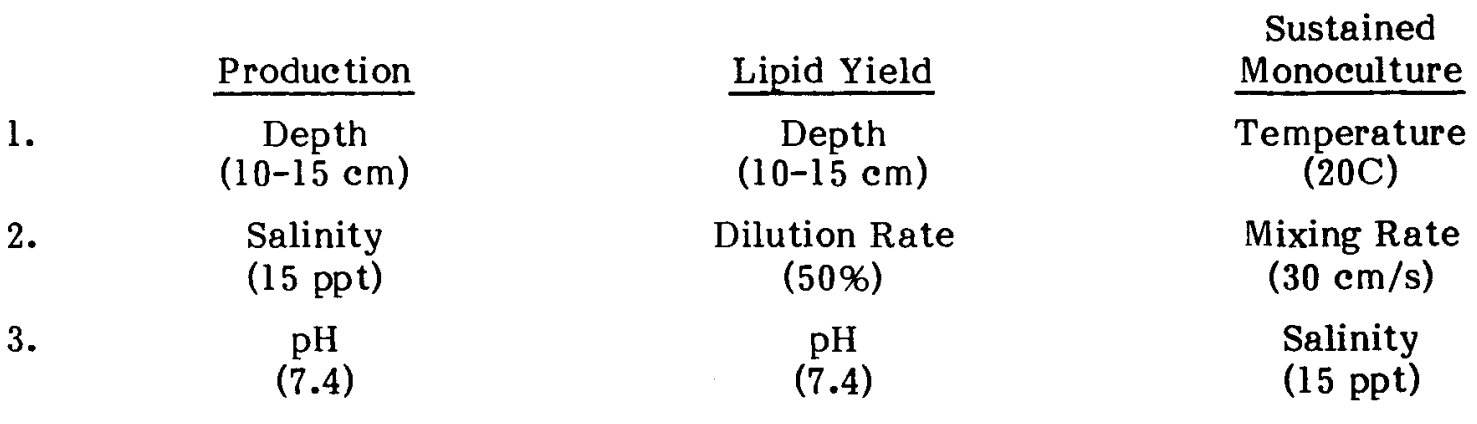

Production rates were optimal with a dilution rate of $60 \%$ and a pH of $7.2-7.4$ (see Figure 2-17). This type of work and experimentation will continue to be emphasized by the subprogram during 1984 .

\subsubsection{Component Development}

One of the more significant problems in producing microalgae-derived oils is the concentration of dilute suspensions into a slurry for subsequent processing. The extent to which present technology for harvesting is economic for microalgae production depends upon the final product value and the type of species used in the growth ponds. For example, existing microalgae facilities producing health food and protein supplements use species such as Spirulina which have a sufficiently large cell size and high enough product value to compensate for a high harvesting expense. Because some of the microalgal species studied in the Aquatic Species subprogram are approximately the size of bacteria and the value of the product fuel is not as high, an effective yet cheaper harvesting technology is required.

The subprogram has developed several research tasks designed to evaluate existing harvesting methods and to propose innovative methods for increasing the density of the product stream from the growth ponds. Work on harvesting technology is being evaluated at Ben Gurion University, and during 1984 subcontracts will be issued for the design of innovative culture and harvesting concepts. 


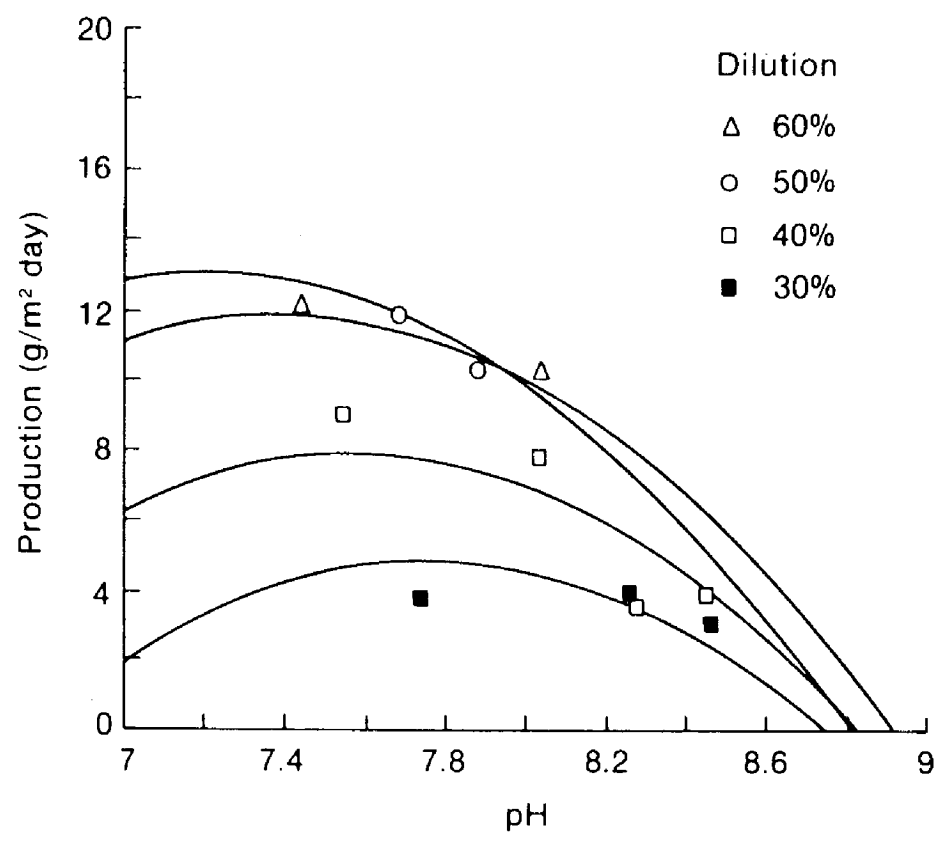

Figure 2-17. Production in Experimental Flumes as a Function of $\mathrm{pH}$ and Dilution Rate

\subsubsection{Technology Analysis}

The technology analysis activities provide $R \& D$ guidance for the Aquatic Species subprogram by analyzing and integrating the results of the biological and engineering research tasks. This in-house work is accomplished by conducting systems studies of the various research initiatives and identifying the $R \& D$ options that of fer potential gains to the overall program objectives. There are two tasks in the activity: resource assessment and economic evaluations.

\subsubsection{Resource Assessment}

The objective of this project is to assess and evaluate the availability and location of resources required for support of microalgal oil production. A resource assessment of the American Southwest was conducted by SERI's Renewable Resource Assessment and Instrumentation Branch. The researchers collected critical resource data for microalgal production. Available land and water resources found in the region were quantitatively and qualitatively estimated, and essential climatic data was gathered. These data were assembled in map for $\mathrm{m}$ to aid identification of suitable sites for future production facilities. Climate, land, and water maps were overlaid in a computer geographic information system to stratify the Southwest into zones of suitability for microalgal productions (mapped data is shown in Figure 2-18). The composite maps will enable future researchers to identify and quantify site-specific parameters that may affect facility design and operation.

Data bases were developed in the following areas: 
Climate. Combining evaporation and precipitation maps produced a map of makeup water requirements. A map of relative productivity was prepared by combining the parameters of insolation and freeze-free periods. A composite map of overall climatic suitability combined the two preliminary composite maps of makeup water requirements and relative productivity plus thunderstorm days. In this composite, equal weights were designated for makeup water and relative productivity; thunderstorm days were weighted at one-quarter of the value of the other two parameters.

Water. A composite map of water suitability was obtained by combining maps of water salinity and water depth below the surface, which were derived from the original parameter map. Equal weights were assigned to the ranges of values for salinity and depth such that various combinations of these conditions were ranked in a hierarchy of desirability.

Land. Combination of the three maps of $10 \%$ slope, land ownership, and land use/cover produced a map of relative land suitability. Equal weights were assigned to land ownership and land use/cover; the $10 \%$ slope map was weighted at $40 \%$.

Overall Resource Suitability. From the three composite maps of climate suitability, water suitability, and land suitability, a final composite map was generated to show overall resource suitability for microalgae production systems. For this very preliminary composite, the three component maps were given equal weights (Figure 2-18).

In addition to this effort, Scripps chemically characterized water from the California and Nevada deserts. Salinities generally ranged from 3-10 g dissolved solids/L. The water was highly basic ( $\mathrm{pH}=9$ ) with sodium, chloride bicarbonate, and potassium being the predominant ions (see Table 2-11).

Table 2-11. Chemical Characteristics of Water from California and Nevada Desert Regions

\begin{tabular}{lccc}
\hline \multicolumn{1}{c}{ Characteristic } & $\begin{array}{c}\text { Pyramid } \\
\text { Lake }\end{array}$ & $\begin{array}{c}\text { Walker } \\
\text { Lake }\end{array}$ & $\begin{array}{c}\text { Black } \\
\text { Lake }\end{array}$ \\
\hline Salinity (g/L) & 5.1 & 9.6 & 19.2 \\
pH & 9.1 & 9.3 & 9.8 \\
Cations (mg/L) & & & \\
$\quad$ Calcium & 10 & 10 & 4 \\
Magnesium & 60 & 77 & 4 \\
Sodium & 1775 & 3900 & 8800 \\
Potassium & 128 & 225 & 825 \\
Anions (mg/L) & & & \\
Carbonate & 222 & 750 & 5880 \\
Bicarbonate & 854 & 1586 & 2526 \\
Sulfate & 140 & 2600 & 3200 \\
Chloride & 2150 & 2600 & 3200 \\
\hline
\end{tabular}




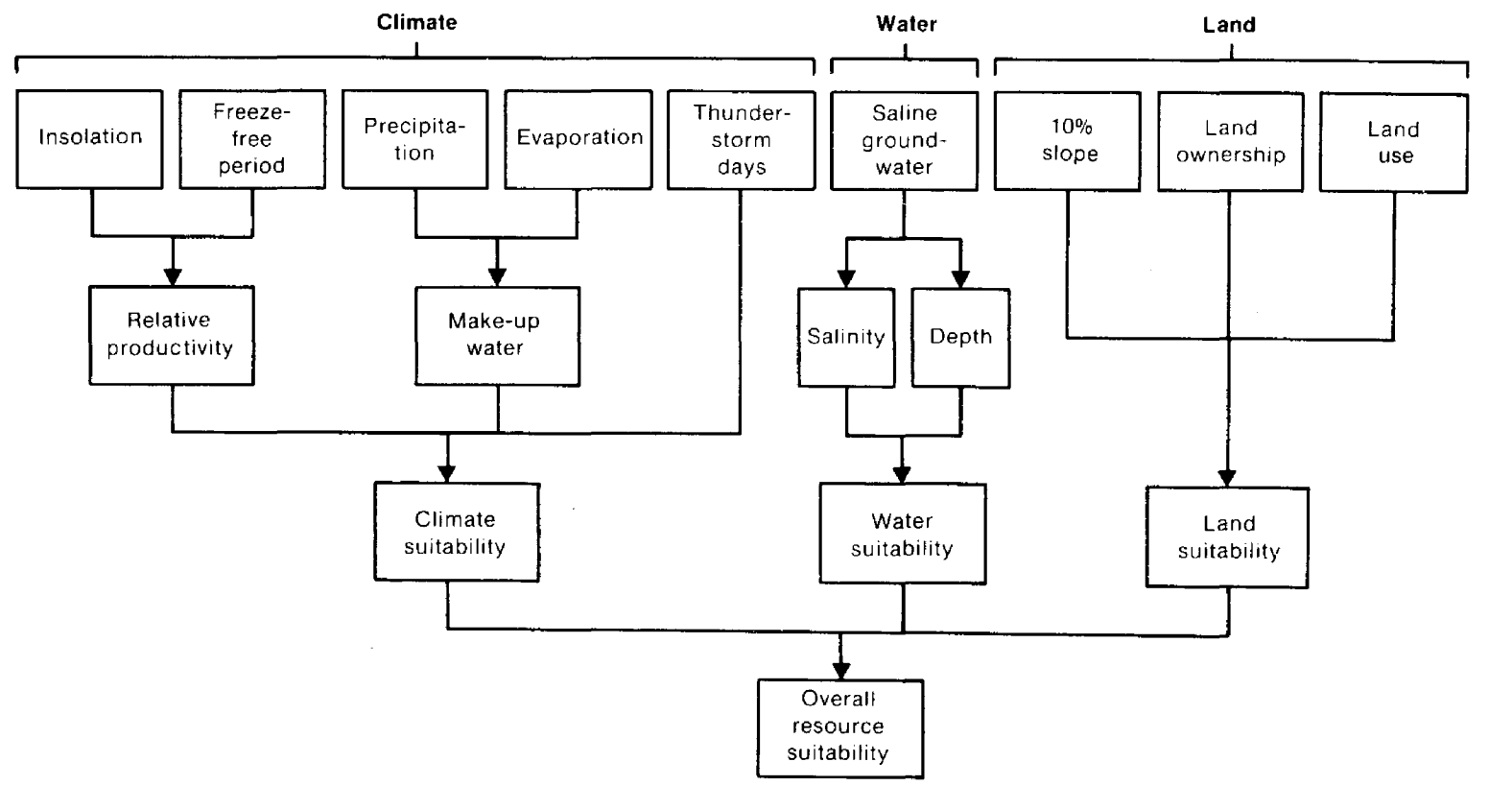

Figure 2-18a. Resource Data Mapping from Baseline Parameter Maps through Intermediate Composite Maps to the Final Composite Stratification Map

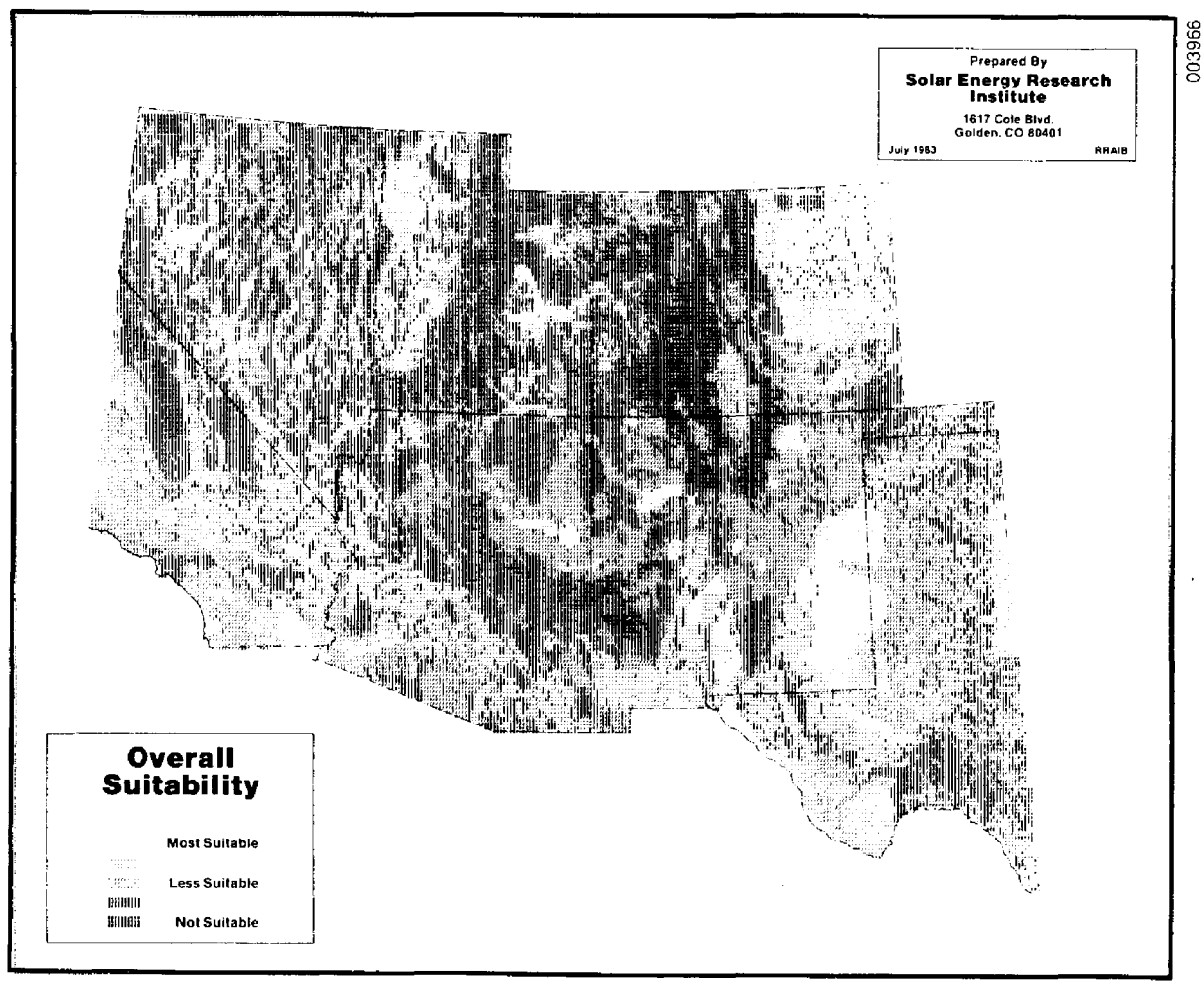

Figure 2-18b. Computer-Generated Map of Overall Suitability for Microalgae Culture 


\subsubsection{Economic Evaluation}

The objective of this project is to evaluate and analyze microalgae production designs and establish research priorities through sensitivity analyses. During the past year, market cost goals for microalgae production were established, based on recent EIA (April 1983) price forecasts for wellhead crude petroleum. These price forecasts, to the year 2000 , were used to establish market prices for microalgae-derived fuels that would be cost competitive and independent of the particular technology. Price forecasts for establishing the market cost goals are presented in Table 2-12. These projections indicate the unit price for microalgae-derived fuels must be less than $\$ 86.0 /$ barrel (1983 $\$$ ) to compete with petroleum fuels.

An economic-production model was developed to allow evaluations of microalgal culture technologies. The model has three parts:

- Production. This provides the basis for estimating gross yields of algal biomass and uses an equation most appropriate for steady-state, continuous flow culture systems. The input parameters are depth, detention time, and culture density.

- Capital Costs. Inputs are for growth pond construction, harvesting mechanisms, and land.

- Operating Costs. Inputs include direct labor, overhead, maintenance, utility costs and nutrient expenses. This model is now being used to trace state-of-the-art costs and develop areas of cost sensitivity.

\subsection{SUMMARY}

During the past 30 years the state-of-the-art production of aquatic species has increased from about $5 \mathrm{~g}$ dry biomass $\mathrm{m}^{-2}$ day $^{-1}$ to the present $25 \mathrm{~g} \mathrm{~m}^{-2}$ day ${ }^{-1}$. These increases are

Table 2-12. World Oil Price Projections for High, Middle, and Low World Oil Price Scenarios, 1983 to 2000 (1983 $\$ /$ barrel $)^{\mathrm{a}}$

\begin{tabular}{llcc}
\hline & \multicolumn{3}{c}{ Price Scenario } \\
\cline { 2 - 4 } Year & Low & Middle & High \\
\hline 1983 & 29.0 & 31.0 & 33.0 \\
1985 & 32.0 & 26.0 & 36.0 \\
1990 & 29.0 & 39.0 & 50.0 \\
1995 & 39.0 & 58.0 & 76.0 \\
2000 & 44.0 & 62.0 & 86.0 \\
\hline
\end{tabular}

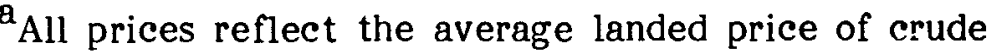
oil in the United States.

Source: U.S. Department of Energy, Energy Information Administration, Annual Energy Outlook with Projections to 1990, DOE/ EIA-0383 (83), April 1983. 
the result of the application of biological principles and from knowledge gained through a number of disciplines. The AS subprogram has focused research on accelerating the advancement of these technologies.

Work with macroalgae and emergents has concentrated on the selection of the most productive species and culture management strategies that maximize yield, while keeping costs low. Two very promising macroalgal species have been found and improved, Ulva and Gracilaria. The approach used this past year of lowering costs through energy and nutrient reductions has been rewarding, and provides a model for future efforts by the AS subprogram. The most promising emergent plant for culture in the Great Lakes region seems to be Typha. Work is continuing on determining the nutrient requirements and effect of stand establishment on yields.

The emphasis of the AS subprogram since 1982 has been developing microalgae culture technology. The program has concentrated on the screening of microalgae for rapid growth in a saline media at high densities and high lipid yields. Ankistrodesmus, collected from Pyramid Lake, Isochrysis, various Chlorella strains, and Platymonas seem promising. Characterizations of microalgae will continue.

Lipids derived from microalgae are being emphasized, since lipids are high energy compounds, and various lipid fractions may either be used directly as liquid fuels or are easily converted to liquid fuels. It has been learned that lipid synthesis may be controlled through culture manipulation. This is very important, and work on the control of lipid metabolism will be continued.

Two outdoor facilities have been operated during the past year, a shallow raceway in Hawaii and a deep pond system in California. The productivities have been highly dependent on climatic conditions and species being culthred. Productivities have been $20-25 \mathrm{~g} \mathrm{~m}^{-2} \mathrm{day}^{-1}$ for the raceway, and $16-20 \mathrm{~g} \mathrm{~m}^{-2} \mathrm{day}^{-1}$ for the pond. Valuable experience has been acquired in culture management strategy development. In addition, a technique has been developed in Hawaii for optimizing culture parameters to a particular species in a rapid, efficient manner.

Technology analysis activities involved work on resource assessment, including a review of existing research literature descri'ing the local environment, climate, water resources, hydrology, and biota of the southwestern United States. Also involved is the development of a mass culturing model at SERI to provide an analytical tool for evaluating microalgal production systems, taking into account the effects and complex interactions of the many biological, physical, chemical, and engineering factors involved in algae production and harvesting and in processing algae into final products. 


\section{SECTION 3.0}

\section{ANAEROBIC DIGESTION SUBPROGRAM}

\subsection{BACKGROUND}

Anaerobic digestion involves the use of natural biological processes in the absence of oxygen for the breakdown of organic materials with the simultaneous production of methane, carbon dioxide, and ammonia. Methane, the major component of commercial natural gas, is a clean burning, easily transported fuel which is presently in short supply. The production of methane during the decomposition of organic material was first observed in the 1700s. In the middle of the nineteenth century scientists discovered that bacteria were involved in anaerobic digestion. In 1881 anaerobic digestion was reported to be a useful method for reducing the mass and offensive nature of the organic material present in sewage and wastewaters. Since that time the applications of anaerobic digestion (also called fermentation) have grown steadily, along with knowledge concerning the chemistry and microbiology involved. In the past several years, interest in anaerobic digestion has increased because of the methane by-product.

The emphasis of the Anaerobic Digestion subprogram has shifted from short-term, onfarm research and development to long-term, high-risk basic research. It is hoped that with a basic research approach, leading to an understanding of the fundamental biological processes involved in anaerobic digestion, large improvements in efficiencies and rates can be realized in the production of fuels from biomass.

The microbiological conversion of agricultural residue to methane gas has the potential of supplying a significant proportion of the current natural gas demand in the United States. Pfeffer (1973) has outlined the potential benefits that would result from the development of an economical means for biologically converting organic residues into methane gas. The total energy demand in the United States is rising rapidif from over $60 \times 10^{18} \mathrm{~J}$ (60 quadrillion Btu) in 1970 to an estimate of more than $90 \times 10^{18} \mathrm{~J}$ (90 quadrillion Btu) by 1990. Natural gas (largely methane) represented about $31 \%$ of the total energy demand in 1968. However, the natural gas reserves are quite limited and are not increasing as rapidly as the demand. For example, between 1947 and 1968, the reservesto-product ratio declined from 29.5 to 14.6 . It is expected that the future demand for gas will remain greater than additions to reserves. Thus, additional sources of gas must be developed.

Studies on the bioconversion of agricultural residue to methane have emphasized one significant problem that both adds to the cost of methane production and limits the actual gas production to $20 \%-60 \%$ of the potential yield. This problem is the inability of microorganisms to completely consume all the organic matter in residues (usually measured as volatile solids [VS]).

The cost of methane production from organic decomposition is tied closely to the percentage of the available material that can be decomposed. A report by Dynatech (1973) describes a sensitivity analysis for a proposed system for the conversion of municipal refuse into methane. Assuming refuse is $75 \%$ degradable by this process, Dynatech estimated the cost per million Btu equivalents of methane gas was $\$ 0.99$. However, the estimated cost varied from $\$ 0.24$ if the refuse was assumed $100 \%$ degradable to $\$ 3.68$ if it was assumed only $40 \%$ degradable. Thus, there is a high penalty for treating waste with a large nondegradable fraction. According to Dynatech researchers, the cost of 
methane production from refuse with a lower digestible fraction is higher because less methane is produced per unit of treated waste and the costs for residual disposal are higher. Because many agricultural residues that could be used for methane fermentation are less than $50 \%$ biodegradable, there is clearly a need to find means to increase the degradability if the process is to produce methane economically.

Lignocellulosics, the cell-wall materials in vascular land plants, are the most abundant renewable source of chemical energy on earth, yet their potential remains highly unrealized, primarily because of their complex physical and chemical structure. Anaerobic digestion has the ability of capturing up to $90 \%$ of the heat content (heat of combustion) or organics in the form of methane gas. Lignocellulose is composed predominantly of three components-cellulose, hemicellulose, and lignin-all in varying proportions depending on the source (e.g., hardwoods, softwoods, grasses, corn stover). Because of its large molecular size, poor solubility, and chemical complexity, lignin is highly refractory (nonbiodegradable). Apparently, there are no known environments in which the rate of lignin destruction through microbial action is rapid. Consequently, progress in the study of its microbiological degradation has been limited. Even less is known concerning the rates of decomposition of chemically altered lignins such as kraft lignins, generated during the alkaline pulping of wood for paper production.

Physical and chemical processing of lignocellulose to separate constituents is not a new technology. In fact, the primary goal of chemical pulp processing for over 100 years has been quite similar to our objectives: to separate carbohydrate and noncarbohydrate constituents of wood with minimal chemical degradation of the polysaccharides. Furthermore, the forest-products industries are continuously investigating new technologies for separating and concentrating the components of lignocellulose with the intention of better utilizing the vast quantities of wood-processing residues. The groundwork for lignocellulose pretreatment has been laid, yet application is still relatively limited.

Work must be done to determine the best and least expensive pretreatment for a given feedstock. Acids, alkalis, and enzymes are all expensive and their use must be minimized in order to minimize the cost of methane while yet maximizing the conversion of the biomass to methane.

Anaerobic digestion for the recovery of methane has two significant advantages over other chemical and biological means for extracting useful products from lignocellulose: (1) It employs a mixed bacterial population that can adapt or acclimate to most of the organic products that are formed by the harsh reactions required for separation of feedstock constituents. Also, the mixed bacterial system permits the use of sewage sludge, waste-water effluents, or other complex wastes as a source of nutrients for bacterial growth instead of the more expensive nutrient additions that would be necessary for a pure microbial system. (2) The usable product, methane gas, is readily extractable from the main processing stream.

The microbiology involved in anaerobic digestion has been poorly studied due to the difficulties encountered in work with extreme obligate anaerobes. It has only been in the last 10 years that techniques required for handling such organisms have become available. Fewer than 20 laboratories in the United States are equipped for the competent manipulation of methane-producing bacteria (methanogens).

Effective biological conversion of organic matter in anaerobic digesters depends on a diverse, yet stable microbial population. Present understanding of bacterial populations in anaerobic digesters is rather limited and based mainly on analysis of bacteria routinely 
isolated from sewage sludge and animal manure digesters or from the rumens of cudchewing animals. Research is still urgently needed on enumeration, isolation, and characterization of the predominant microbial populations in anaerobic digesters that process specific wastes. Essentially nothing is known about how the bacterial population varies in digesters that receive different wastes (e.g., municipal sewage sludge, animal manure, crop residue, food processing wastes, and agricultural wastes.

The anaerobic degradation of complex organic matter to methane is a result of the combined and coordinated metabolic activity of the digester population. The population comprises several major physiological groups that carry out different functions. At present, four different physiological groups are recognizable: they include hydrolytic bacteria (Group I) that break down (catabolize) saccharides (sugars), proteins, lipids, and other minor chemical constituents of biomass; hydrogen-producing acetogenic (acetateproducing) bacteria (Group II) that break down certain fatty acids and neutral end products; homoacetogenic bacteria (Group III) that utilize single-carbon compounds (e.g., $\mathrm{H}_{2} / \mathrm{CO}_{2}$ or formic acid) or hydrolyze multicarbon compounds to form acetic acid; and methanogenic bacteria (Group IV) that convert acetate and one-carbon compounds to methane. The coordinated activity of these physiological groups as a whole ensures process stability during anaerobic digestion. Environmental parameters that directly influence the catabolic activity of only one group can indirectly influence the entire bacterial population.

Metabolic interactions between methanogenic and nonmethanogenic species are very important to the anaerobic digestion process. Very little information is available concerning the physiology and nutritional requirements of the four different physiological groups involved with anaerobic digestion. Biological characterization of anaerobic digestion is a difficult task not only because the microorganisms are sensitive to oxygen but also because they are interdependent. Organisms behave differently when isolated than when they are a member of a microbial association. These associations need to be studied and thoroughly understood before a more complete understanding of the biological processes involved in anaerobic digestion is possible.

The Anaerobic Digestion subprogram is examining the physiology and biochemistry of methanogens and fatty acid (e.g., acetic acid) utilizers and producers. Through the study of physiological mutants, the genetics of methanogens are being studied to improve understanding of the physiology and biochemistry of methanogenesis. A future possibility is to be able to either genetically engineer or induce a methanogenic mutant that grows faster, produces more methane, and improves the rates and efficiencies of anaerobic digestion. Also, the nutrients required by methanogens to convert acetic acid to methane are being studied and defined.

Although pretreatment and microbiology are extremely important research areas, the practical aspects of anaerobic digestion must not be overlooked. The engineering involved in the development of a cost-effective anaerobic digestion system must be developed concurrently with other research areas. New and innovative concepts need to be explored, and new designs for digesters need to be developed. Improved operating parameters will help maximize rates of digestion and methane production.

The reactor volume is an inverse function of the feed concentration; thus, an increase in feed concentration would proportionately reduce the required volume. For example, if the liquid and solids are mixed prior to feeding, to retain fluidity the concentration of the mixture can be no greater than $10 \%$. However, if solids and liquids are fed separately, the only limit on feed concentration is the resultant fluidity of the reactor 
contents. With a $30 \%$ feed concentration and $66.6 \%$ conversion to methane, the reactor concentration would be $10 \%$, still a fluid mixture. Such a system would result in a $66 \%$ reduction in reactor volume.

The kinetics (i.e., reaction rate) of continuous anaerobic digestion is limited by the microorganism concentration. Cells are continually discharged with the reactor effluent. The liquid portion of the effluent contains a large fraction of the discharged microorganisms. Separation and recycle of the liquid fraction would substantially increase the cell population and consequently should enhance the reaction rate. Also, less substrate would be required to maintain cell growth so that more substrate would be available for methane production.

Digester design, feed concentration, and cell recycle are just some of the parameters that need to be studied. Engineering research must be maintained so that the information obtained through the study of pretreatment and biological processes may be incorporated into operating systems.

\subsection{OBJECTIVES}

The Anaerobic Digestion subprogram strives to develop the technology base for anaerobic digestion concepts using cellulosic residues which could provide a cost-competitive fuel. As discussed in Section 3.1, this is approached through the study of pretreatment processes, biological processes, and the refining and development of innovative engineering designs. Table 3-1 presents a summary of the tasks being carried out under this program.

Table 3-1. Anaerobic Digestion Program Tasks and Projects

Task I: Pretreatment

Autohydrolysis of Organic Residues-Stanford University

Anaerobic Digestion of Manure and Residues-USDA/MARC

Conversion of Agricultural Residues to Diesel Fuel-JPL

Biotechnology of Anaerobic Digestion-SERI

Electrochemistry of Biomass-SERI

Task II: Biological Processes

Physiology and Biochemistry of Methanogens and Fatty Acid Utilizers and Producers-University of Georgia

Nutrition of Methanogens-Drexel University

Genetics of Methanogens-JPL

Task III: Engineering Parameters

Continuous Culture Biomass Fermentation Studies-University of Arkansas

Dry Fermentation-Cornell University

Anaerobic Digestion of Manure and Residues-USDA/MARC 


\subsection{STATUS}

\subsubsection{Pretreatment}

Pretreatment research is being carried out at Stanford University, the USDA Meat Animal Research Center, the Jet Propulsion Laboratory, and SERI. Pretreatment can increase the biodegradability of cellulosic and lignocellulosic feedstocks so that they can be more efficiently converted to biogas. A broad range of pretreatment techniques are under investigation. These include autohydrolysis with no additives, acid and alkaline hydrolysis at high and low temperatures, and enzymatic hydrolysis of the hemicellulosic components of biomass. Several pretreatments are being investigated not only to find the best pretreatment at the lowest cost, but also to determine which pretreatments are best suited for certain feedstocks (e.g., wood, straw, corn stover).

At Stanford University, a three-year project is underway to evaluate processes for the thermal pretreatment of organic residues in order to increase their biodegradability to methane, and to explore the scale-up of the high-rate baffled reactor that was developed to digest dilute liquid feedstocks. The research consists of five simultaneous, interrelated activities (or "phases"). Under phase 1, a semicontinuous laboratory-scale autohydrolysis unit is to be designed, constructed, and operated using lignocellulosic feedstock. Under phase 2, the kinetics of the autohydrolysis reaction are to be studied. Phase 3 involves the selection and evaluation of a new fermentation reactor design. Phase 4 introduces agricultural residues as feedstock. Phase 5 involves studies of the anaerobic biodegradability of lignin.

The autohydrolysis process being developed involves the heating of feedstock in an aqueous solution to $175^{\circ}-225^{\circ} \mathrm{C}$ in the absence of oxygen. Some of the cellulose and hemicellulose fractions are solubilized and converted to organic acids. This causes the $\mathrm{pH}$ to drop to about 2.5 and brings about the rapid hydrolysis of the remaining polysaccharides in the feedstock. The organic acids can then be extracted from the reactor and fed into an anaerobic digester for conversion to methane and $\mathrm{CO}_{2}$.

During the first and second years of study the kinetics of autohydrolysis of the carbohydrate fraction of lignocellulosics was evaluated, including that of transformation of the intermediate products to both biodegradable and refractory products. Stanford also conducted studies of the efficiency of a new anaerobic digester termed the "baffled reactor," and the decomposition of the lignin fraction of wood. Studies began on the hydrolysis of agricultural residues such as wheat straw and corn stover. Also being evaluated at laboratory scale is an autohydrolysis system for conversion of white fir to methane; the system consists of a two-gallon thermochemical reactor and a $6-\mathrm{L}$ continuous-flow anaerobic baffled reactor.

A major study completed during the second year of research was concerned with optimization of the autohydrolysis process (phase 2). In previous studies it was determined that during autohydrolysis, the carbohydrate fraction of wood was solubilized to produce soluble and biodegradable monosaccharides. Under the high-temperature conditions, however, these monosaccharides were in turn transformed and condensed into other products, some of which were not biodegradable. It then appeared necessary to remove the soluble products from the reactor as quickly as possible to reduce the extent of their subsequent conversions. To determine the best method of operation, a detailed study of the kinetics of transformation of products by thermochemical treatment of lignocellulosic materials appeared necessary. This phase of the study is now complete. 
It is well known that cellulose and hemicellulose hydrolyze rapidly at low $\mathrm{pH}$ and that the carbohydrates formed under such acid conditions are dehydrated to furans. Acid hydrolysis is generally conducted at $\mathrm{pH} 2$ or below, but in autohydrolysis, the $\mathrm{pH}$ generally does not reach a value that low. Very little is known about the rates of transformation and the products formed in the $\mathrm{pH}$ range of 2 to 4 that characterizes autohydrolysis. A study was conducted to improve understanding of monosaccharide transformation reactions and rates in this range.

The methods and detailed results of this study are described in a Ph.D dissertation by Kent Baugh. It was found that the pentoses and hexoses expected from lignocellulose hydrolysis are most stable in the $\mathrm{pH}$ range between 2 and 2.5. Below this range, the decomposition products are primarily furan compounds, which are biodegradable but also somewhat resistant to anaerobic treatment. These compounds can also decompose to a series of other products, some of which are resistant to further biodegradation. There is little interest in operating at a pH below 2 because of the high cost for acid and its subsequent neutralization.

It was found that at a $\mathrm{pH}$ above 2.5 , the pentoses and hexoses decompose into a variety of products, most of which are not readily characterized. They are probably similar to products expected under alkaline conditions, such as saccharinic acids. It appears that condensation reactions also take place because materials with molecular weights near 1000 or more are formed, representing molecules larger than a single monomer. Insoluble condensation products also form that are nonbiodegradable. Because of the reduced biodegradability of the transformation products, it is desirable to minimize their formation.

Figure 3-1 illustrates the effect of $\mathrm{pH}$ and temperature on the first-order rate constant for glucose decomposition. (The decomposition rates for the other carbohydrates behave in a similar fashion.) Figure 3-2 illustrates the effect of $\mathrm{pH}$ on the products formed from glucose decomposition in two treatments of different temperatures and durations. These results suggest that treatment should be conducted at a pH below 3 and above 2 to minimize formation of undesirable products. However, for autohydrolysis and methane fermentation, the higher the $\mathrm{pH}$ can be maintained, the better the process is because chemical costs are lower. If one maintains a pH near 2.5, monosaccharide decomposition is minimized, and a higher monosaccharide concentration could be maintained in the reactor without too much decomposition. This conclusion will direct further studies under phases one and four.

From the work on optimizing anaerobic treatment (phase 3, now complete) emerged the development of the anaerobic baffled reactor, which has good operational characteristics for treatment of the relatively soluble organic streams expected from autohydrolysis. The baffled reactor can operate at high loadings with good efficiency of conversion of biodegradable organic materials to methane. The results of modeling studies indicate that the higher the concentration of organics in the waste stream is, the higher the organic loading can be maintained to the reactor for a given efficiency of treatment. The system is simple in construction and has no major operational problems. Loadings of up to $36 \mathrm{~g}$ of chemical oxygen demand (COD) per day per liter of reactor fluid volume have been obtained with a feed COD of $8 \mathrm{~g} / \mathrm{L}$. The resulting hydraulic detention time is about 5 hours and the efficiency of COD removal is about $65 \%$. Since greater conversion efficiencies are no doubt desirable, loadings in the range of 8 to $15 \mathrm{~g} / \mathrm{L}$ day are probably more desirable. The anaerobic baffled reactor is being used in phase 1 studies within this loading range to evaluate an overall autohydrolysis-digestion system. A computer model incorporating fundamental kinetics of the anaerobic baffled reactor has been completed and used to interpret laboratory results. 


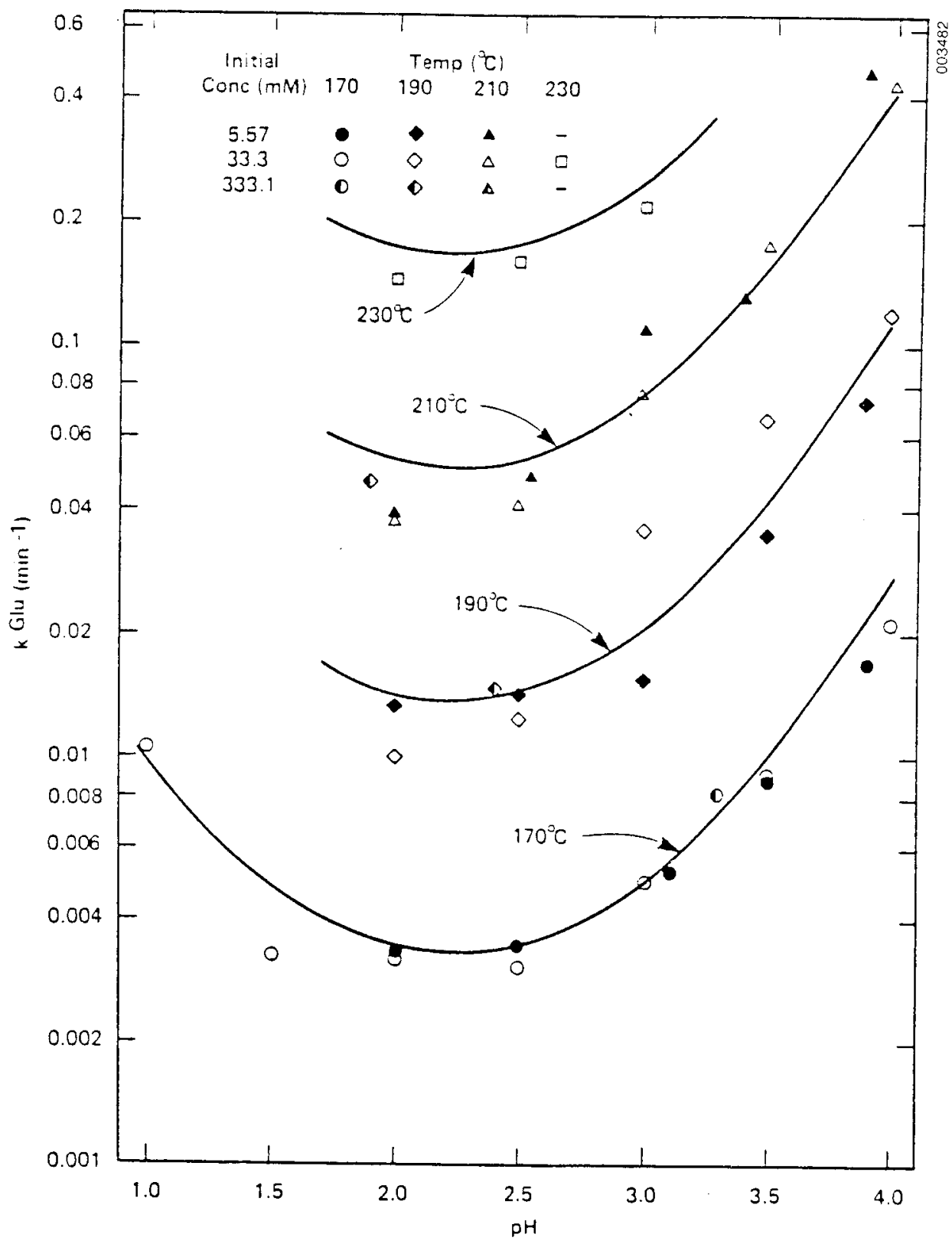

Figure 3-1. Effect of pH and Temperature on the First-Order Rate Constant for Glucose Decomposition 
(a) $15 \mathrm{~min}$ at $190^{\circ} \mathrm{C}$

$$
\begin{aligned}
& =\text { Giucose } \\
& =\text { S.HMF }
\end{aligned}
$$

- Levuliric Acid

$\square$ Unicentified Soivole Producis

Bumic Solids

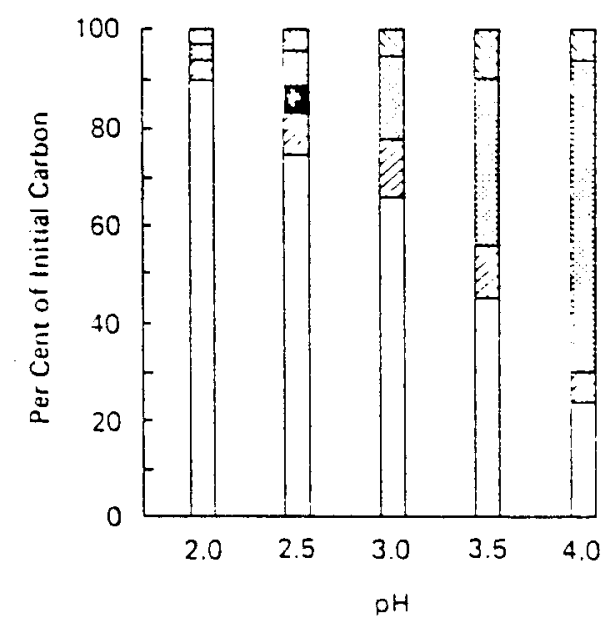

(b) $10 \mathrm{~min}$ at $210^{\circ} \mathrm{C}$

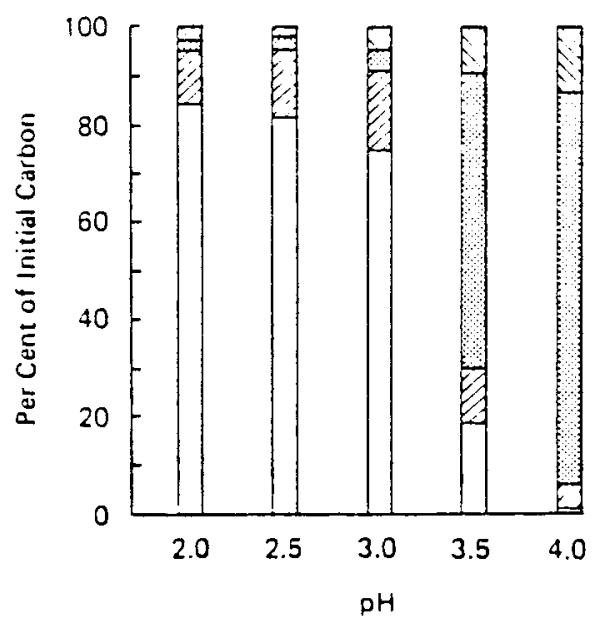

Figure 3-2. Effect of pH on the Products Formed from Glucose Decomposition with Thermochemical Treatment at Different Temperatures and Times 
The semicontinuous autohydrolysis system was fed $100 \%$ autohydrolyzate at a one-day detention time $(8 \mathrm{~g} \mathrm{COD} / \mathrm{L})$, but after one week, the efficiency of COD removal decreased significantly. This may have resulted from nutrient limitation or toxicity. Additions of synthetic waste will help determine whether nutrient limitation is the problem.

Data obtained from the autohydrolysis kinetics studies are being used to operate the autohydrolysis system. A wood slurry containing $100 \mathrm{~g} / \mathrm{L}$ is being thermochemically treated at $\mathrm{pH} 2.0$ and $190^{\circ} \mathrm{C}$ for one hour. This treatment produces about $30 \%-35 \%$ solubilization of the wood COD in a single step. The anaerobic baffled reactor received a $25 \%$ blend of autohydrolysis liquor in a synthetic feed. The reactor was slowly acclimated to the autohydrolysis liquor until it was fed $100 \%$ liquor.

A key element in predicting the performance of an anaerobic digester is the activity of bacteria imbedded in a thin film that covers the interior surfaces of the reactor. Since a baffled reactor has more interior surface area than a conventional digester, a clear understanding of biofilm activity is particularly important. During FY 1983 researchers developed a biofilm model to predict the reaction kinetics of the anaerobic baffled reactor. It is expected that this model can serve as a unified model for the mathematical description of fixed-film reactors and sludge-blanket reactors. In general, the model appears to be most applicable at higher loading rates (greater than $10 \mathrm{~kg} \mathrm{COD} / \mathrm{m}^{3}$ day).

This research project is being renewed to complete the final year's research. Stanford plans to complete studies on enzymatic hydrolysis of agricultural residues and an evaluation of thermochemical treatment of the residues. This will include an evaluation using the laboratory system for autohydrolysis of wheat straw. In addition, analyses of heat and energy balances for the most promising systems will be conducted, together with a study of the economics of methane gas produced by a complete system.

At the Jet Propulsion Laboratory, a project entitled "Production of Aromatic Aldehydes and Aliphatic Compounds" was completed during FY 1983. This was a one-year contract for the bench-scale testing of a process for converting agricultural wastes (bagasse and other residue) by hydrolysis to aliphatic compounds and fuel substitutes. The research was designed to verify the concept and to optimize parameters.

A bottoming reactor was designed and constructed to run on representative sugarcane bagasse residue. The residue undergoes two acid/heat extractions. The first heat extraction with dilute acid at approximately $150^{\circ} \mathrm{C}\left(300^{\circ} \mathrm{F}\right)$ produces furfural. The resulting residue is rehydrolyzed with concentrated acid at $275^{\circ}-300^{\circ} \mathrm{C}\left(525^{\circ}-575^{\circ} \mathrm{F}\right)$ to decompose the cellulose component. The resulting sugar solution is neutralized and concentrated. Finally, the sugar solutions are fermented using specific strains of Clostridium thermocellum or $\mathrm{C}$. acetobutylicum to yield desirable aliphatic compounds. The process was analyzed at each step to determine yields and optimization requirements.

This research has shown that the choice of equipment is very important. To reduce costs, the acid concentrations should be as low as possible. Both time and temperature are critical to the formation of the sugars and furfural and to the undesired decomposition of the products. Yields can approach stoichiometric levels if the rate of formation can be maintained higher than the rate of decomposition. Furfural can be produced in yields approaching theoretical if the material can be continuously removed from the acid hydrolysis reaction mixture. A method has been discovered for removing the furfural as it is generated. By performing the acid hydrolysis in a mixture containing a heat-stable 
solvent (HTF), the furfural can be continuously withdrawn from the reaction mixture. This is possible because the solubility of furfural is greater in the solvent than in the water-acid. A simple vacuum flash method can then separate the furfural from the solvent by taking advantage of the great differences in vapor pressures. This method can reduce the energy required for the distillation by many orders of magnitude. The remaining reaction mixture can then be used to process the residual cellulose to sugars by simply increasing the temperature to the required ranges. Lignin degradation produces toxic substances in the hydrolyzate which appear to inhibit clostridial fermentation and the production of butyric acid, acetic acid, ethanol, butanol, and carbon dioxide. A heat-stable solvent system may help to reduce this biotoxicity problem.

From the results of a preliminary analysis of the partition coefficients for the solventfurfural system, it appears feasible to extract the furfural during the low acid hydrolysis phase of the operation, thereby minimizing the energy required.

The agricultural residue reactor produced furfural from sugarcane bagasse at a yield of $71.7 \%$ of theoretical and sugar at a yield of $63 \%$ of theoretical. These high yields were obtained with a very low concentration of acid catalyst.

The composition of the hydrolyzate solution was determined by high pressure liquid chromatography. Glucose and xylose were present in a one-to-one ratio. A culture of Clostridium acetobutylicum was obtained and a fermentation medium formulated.

At SERI a pretreatment project is underway involving chemical and enzymatic processes. The objective of this project is to increase the rate and yield of methane produced biologically from the hemicellulosic portion of biomass.

This project has focused initially on isolation and identification of thermophilic anaerobic bacteria that can hydrolyze xylan polymers. Ther mobacteriodes saccarolyticum, a xylandegrading organism, was grown in media containing various natural solid substrates, and the induction of xylanase was measured. An ATP assay was standardized to monitor growth of this thermophile. (Because this organism will be cultured on insoluble substrates, plate count assays of this microorganism would not provide reproducible results.) Growth of the microorganism and induction of xylanase and $\beta$-xylosidase activities on insoluble xylan substrate were correlated using ATP and enzyme assays. Maximum production of both enzymes occurs during the early stationary phase of growth.

Studies on induction of xylanase by various xylan preparations and other natural substrates were completed. Wheat straw particles, 30-60 mesh, were the best substrate for xylanase production. Experiments were performed defining the temperature optimum and temperature stability of xylanase activity in crude preparations. Similar experiments defined the $\mathrm{pH}$ optimum and $\mathrm{pH}$ stability of this enzyme. Inhibitory effects of hydrolyzate components on xylanase activity were examined. The enzyme complex was completely inhibited by $100 \mathrm{mM}$ phosphate ions and $1 \mathrm{mM}$ hydroxymethyl furfural. Buffer effects were also investigated on a partially purified xylanase preparation.

A preliminary method for purification of component enzymes in the xylanase complex was devised and $\boldsymbol{\beta}$-xylosidase was purified. Researchers investigated the specificity of $\boldsymbol{\beta}$-xylosidase by testing 13 different p-nitrophenyl glycosides. Significant activity on p-nitrophenyl-D-galactopyranoside was observed.

Four packed-bed upflow anaerobic reactors packed with crushed fiberglass or crushed ceramic have been set up. One stir tank reactor is operating to obtain baseline data. 
Experimental work on preparative hydrolysis of wheat straw was begun. Large-scale $(10-20 \mathrm{~L})$ acid hydrolysis of straw has been optimized to provide sufficient feedstock to the anaerobic reactors.

Research activities planned for FY 1984 will focus on the development of systems for anaerobic digestion of cellulose, the second component of lignocellulosic solid residue. This substrate poses different problems with respect to biological conversion to methane. Mechanical or combined chemical-mechanical treatment is needed to reduce particle size and increase accessibility to hydrolytic enzymes. Also, cellulolytic, methanogenic cultures need to be developed that will convert cellulose to methane in slurry digestion.

Researchers at SERI are also responsible for a biomass electrochemistry project. This project is a continuing effort with potentially broad applications and high payoff possibilities. It involves electrochemically altering feedstocks or end products to produce a higher value product or a lower cost fuel. Successful development of this technology could have a major impact on the production of fuels and chemicals from renewable feedstocks.

Biomass and biomass-derived materials are being electrochemically processed to (1) upgrade their energy content as fuels and fuel additives; (2) produce petrochemical substitutes; and (3) increase the reactivity and value of the lignin fraction, thereby creating uses of this by-product that can lead to an overall favorable economics of fuels production from biomass sources.

High-field ${ }^{13} \mathrm{C}$ spectra of acetylated lignins have been obtained with a Fourier Transfer NMR (nuclear magnetic resonance) spectrometer. The following lignin samples were acetylated: high purity milled-wood aspen lignin (the type of lignin described most extensively in the literature); $\mathrm{CO}_{2}$-precipitated kraft aspen lignin; sodium hydroxideextracted explosively depressurized aspen lignin; and EEEDAL (from different batches of wood, for sun conditions, and after different lengths of storage). In addition, spectra were obtained for a freeze-dried sample of lignin from black cottonwood obtained by the organosolv method. The interpretation of these data, plus data from infrared analyses, UV-Vis absorption spectroscopy, and elemental analysis, will provide detailed structural and reactivity information on lignin materials.

A large-scale $(160 \mathrm{~g})$ extraction of the lignocellulosic complex of exploded aspen wood was performed (after extraction of the hemicellulosic fraction with water). The lignocellulosic complex was first extracted with carbon tetrachloride to remove impurities such as fatty acids, fatty alcohols, and other materials (yield: $1.1 \%$ of extracted material or $5.4 \%$ of the lignin material). The material was then dried and subjected to methanol extraction. The yield of methanol-extracted lignin was $21 \%$. The methanolic solutions will be used for direct electrochemical processing. Successful small-scale electrolyses were performed on amalgamated zinc electrodes at $-2.1 \mathrm{~V}$ versus $\mathrm{Ag} / \mathrm{AgCl}$.

SERI investigators performed exploratory oxidative electrochemical investigations of ethanol extracted explosively depressurized aspen lignin (EEEDAL). A variety of electrodes have been tested-vitreous carbon, copper, platinum, and graphite. Anodic oxidations at $0.6 \mathrm{~V}$ versus $\mathrm{Ag} / \mathrm{AgCl}$ in alkaline solutions lead to reactive lignins of increased weight-average molecular weight. Dimethylation (or demethoxylation) reactions will be used to decrease the methoxy content of the lignins and increase their suitability for polymeric application. A packed-bed flow cell was designed and partly constructed to carry out reduction on zinc amalgams, which look to be promising cathodes. Results of 
permanganate degradation analysis and functional group analysis will complete the characterization of EEEDAL.

The electrolytic studies of EEEDAL have been extended from $\mathrm{pH} 12$ to $\mathrm{pH} 8-9$. In addition, larger scale $(20 \mathrm{~g})$ parallel plate, flow cell electrolyses have been carried out on mercury cathodes. Replacement of the liquid mercury electrodes by amalgamated cathodes with metals such as zinc and lead is actively being sought because amalgamated zinc cathodes perform better than amalgamated lead cathodes in the lignin electrolyses.

The lignin obtained by reaction of EEEDAL with formaldehyde has been characterized. This derivative can replace $25 \%$ of phenol in a phenol/formaldehyde resin without degradation of performance. Tests of this electrochemically modified lignin are proceeding.

Electrochemical oxidation studies of alkali-extracted steam-exploded aspen lignin (AESEAL) continue. Large electrolyte modified, chemically modified, and neat samples (5-10 g) will be subjected to adhesive testing.

Valeric acid electrolysis experiments on carbon anodes were performed. The analyses of gaseous and liquid products by gas and liquid chromatography now give sufficiently accurate data for a good mass and charge balance. These experiments provide the baseline for the testing of the effects of electrode catalysts on this electrolytic reaction.

The investigation of photoelectrochemical reactions of lactic acid on doped platinized anatase powders continued. Acetaldehyde is the major product of the reaction, and the conversion rates are much higher than for any of the carboxylic acids previously studied (4-oxopentanoic and saturated carboxylic acids).

Parallel plate, flow cell electrolyses of pentanoic acid have been carried out. Butene-1, a very important petrochemical, is the major product among several fuel products. Investigators are assessing the influence of the electrode materials and catalysts on the product composition and the overall cell voltages.

The results from studies of the cyclic voltammetry of some sugars, using a glassy carbon electrode, are presented in Table 3-2.

All voltammetry measurements were recorded between the potentials of $+2.3 \mathrm{~V}$ to $-2.3 \mathrm{~V}$.

No oxidation or reduction was observed in any of the samples listed in Table 3-2 when a platinum electrode (versus $\mathrm{Ag} / \mathrm{AgCl}$ ) was used.

Two separate experiments on the periodic acid oxidation of levoglucosan were performed. Infrared, mass spectroscopy (MS), and NMR results were consistent with structure (see Table 3-3). The following conclusions were made:

- The synthesis of methyl glucosides with one less carbon in the sugar by anodic oxidation in methanolic solutions is a very efficient electroorganic synthesis. For instance, from glucose one can synthesize methyl arabinoside. The potential for making unusual and expensive carbohydrates electrochemically is promising.

- Levoglucosan carbon-carbon electrochemical bond cleavage competes with acidcatalyzed hydrolysis. Experiments are underway to perform electrolysis at constant $\mathrm{pH}$ and test the two processes. 
Table 3-2. The Cyclic Voltammetry of Sugars Using a Glassy Carbon Electrode

\begin{tabular}{|c|c|c|}
\hline \multicolumn{2}{|r|}{ Sugar } & Results \\
\hline Levogl & osan & $\begin{array}{l}\text { Gave a distinct oxidation wave at }+2.04 \mathrm{~V} \text {, but } \\
\text { no reduction wave even as far as }-2.3 \mathrm{~V} \\
\text { cathodic }\end{array}$ \\
\hline Levogl & osan triacetate & No wave observed \\
\hline $\begin{array}{l}\boldsymbol{\beta}-\mathrm{met} \\
\boldsymbol{\alpha}-\mathrm{met} \\
\text { Methy }\end{array}$ & $\begin{array}{l}\text { glucoside } \\
\text { glucoside } \\
- \text { D-arabinopyranoside }\end{array}$ & $\begin{array}{l}\text { No observable oxidation or reduction wave } \\
\text { within the solvent system window, but some } \\
\text { increase in current detectable upon addi- } \\
\text { tion of the sample }\end{array}$ \\
\hline 10 & $\begin{array}{l}\text { Electrolyte: } \\
\text { Electrode: }\end{array}$ & $\begin{array}{l}\text { BAP in methanol } \\
\text { arbon vs. } \mathrm{Ag} / \mathrm{AgCl}\end{array}$ \\
\hline
\end{tabular}

Table 3-3. Results of Electrolytic Experiments Using Levoglucosan

\begin{tabular}{|c|c|c|c|c|c|}
\hline \multirow{2}{*}{$\begin{array}{l}\text { Weight of } \\
\text { Levoglucosan }\end{array}$} & \multirow{2}{*}{$\begin{array}{l}\text { Current } \\
\text { Density }\end{array}$} & \multirow{2}{*}{$\mathrm{E}_{\text {used }}$} & \multicolumn{2}{|c|}{ Q (coulombs) } & \multirow{2}{*}{ Product $(s)^{a}$} \\
\hline & & & Calculated & Actual & \\
\hline $162 \mathrm{mg}\left(10^{-3} \mathrm{~mol}\right)$ & $36 \mathrm{~mA} / 5 \mathrm{~cm}^{2}$ & $+2.26 \mathrm{~V}$ & $\begin{array}{c}425^{\circ} \mathrm{C} \\
(4 \mathrm{~F} / \mathrm{mol})\end{array}$ & $412^{\circ} \mathrm{C}$ & $\begin{array}{l}1 \text { major product }(3.7) \\
1 \text { minor product }(1.4) \\
1 \text { trace product }(1.0)\end{array}$ \\
\hline $\begin{array}{l}194 \mathrm{mg} \\
\left(1.2 \times 10^{-3} \mathrm{~mol}\right) \\
\text { in } 19 \mathrm{~cm}^{3}\end{array}$ & $12 \mathrm{~mA} / \mathrm{cm}^{2}$ & $+2.26 \mathrm{~V}$ & $\begin{array}{c}462^{\circ} \mathrm{C} \\
(4 \mathrm{~F} / \mathrm{mol})\end{array}$ & $366^{\circ} \mathrm{C}$ & $\begin{array}{l}\text { Same result as above } \\
\text { with ratio } 3.7: 1: 1.4\end{array}$ \\
\hline $502 \mathrm{mg}$ in $19 \mathrm{~cm}^{3}$ & $7.6 \mathrm{~mA} / \mathrm{cm}^{2}$ & $+2.29 \mathrm{~V}$ & $598^{\circ} \mathrm{C}$ & $606^{\circ} \mathrm{C}$ & $\begin{array}{l}\text { One product plus small } \\
\text { amount of starting } \\
\text { material }(3.5: 1)^{\mathrm{b}}\end{array}$ \\
\hline $502 \mathrm{mg}$ in $19 \mathrm{~cm}^{3}$ & $8.0 \mathrm{~mA} / \mathrm{cm}^{2}$ & $+2.34 \mathrm{~V}$ & $\begin{array}{c}598^{\circ} \mathrm{C} \\
(2 \mathrm{~F} / \mathrm{mol})\end{array}$ & $482^{\circ} \mathrm{C}$ & $\begin{array}{l}\text { One product plus small } \\
\text { amount of starting } \\
\text { material }(3.5: 1)^{b}\end{array}$ \\
\hline
\end{tabular}

${ }^{\mathrm{a}}$ Area ratio is given in parentheses.

${ }^{\mathrm{b}}$ Subjected to IR, NMR, and MS analyses; HPLC behavior compared with known carbohydrate derivatives: none matched. 
- Levoglucosenone can undergo electrochemically initiated polymerization in acetonitrile solutions. These experiments consume a very small amount of electricity and may lead to useful novel polymers.

Future research will focus on characterization and upgrading of lignin materials produced in anaerobic digestion of agricultural wastes. The testing of such materials as a replacement for phenol in phenol-formaldehyde thermosetting resins is included in this plan.

Preliminary experiments are proposed in the new area of simultaneous conversion of methane to methanol and electricity in a fuel cell. This is an electrogenerative system. This is a new research initiative that is quite basic but has a large potential payoff. This research could lead to a device that would enable a farmer to obtain either a gaseous fuel (methane) or an easily storable liquid fuel (methanol) and electricity, depending on the demand. Electrochemical research in this area is new and requires basic electrocatalysis research so that it can be possible to stop at the methanol stage, rather than progress to formation of formaldehyde and formic acid.

At the USDA Meat Animal Research Center, pretreatment of straw to increase its biodegradability in combination with manure mixtures is being studied. The objective of this research is to assess the technical and economic feasibility of recovering methane and high-protein biomass through the anaerobic digestion of beef cattle manure and crop residues. This is a two-year project to investigate the potential of a pilot-scale, twostage fermentation design. Because funds available from the USDA are not sufficient to conduct a thorough laboratory-scale investigation of the digestion kinetics of manurecrop residue mixtures, and because the results of this research are beneficial to the Anaerobic Digestion subprogram, a cofunding arrangement was established between SERI and the USDA. SERI is funding the laboratory-scale work.

The first stage of the digestion system converts organic matter into fermentable sugars and/or volatile fatty acids; the second stage is an alkaline pretreatment process that breaks down first-stage solid residues. The kinetics of methane fermentation in a reactor receiving output from the second stage of the digestion system are also being assessed.

The effect of preftreatment process variables (substrate concentrations from 20 to $90 \mathrm{~kg}$ volatile solids $/ \mathrm{m}^{3}$, temperatures between $30^{\circ}$ and $85^{\circ} \mathrm{C}$, and alkaline dosage between 0 and $80 \mathrm{~g} \mathrm{NaOH} / \mathrm{kg}$ volatile solids) on acidogenesis and methanogenesis from causticized ball-milled straw was investigated. Rates of acidogenesis and methanogenesis were determined using an exponential model, and ultimate acid and methane yields were also determined. The acidogenesis rate was constant up to an alkaline concentration of about $6.4 \mathrm{~kg} \mathrm{NaOH} / \mathrm{m}^{3}$, at which point it began to decline. The decline in acidogenesis rate may have been caused by $\mathrm{Na}^{+}$salt toxicity. The total organic acid yield increased as the caustic concentration increased from 0 to $6 \mathrm{~kg} \mathrm{NaOH} / \mathrm{m}^{3}$ to a maximum yield of $0.17 \mathrm{~g}$ total organic acid/g volatile solids fed, and it remained constant above $6 \mathrm{~kg} \mathrm{NaOH} / \mathrm{m}^{3}$. The pretreatment temperature had no effect on the rates and yields of acidogensis and methanogenesis. Table 3-4 shows the variables used in the experimental design. The overall experimental scheme is shown in Figure 3-3.

Analysis of data from experiments on biomethanation of ammoniated straw is nearly complete; preliminary results show no effect of ammoniation on the yield of methane. Irradiation of straw also appears to have no effect on the methane yield. Experiments on semicontinuous fermentation of pretreated straw are complete. As Table 3-5 shows, only the $\mathrm{NaOH}$ pretreatment increased the $\mathrm{CH}_{4}$ production rate significantly. 
Table 3-4. Pretreatment Process Variables Tested

\begin{tabular}{|c|c|c|c|c|c|c|c|}
\hline \multirow{2}{*}{ Treatment } & \multicolumn{2}{|c|}{ Temperature $\left({ }^{\circ} \mathrm{C}\right)$} & \multirow{2}{*}{$\underset{\text { (h) }}{\text { Time }}$} & \multicolumn{2}{|c|}{$\begin{array}{l}\mathrm{NaOH} \text { Dosqge } \\
(\mathrm{g} / \mathrm{kg} \mathrm{VS})^{\mathrm{b}}\end{array}$} & \multicolumn{2}{|c|}{$\begin{array}{c}\text { Straw Concentration } \\
\left(\mathrm{kg} \mathrm{VS} / \mathrm{m}^{3}\right)\end{array}$} \\
\hline & Nominal & Actual $^{\mathrm{a}}$ & & Nominal & Actual & Nominal & Actual \\
\hline $1 \mathrm{~A}$ & 50 & NR & 24 & 80 & 88.9 & 100 & 89.9 \\
\hline $1 B$ & 50 & NR & 24 & 80 & 86.2 & 60 & 55.7 \\
\hline IC & 50 & NR & 24 & 80 & 83.3 & 40 & 38.4 \\
\hline $1 D$ & 50 & NR & 24 & 80 & 82.9 & 20 & 19.3 \\
\hline $2 \mathrm{~A}$ & 30 & 31 & 24 & 80 & 90.3 & 80 & 70.9 \\
\hline $2 B$ & 50 & 57 & 24 & 80 & 82.5 & 80 & 77.6 \\
\hline $2 \mathrm{C}$ & 70 & 82 & 24 & 80 & 81.1 & 80 & 78.9 \\
\hline $2 D$ & 80 & 85 & 24 & 80 & 81.1 & 80 & 78.9 \\
\hline $3 \mathrm{~A}$ & 80 & NR & 24 & 60 & 59.7 & 80 & 80.4 \\
\hline $3 B$ & 80 & NR & 24 & 40 & 40.4 & 80 & 79.1 \\
\hline $3 \mathrm{C}$ & 80 & NR & 24 & 20 & 20.1 & 80 & 79.7 \\
\hline $3 \mathrm{D}$ & 80 & NR & 24 & 0 & 0.0 & 80 & 79.4 \\
\hline
\end{tabular}

${ }^{a}$ NR: not recorded.

bV: volatile solids.

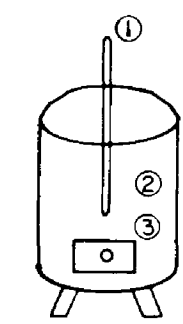

ALKALINE PRETREATMENT STAGE

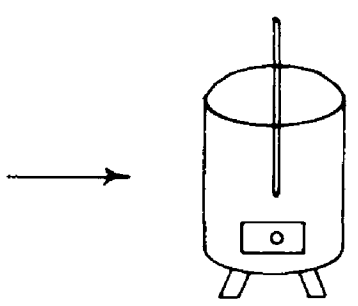

ACIDOGENESIS STAGE

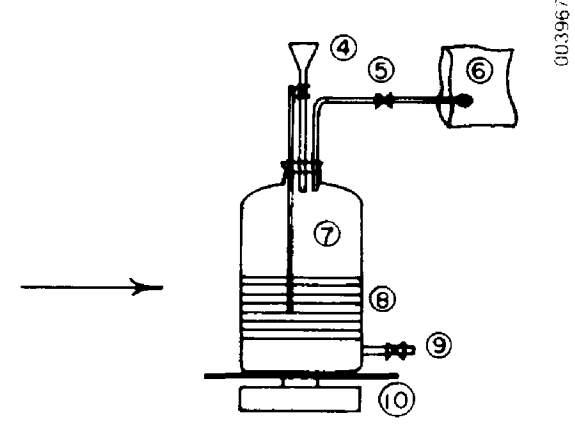

METHANOGENESIS STAGE

Figure 3-3. Overall Experimental Scheme for Manure/Residue Digestion 
Table 3-5. Effect of Alkaline Pretreatment of Straw on Methane Yield

\begin{tabular}{lc}
\hline Pretreatment $\left(95^{\circ} \mathrm{C}, \mathrm{l} \mathrm{h}\right)$ & Methane Production $\left(\mathrm{m}^{3} / \mathrm{m}^{3}\right.$ day $)$ \\
\hline Ball-milled straw (BMS) & 3.11 \\
2 eq. $\mathrm{NaOH} / \mathrm{kg}$ vs. BMS & 3.82 \\
2 eq. $\mathrm{NH}_{4} \mathrm{OH} / \mathrm{kg}$ vs. BMS & 3.47 \\
2 eq. $\mathrm{Ca}(\mathrm{OH})_{2} / \mathrm{kg}$ vs. BMS & 3.21 \\
4 eq. $\mathrm{Ca}(\mathrm{OH})_{2} / \mathrm{kg}$ vs. BMS & 3.07 \\
\hline
\end{tabular}

Batch fermentations (using laboratory scale fermenters) of various straw-manure mixtures showed that methane yields were directly proportional to the methane yields of the individual components. Kinetic analysis showed that fermentation stress occurred when the straw content was higher than $40 \%$ at $35^{\circ} \mathrm{C}$ and higher than $75 \%$ at $55^{\circ} \mathrm{C}$. Also, fermentation stress occurred when the free-ammonia concentration was below $10 \mathrm{~g} / \mathrm{m}^{3}$. Surprisingly, pretreatment of the straw through hammer- or ball-milling did not increase the biodegradability of the feedstock. This finding runs contrary to the results of most previous research on pretreatment.

\subsubsection{Biological Processes}

To better understand the process involved in anaerobic digestion, a better understanding of the microbiological processes involved is required. The microbiology involved in anaerobic digestion has been poorly studied due to the great difficulty encountered when working with strict anaerobes.

Studies of the physiology of the anaerobic bacteria will result in a better understanding of the biological processes leading to the formation of methane. With this better understanding, anaerobic digestion may be more effectively engineered and become more reliable and efficient. The enzymes and trace nutritional requirements (iron, sulfur, vitamins, etc.) need to be characterized to optimize the anaerobic digestion process.

At the University of Georgia a 3-year project is underway with the goal of increasing the biological production of methane by supplementing fermentations of biomass with various microbial, nutritional, and chemical components. Roles for trace nutrients have been studied; addition of pyrophosphate to methanogenic cultures, for example, increases methane production severalfold without a significant increase in cell mass. The work includes investigation of the interactions of methanogenic bacteria with producers and utilizers of fatty acids. New microorganisms are being isolated and their biochemistry and physiology determined.

Researchers examined the physiology and biochemistry of the enzymes crucial to the process of methane production during anaerobic digestion. Laboratory strains of Desulfovibrio vulgaris, D. gigas, M. barkeri, and $M$. thermoautotraphicum need the metals iron, nickel, cobalt, molybdenum, and sulfur. The most important findings of the research on these needs are summarized here. 
Iron is required for the biosynthesis of hemes and the various nonheme iron clusters in electron transfer proteins, dehydrogenases, and reductases. The growth of the acetateforming, hydrogen-producer Desulfovibrio is stimulated by an iron chelator which is found in the sodium lactate reagent utilized for the growth of this organism. This chelator is being isolated by dialysis, followed by ion exchange chromatography. The iron requirements for species of Desulfovibrio differ greatly. For example, $D$. vulgaris has exhibited optimal growth in the presence of $0.2 \mathrm{ppm}$ of iron. D. gigas and D. desulfuricans grow poorly under such conditions and require the equivalent of $2.0 \mathrm{ppm}$ iron.

Nickel has recently been demonstrated to be a redox-active component of purified hydrogenases from $\mathrm{D}$. gigas and $\mathrm{D}$. desulfuricans. The purification and identification of a highly active hydrogenase from the sulfate reducer Desulfovibrio vulgaris has been pursued. Unlike the hydrogenases of other sulfate-reducing bacteria, the enzyme from $D$. vulgaris does not appear to contain any nickel. It has been found that $D$. vulgaris is a more efficient partner of $M$. barkeri in coculture than $D$. gigas. This suggests that the two types of hydrogenase (with and without nickel) may have some competitive significance (i.e., D. vulgaris may not compete with $M$. barkeri for the available nickel and is thus a more efficient partner). Another high activity hydrogenase from Clostridium pasteurianum does not contain nickel. This latter enzyme is very sensitive to oxygen, while the $\underline{D}$. vulgaris hydrogenase is not, and therefore no correlation can be made between the presence of nickel and stability toward oxygen.

The problems raised by the presence of a dissimilatory sulfite reductase in $M$. barkeri are not yet solved. Growth experiments using sulfite as a terminal electron acceptor have been negative. An active reduction of sulfite occurs, however, with resting cells in the presence of molecular hydrogen. This indicates that sulfite will inhibit methanogenesis in complex fermentations when methanogenic bacteria having physiological profiles similar to $\mathrm{M}$. barkeri are present.

Researchers at the University of Georgia will study the recently crystallized assimilatory-type reductases present in $\underline{D}$. vulgaris in collaboration with researchers at the University of Washington.

During the course of the purification of the hydrogenase of Desulfovibrio desulfuricans strain $\mathbf{2 7 7 7 4}$, a flavodoxin was found that is very stable to oxidation by air and possesses a semiquinone form. Researchers in Germany and France used this new protein in the chloroplast/hydrogenase system and found that it is possible to obtain hydrogen evolution without the utilization of an oxygen trap such as the glucose/glucose oxidase system.

It was previously reported that inorganic pyrophosphate stimulates methane production in test-tube cellulose-enrichment cultures. Four fermenters were designed and built to confirm this on a larger scale, using cellulose and inoculum from a freshwater swamp with two different media. Pyrophosphate appeared to stimulate methane and gas formation 10 -fold over the control.

A propionate-oxidizing, sulfate-reducing organism has been isolated. Mass cultivation of the organism has been carried out to obtain information on its biochemistry and its ability to transfer hydrogen to methane-producing bacteria.

Four strains of sulfate-reducing, fatty acid oxidizers are being studied. These include D. sapovorans strain $1 \mathrm{pa}^{3}$, which was isolated on Na-palmitate but can also utilize soluble fatty acids down to butyrate, and D. baarsii, which oxidizes monocarboxylic acids 
from formate to stearate; neither of these organisms requires vitamins. The two other strains are more recent isolates. One is a gram-negative motile bacillus, isolated on propionate. The other was also isolated on propionate from microbial mat enrichments; morphologically, it is a motile vibrio species, similar to but somewhat smaller than D. gigas, and can grow on lactate, malate, succinate, or pyruvate in the presence of sulfate.

A sarcina-type, acetate-utilizing methanogen is being purified from enrichments of mud. A short-rod-type methanogen capable of association to form filaments is also usually present. In mud enrichments of low acetate concentration, the rod type seems to out-compete the sarcina type. Both organisms are resistant to vancomycin $(6 \mu \mathrm{g} / \mathrm{mL})$ or a mixture of penicillin $\mathrm{G}(2 \mu \mathrm{g} / \mathrm{mL})$ and D-cycloserine $(0.1 \mu \mathrm{g} / \mathrm{mL})$, the antibiotics used for their selection. These results support earlier observations by other contractors. The rod organism has a higher affinity for acetate than the sarcina and is typically the most prevalent aceticlastic methanogen in low-acetate environments.

Several of the most productive new isolates and stock cultures were selected for more intensive study with the aim of using these organisms to improve the efficiency of the digestion process. These include a new fatty acid oxidizer (strain SC) capable of growing on fatty acids, glucose, and lactate. Another strain (FP), capable of growing on propionate and sulfate media, is under further study and has been mass-cultured. Strain SC (tentatively classified as Desulfobulbus propionicus) contains a very unstable hydrogenase which can be detached only when the bacteria have been grown on a $\mathrm{H}_{2} / \mathrm{CO}_{2}$ medium. The organism's sulfite reductase is a desulforubridin similar to the enzyme found in Desulfovibrio desulfuricans strain Norway 4. The bacteria contain several c-type cy tochromes that are related to cytochrome $\underline{c}_{3}$ or $c_{7}$. No hydrogenase could be detected in Desulfovibrio saporovorans. Because, according to the theory of hydrogen recycling, this enzyme is compulsory for sulfate-reducing bacteria, it will be necessary to check for its presence by the $\mathrm{H}_{2} / \mathrm{D}_{2}$ exchange reaction. The sulfite reductase is of the $\mathrm{P}_{582}$ type, similar to the one present in Desulfotomaculum. This species has only small amounts of cytochrome. Because Desulfobulbus proprionicus and Desulfovibrio saporovorans are either devoid of hydrogenase or contain small amounts of a very unstable enzyme, they are unsuitable for mixed culture experiments with methanogenic bacteria.

A new strain of fatty acid utilizer has been isolated. This organism can grow on butyrate, propionate, or lactate with sulfate as the terminal electron acceptor; it does not require addition of yeast extract. This strain contains high levels of hydrogenase: butyrate-grown cells produce $1020 \mu \mathrm{mol} \mathrm{H} / \mathrm{min}$ g-cells, and propionate-grown cells produce $862 \mu \mathrm{mol} \mathrm{H} /$ min g-cells. These values can be compared with a specific activity of $411 \mu \mathrm{mol} \mathrm{H} / \mathrm{min}$ g-cells for $\mathrm{D}$. gigas, an organism that grows in mixed cultures with Methanosarcina barkeri but is unable to utilize fatty acids.

The biochemistry and physiology of acetate-utilizing microorganisms will continue to be studied. Emphasis will be placed on new isolates with the hope of developing a better understanding of the biochemistry and mechanisms involved in microbial interactions.

At Drexel University, a 2-year project was completed which looked at the nutritional stimulation of methanogenesis in $\mathrm{pH}$ stat controlled mixed cultures, with acetate as the main carbon source (see Figure 3-4). The objective of this research was to investigate the stimulatory effects of phosphate, nickel, iron, cobalt, and yeast extract, both individually and in combination, and to sustain rapid methane formation for an extended period of time. The experiments were held in 2-L bioreactors where the acetate 


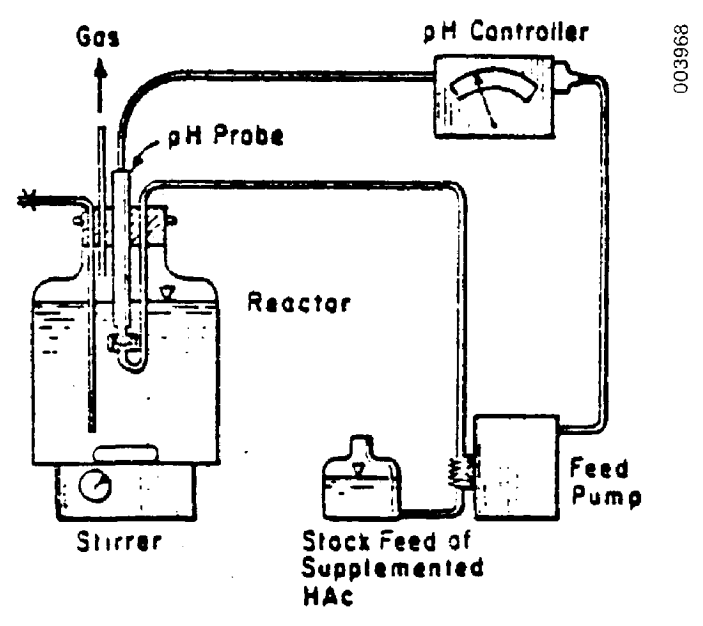

Figure 3-4. pH Stat Schematic Diagram concentration was held constant. Culture acetate utilization as a function of nutrients was also monitored.

There appears to be no practical limit to the maximum potential rate of acetate fermentation under proper environmental conditions and process control. Conventional "high rate" digestion rates of 2 to $4 \mathrm{~g} / \mathrm{L} \mathrm{d}$ have been exceeded 20-fold in this research. "Proper environmental conditions," however, are quite complex and dynamic, requiring very careful attention to process control. Apparently the requirements for the trace metals cobalt and nickel, as well as possibly molybdenum, tungsten, and selenium, can be satisfied relatively easily. This does not appear to be the case with iron. The chemical environment of an anaerobic digester strongly favors precipitation of iron, making it difficult to keep sufficient amounts of iron available to the methanogens.

The requirement of methanogens for relatively large amounts of sulfide is also a problem. The volatility and mutual precipitaion of sulfide with heavy metals makes it very difficult to maintain adequate concentrations in solutions. The greatest problem appears to be the mutual precipitation of sulfide and iron. Both are required in much more than trace concentrations and cannot coexist. Therefore, it appears that a "syncopated pulsing" of these elements at different time intervals may be the most effective way to satisfy a methanogen's needs for both. It is postulated that the methanogens indulge in a "luxury" uptake of both iron and sulfide during temporary exposure to elevated concentrations of each element that allows high metabolic rates to be maintained for at least a day. To complicate matters further, there appears to be a relatively small difference between stimulatory and inhibitory concentrations of both iron and sulfide. The inhibition may be directly related to each element itself or indirectly to the precipitation of the other element.

If phosphate is supplemented daily, stimulation of the AUR is inhibited. If phosphate is not supplemented, the acetate-utilizing rate (AUR) manifests stimulation to 25 to $35 \mathrm{~g} / \mathrm{L}$ d after about a 2-week lag period. Thus, phosphate is required, but it must be maintained at relatively low concentrations to promote stimulation.

Dessicated liver supplementation resulted in the maximum AUR observed in this study. The relatively high vitamin $\mathrm{B}_{12}$ content of the liver may be a key factor.

Propionic acid accumulation was commonly observed in these systems, which received only acetic acid as the organic carbon substrate. Although approximately only $1 \%$ of the acetic acid was synthesized into propionic acid, the systems were operating at highly stimulated AURs. Since the population of acetogens available to convert propionic acid to acetic acid and hydrogen was negligible, propionate concentrations in excess of 
$5000 \mathrm{mg} / \mathrm{L}$ were observed. These high propionate concentrations resulted in comparably reduced acetate concentrations in the $\mathrm{pH}$ stat reactors with controlled alkalinity. At times, the acetate concentration decreased to levels sufficient to limit the overall assay, and bicarbonate alkalinity had to be supplemented.

In tests of the toxicity of propionate to acetate-utilizing methanogens, no toxicity was noted at a propionate concentration of $2000 \mathrm{mg} / \mathrm{L}$. Severe, irreversible toxicity was observed, however, with $4000 \mathrm{mg} / \mathrm{L}$ propionate. It is not known if propionate is responsible for the abrupt "crashes" in AUR after periods of high stimulation or if propionate contributes to the lysis of the microorganisms commonly noted after periods of high stimulation. The potential should be explored for toxicity acclimation of acetateutilizing methanogens to propionate.

Previous research has indicated that riboflavin might stimulate the AUR. In two assays performed by this subcontractor, however, the reactors supplemented with riboflavin did not demonstrate a higher AUR than the control reactor, which received no riboflavin.

\section{At JPL, genetic techniques for methanogens are being developed.}

The first year's effort of this two-year project was successful in developing methods for the induction and isolation of methanogenic mutants. Very little information exists concerning the genetics of methanogens because they are extremely sensitive to oxygen and generally grow slowly. A fairly detailed knowledge of the genes involved in methanogenesis, their products, and their regulation should stimulate significant progress in the exploitation of methanogenesis. The isolation of mutants is a necessary first step for any project in cultural genetics and complements experimentation in molecular genetics. Once mutants have been isolated, gene transfer mechanisms in methanogens may be tested. The objective of this project is to characterize the genetic system of one or two strains of methanogenic bacteria.

Two species, Methanococcus voltae and Methanobacterium thermoautotrophicum, are being subjected to extensive screening and manipulation. Both ultraviolet exposure and chemical screening have been used to isolate mutant species. Bacteriophages and plasmids are sought. Two types of genetic recombination experiments (conjugation and DNA transformation) are being performed with some of the isolated mutants.

Since the last report, four (possibly five) additional UV-induced mutants of M. voltae have been isolated that do not grow in minimal medium at $41^{\circ} \mathrm{C}$. Two difficulties are being encountered, however. First, all of these mutants-if incubated long enough-will grow somewhat under these conditions. Therefore, either the mutations primarilv affect the capacity to start growing under these conditions or a high frequency of reversion is occurring. Second, the wild type of $M$. voltae grows poorly under these conditions in the sense that colonies grow at $41^{\circ} \mathrm{C}$ but will die at a faster rate than at $30^{\circ} \mathrm{C}$.

The wild-type methanogen Methanococcus voltae was determined to be sensitive to 5-methyl tryptophane (MTP, a structural analog of trytophane), and mutants have been isolated that can withstand high concentrations of this analog. Such mutants are present in cultures at the high frequency of $10^{-4}$ to $10^{-5} / \mathrm{ML}$ and therefore connot be used alone as genetic markers for selection in genetic experiments. From a bes ${ }^{R}$ mutant (resistant to BES [bromoethane sulfonate] and described in last year's report), a mtp ${ }^{R}$ mutation has been isolated, thus providing a doubly marked strain, bes ${ }^{\mathrm{m}} \mathrm{tp}^{\mathrm{R}}$, that can be used in certain selection experiments. To date, test of conjugational recombination of $\mathrm{M}$. voltae and $M$. vannielii have been negative. M. voltae requires acetate for growth: $M$. vapnielii does not. A mixed culture of $M$. vannielii wild type and of $M$. voltae bes $m$ tp was 
plated at very high concentrations on agar lacking acetate and containing both BES and MTP (to which $M$. vannielii is, like wild-type $M$. voltae, fully sensitive). While no recombinants were found, the selection was absolutely tight (no survivors on the selective agar) and will allow the use of even higher bacterial concentrations in future experiments.

The possibility of transformation was studied using several different experimental approaches. The transforming DNA used in this study was isolated from M. vannielii, a strain that has molecular and physiological similarities to $\mathrm{M}$. voltae. The two strains differ in their response to $\mathrm{pH}$ and salt concentrations and in their nutritional requirements.

An attempt was made to transform a $M$. voltae bes ${ }^{R}$ strain into strains not requiring isoleucine, leucine, or acetate. M. voltae bes $^{\text {th }}$ cells were grown in basal media, treated with donor DNA, and plated onto selective media lacking isoleucine, leucine, or acetate. The investigators have not yet found any leucine-, jsoleucine-, or acetateindependent $M$. voltae cells. The selection is very tight: with $10^{8}$ washed $M$. voltae cells per plate, no colonies were found on the selective plates, while the control plating (basal medium) produced a bacterial lawn. It is therefore reasonable to believe that if M. voltae was transformed, it would be easily selected and identified.

A technique has been adopted for storage of $\mathrm{M}$. voltae stocks at $-80^{\circ} \mathrm{C}$, thus allowing repeated sampling from the same stored cultures. This technique is working well for M. voltae, but results for $M$. thermoautotrophicum are not yet satisfactory. Also, 40 rumen samples have been gathered and the contents of each sample have been prepared, through high- and low-speed centrifugation, for use in the attempts to isolate phage.

A methanophage (a virus specific for a methanogen) was isolated for the first time. This could be the first major step toward developing a genetic transfer mechanism for methanogens.

\subsubsection{Engineering Parameters}

Although the biology of anaerobic digestion is a critical research area, the engineering and practical aspects of anaerobic digestion cannot be overlooked. Therefore, research into novel digester designs, important engineering parameters, and new low-cost methods of running anaerobic digestion processes are being investigated.

Investigators at the University of Arkansas are developing methods for decreasing the capital costs of anaerobic digestion systems. This work is directed toward finding ways to increase the rate of fermentation and to decrease the size of reactors used to anaerobically digest corn stover.

During the first year of this two-year project, semicontinuous laboratory reactors were operated at mesophilic temperatures to measure the kinetics and yields of the conversion of corn stover into methane by anaerobic digestion. These investigations showed that an ultimate conversion of $78 \%$ is possible. First-order kineties were consistent with projections, and the biodegradability coefficient was $0.045 /$ day $^{-1}$. Methods to enhance the kinetics by adding cellulolytic and acetate-producing microorganisms to the standard culture were tested and a $20 \%$ improvement in reaction rate was achieved. Batch studies were conducted with 60-day cycles and $10 \%$ solids concentration; conversions of $30 \%-50 \%$ were achieved over the course of six cycles. A pilot facility was operated for 5 months to produce methane and electricity from corn stover. 
Increased solids loading, cell recycle, and culture enhancement have all been studied to determine the effects these modifications have on digester size and reaction kinetics. If the concentration of the feed solids is increased to $20 \%$, the reactor volume can be decreased $50 \%$ without a decrease in the reaction rate or conversion. At a 60 -day retention time, only a $38 \%$ volume reduction can be achieved with a $25 \%$ solids feed because the conversion decreases. Perhaps at longer retention times no impairment in kinetics will result. Also, higher solids concentrations, perhaps to $30 \%$ are expected to be possible with an improved agitation system in the reactor.

The reactor volume can be reduced by $24 \%$ with a $25 \%$ cell recycle, and by $39 \%$ at a $50 \%$ recycle. No improvement is evident if the recycle rate is increased to $72 \%$, probably because the benefits of recycle are negated by the buildup of toxic materials. Enhancement of the standard anaerobic culture with $\mathrm{C}$. butyricum can allow a decrease in the reactor volume of $15 \%$ by increasing the rate constant to 0.053 /day (a $20 \%$ increase).

Cell recycle, high solids loading, and culture enhancement have all been demonstrated to be viable methods for improving the reaction rates and reducing the reactor volume in anaerobic digestion. In combination, these methods have the potential to reduce the reactor volume for anaerobic digestion to only $17 \%$ of that required for the base-case system. These effects may not be additive, however. Further research on these promising methods of improving reaction rates in anaerobic digestion is deemed appropriate to confirm the kinetic relationships and to determine whether the combination of these methods would lead to even greater improvements.

Finally, at Cornell University, a project to establish the technical feasibility of dry fermentation was completed in early FY 1983. This project was originally designed as a 3-year study of the new concept of dry fermentation as a low-cost approach to anaerobic digestion of animal and crop residues. Funding for this research lapsed at the end of 1981 , although some support was provided during 1982 for collecting final data and for close-out costs. As of December 1981 research was progressing on schedule and approximately $75 \%$ of the concept definition tasks for dry fermentation had beên completed. In addition, an initial scale-up experiment with a prototype reactor $\left(110 \mathrm{~m}^{3}\right)$ was successful (see Figure 3-5).

The majority of the research on this project was completed during FY 1982. However, the research was wrapped up during the first quarter of FY 1983. The final report was published during FY 1983 and is summarized here.

The overall objective of this research was to establish the technical feasibility of dry fermentation.

Researchers tested low-cost, farm-scale systems for producing energy from residue materials. Both conventional and plug-flow manure digesters were operated and compared, and a dry fermentation process using straw as the feedstock was tested. An engine-generator converted the product methane to electricity. Waste heat from the engine was used to heat washwater in the dairy.

The primary accomplishment of this research was the examination of various factors affecting dry fermentation of three substrates-corn stover, wheat straw, and old grass. The controlling parameters are substrate composition, moisture content, inoculum needs, reaction temperature, and $\mathrm{pH}$. Other variables examined include density of solids, particle size, reactor size, and separation of anaerobic digestion (hydrolysis and methane production). Experiments were conducted at scales varying from $1 \times 10^{-3} \mathrm{~m}^{3}(1 \mathrm{~L})$ to 


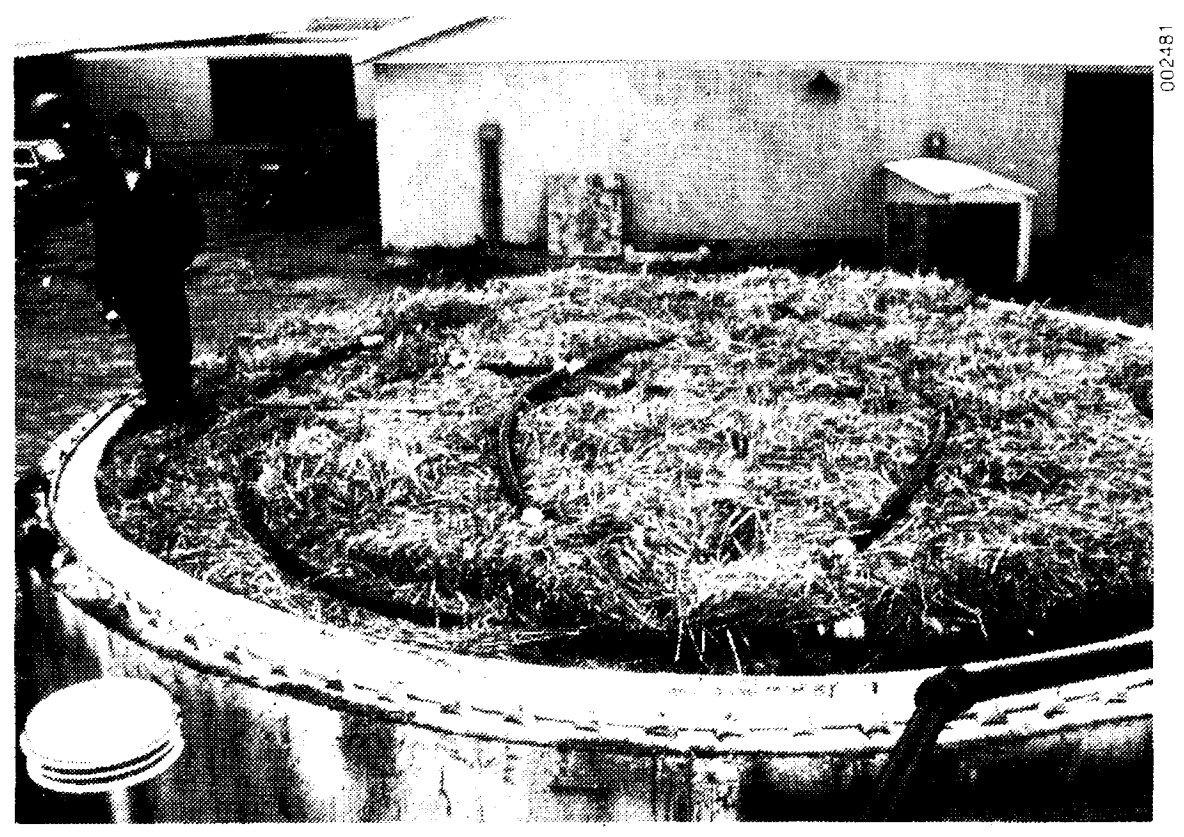

Figure 3-5. The 110-m $\mathrm{m}^{3}$ Dry Fermentation Shown Loaded with Straw Prior to Installation of the Cover. The distribution grid through which leachate was recycled for moisture and temperature control is visible

$110 \mathrm{~m}^{3}$. The overall conclusion of this research is that dry fermentation is a highly promising technology for farm-scale applications. Further analysis will be required, however, before feasibility is completely established. This is especially true with regard to the feasibility of centralized facilities.

The average ultimate biodegradability of the crop residues used in all dry fermentation studies was calculated from fiber composition analyses and expressed as the fraction of total volatile solids. For wheat straw the ultimate degradability is 0.56 ; for field grass, 0.60; and for corn stover, 0.65. The fermentation temperature does not appear to change the extent of the biodegradable fraction. The conversion rate of feedstock in conventional, continuously stirred wet digesters is about $70 \%$. The small difference of $10 \%$ is a favorable result considering the substantial advantages of dry fermentation in terms of energy input, cost, etc.

Field age affects feedstock composition and ultimate biodegradability. The cell soluble content of six-week old corn stover, for example, is $45 \%$ lower and the lignin content is almost $40 \%$ higher. The result of these changes is a $7 \%$ reduction in biodegradability.

The results of hundreds of small-scale laboratory tests showed that at low substrate densities (approximately $6 \mathrm{lb} / \mathrm{ft}^{3}$ ), a substrate with an initial total solids content of $30 \%$ or less allows efficient conversion to biogas (90\% in less than a year). Successful start-up of corn stover and wheat straw dry fermenters in the range of $15 \%$ to $30 \%$ initial total solids depends more on the quantity of digested dairy cow manure inoculum than the initial substrate solids content. The conversion of corn stover was more efficient than that of wheat straw at each temperature studied. The seed quantity necessary for successful start-up was not the same for wheat straw and corn stover at each substrate solids content and temperature studied. 
The results of the small-scale studies also emphasized the need to minimize the amounts of inoculum and buffer added to the reactor. Additions of inoculum must be accompanied by buffer, which is expensive. Reactors operated at $55^{\circ} \mathrm{C}$ required the least amount of buffering. Recycled dry fermenter effluent can replace the bacterial inoculum. Also, initiation of the reaction at lower solids content ( $25 \%$ or less) eliminated the need for a chemical buffer.

The conversion rates of small-scale tests of thermophilic digestion were rapid. There was a tendency, however, for conversion of substrate to nonbiodegradable material.

The possibilities of pretreatment of three crop residues were investigated. Included were hydrolysis to remove soluble organics and aerobic pretreatment to volatilize soluble products. None of the low-cost pretreatments tested appear to be promising means of improving crop residue digestion.

After six pilot-scale tests $\left(5-\mathrm{m}^{3}\right.$ reactor volume), experiments began with a prototype reactor $\left(110-\mathrm{m}^{3}\right.$ reactor volume). After 100 days, $26.4 \%$ of the total volatile solids were converted; the conversion was $48 \%$ after 280 days. These conversion rates correspond to a conversion of biodegradable volatile solids. This result is quite favorable because it indicates that conversion efficiency for dry fermentation is comparable to the efficiency of conventional wet digestion processes. Biogas production averaged $0.25 \mathrm{vol} / \mathrm{vol}$ day without any large peaks for 100 days. This fairly steady rate of gas production should be useful for on-farm applications. Energy requirements to maintain steady mesophilic temperatures in the reactor amounted to less than $15 \%$ of the total methane production during cold winter months.

Complete fermentation can be attained in dry fermentation systems in 60-90 days at $55^{\circ} \mathrm{C}$ or in $120-200$ days at $35^{\circ} \mathrm{C}$. Thus, the process is feasible at either temperature and does not necessarily require significant energy inputs to heat the reactor.

\subsection{SUMMARY}

The Anaerobic Digestion Program is making significant progress toward its goal of providing a cost-competitive fuel on a site-specific basis. The development of a costeffective pretreatment process for cellulosic residues could have a large impact on the overall cost of anaerobic digestion. The proper pretreatment would increase the percentage of cellulosic residue that could be converted to a fuel and increase the rate at which the feedstock could be digested. Work will continue on the development of pretreatment systems. New innovative ideas need to be encouraged and developed to improve the probability of developing a low-cost pretreatment for anaerobic digestion.

The microbiology underlying anaerobic digestion is not sufficiently understood. Significant improvements are possible through manipulation of the microorganisms. Therefore, although the Anaerobic Digestion subprogram has supported a significant biological effort, a greater effort relating to the first stages of digestion is planned for next year. The microbiology of the hydrolysis of feedstock polymers and the ensuing acidogenesis and acetogenesis steps merit careful examination. This work would complement the ongoing research on methanogenic and fatty-acid-utilizing organisms that has thus far produced excellent results. The identification of stimulating nutrients and an expanded understanding of the physiology and ecology of the organisms involved in the latter stages of anaerobic digestion have a great number of applications in future research. This work will continue and produce an even better understanding of anaerobic digestion. 
Research into new digester designs, new dry fermentation techniques, and important engineering parameters, such as loading rate and cell recycle, will continue in order to establish the practical and theoretical limits of anaerobic digestion.

\subsection{REFERENCES}

Golueke, C. G., 1958, "Temperature Effects on Anaerobic Digestion of Raw Sewage Sludge," Sewage and Industrial Wastes, Vol. 30, pp. 1225-32.

Pfeffer, J. T, 1973, Reclamation of Energy from Organic Refuse, prepared for EPA, Grant No. EPA-R-800776, by the Civil Engineering Department of the University of Illinois. 


\section{SECTION 4.0}

\section{PHOTO/BIOLOGICAL HYDROGEN SUBPROGRAM}

\subsection{BACKGROUND}

In 1978 DOE's solar hydrogen program was transferred to SERI for management. At that time, research was being conducted on three means of hydrogen generation: (1) the use of microorganisms, (2) direct photoelectrolysis of water, and (3) chemical treatment of biomass. Since 1982 the program has been concentrating on developing technologies based on the use of microorganisms either as whole cells or cell fragments.

The ability of photosynthetic microorganisms, such as photosynthetic bacteria (PSB), cyanobacteria, and algae, to evolve hydrogen under specialized culture conditions is being explored as one major thrust for the subprogram. It is also possible to remove the components of the photosynthetic systems found in these organisms, reassemble them outside the cell, and form a water-splitting system which will generate hydrogen and oxygen when exposed to light. Such "cell-free" water-splitting systems form the basis for the second major developmental thrust of this subprogram.

\subsubsection{Whole-Cell Hydrogen Technologies}

Biological hydrogen production is based on the following reaction:

$$
2 \mathrm{H}^{+}+2 \mathrm{e}-\stackrel{\text { enzyme }}{\rightleftarrows} \mathrm{H}_{2},
$$

where an enzyme (nitrogenase or hydrogenase) supplies the two electrons required by two protons to form hydrogen. In photosynthetic organisms the electrons necessary to perform this reduction are usually generated by light. The manner in which the light performs this function is shown in Figure 4-1. Photosynthetic organisms usually contain two photosystems, which, when connected by an electron transport chain, are referred to as the "Z-scheme" of photosynthesis. Photosystem II splits water to evolve oxygen. Hydrogen evolution is associated with photosystem $\mathrm{I}$, which normally provides the reducing power to fix carbon dioxide as sugars.

In photosynthetic bacteria only photosystem I is present. Normally PSB grow by absorbing carbon compounds from their environment but they are capable of fixing carbon dioxide as sugars when they are exposed to light in a hydrogen atmosphere. Ammonia which is also necessary for growth is synthesized by the cell from atmospheric nitrogen; this reaction is carried out by the enzyme nitrogenase. When no nitrogen is available and air is excluded from the culture, PSB will continue to absorb organic compounds from the environment and use these compounds to support hydrogen evolution via nitrogenase. PSB are relatively efficient at recycling cellular nitrogen compounds and remain viable and able to evolve hydrogen for long periods of time in the absence of atmospheric nitrogen.

Both photosystems are present in cyanobacteria (blue-green algae), which normally grow in long filaments. In these filaments, 1 out of every 6 to 10 cells is morphologically and functionally very different from the others. These specialized cells, called heterocysts, contain nitrogenase and supply the ammonia which the remaining vegetative cells in the filament need for growth. In turn, the vegetative cells supply the heterocysts with 


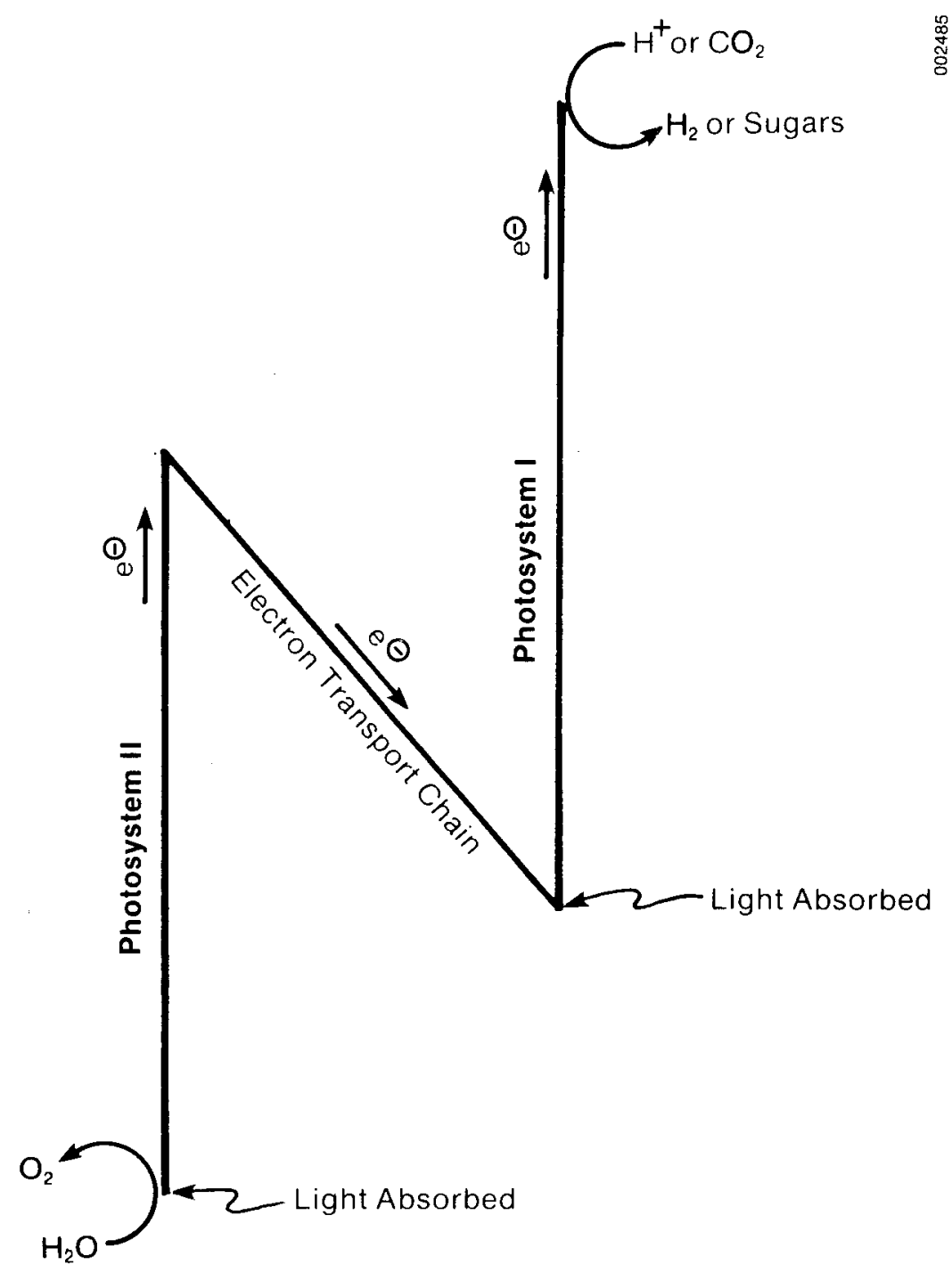

Figure 4-1. Z-Scheme of Photosynthesis Showing the Flow of Electrons from Water to Hydrogen Evolution or Carbon Fixation under the Influence of Light 
reduced carbon compounds to support nitrogen fixation. When no atmospheric nitrogen is available, the heterocysts evolve hydrogen. Hydrogen-evolving enzymes are sensitive to oxygen, and the separation of these enzymes in the heterocysts from the oxygen-evolving system in the vegetative cells protects them. The ammonia normally generated by the heterocysts is necessary to maintain viability of the vegetative cells, and thus a balance between ammonia production and hydrogen generation must be struck in cyanobacteia.

Green algae are reported to produce hydrogen from water. The enzyme involved in this hydrogen evolution reaction is hydrogenase. In green algae both the oxygen-evolving and carbon-fixing functions of photosynthesis are present and algae have no specialized means, such as heterocysts, for protecting their hydrogen enzyme from oxygen inactivation. As soon as photosynthetic production of hydrogen commences in green algae, it is shut off by the concurrent oxygen production. Therefore, in order for hydrogen production to continue, oxygen must either be removed from the environment or the hydrogenase must be rendered insensitive to oxygen.

The theoretical limit for the photosynthetic efficiency of production of any chemical in the living cell appears to range between $12 \%$ to $15 \%$. In the laboratory it is now possible to generate hydrogen at $5 \%$ to $6 \%$ conversion efficiency using PSB, while the efficiency using cyanobacteria and green algae ranges between $1 \%$ and $2 \%$. As this indicates, the technology for hydrogen production using PSB is a good deal more advanced than that using green algae.

\subsubsection{Cell-Free Hydrogen Technologies}

The use of light to produce hydrogen in cell-free hydrogen technologies is based on the isolation of stable, photochemically active portions of the biological hydrogen-producing systems. The best-known source organism can thus be used to produce each component. The objective is then to recombine these components outside the cell to form a system for splitting water into hydrogen and oxygen.

Several technical challenges are associated with developing a practical cell-free hydrogen technology. For example, once removed from the cell, the integrity of biological component is no longer maintained by the cell. Hence, a methodology for stabilizing components against degradation is an important aspect of research in the photo/ biological hydrogen subprogram. In addition, the efficiency with which light-generated electrons are produced by the components must be maintained. Moreover, the manner in which the components are recombined must be such as to ensure that the generated electrons contribute to the production of desired products, i.e., hydrogen.

The great advantage of the cell-free technology is that it separates the production of hydrogen from the energy-consuming reactions of the living cell. Hence, solar conversion efficiencies are not limited by cell metabolism and should approach the theoretical limit for photochemical systems, i.e., approximately $30 \%$. In the laboratory such systems are now operating at $1 \%$ to $2 \%$ solar conversion efficiency.

\subsubsection{Biochemical Engineering Research}

The photo/biological hydrogen subprogram includes an engineering research component which supports system concept development and is based on information generated from research on whole cells and cell components. Concepts for design of system components 
as well as the overall system are proposed, tested, modeled, and evaluated. Engineering research is initiated when laboratory experiments begin to show promise of leading to a practical system. Currently, only hydrogen production based on photosynthetic bacteria has reached this stage.

\subsection{OBJECTIVES}

The overall goal of this subprogram is to reduce the risks associated with new solar biotechnologies for producing hydrogen to a level acceptable to the private sector. Certain research objectives have been identified for the various subprogram tasks in the three major areas of research: (1) whole cells, (2) cell-free systems, and (3) biochemical engineering. Each of these tasks is divided into several subtasks. A summary of the tasks, subtasks, and specific projects in each subtask can be found in Table 4-1.

Table 4-1. Photo/Biological Hydrogen Program Tasks, Subtasks, and Projects

\section{Task I: Whole-Cell Research}

Species Isolation

SERI-Hydrogen Production by PSB

Oak Ridge National Laboratory-Photosynthetic Water-Splitting

University of Miami-Hydrogen Production by Tropical Marine PSB

Biochemical/Biophysical Studies

SERI-Hydrogen Production by PSB

Oak Ridge National Laboratory, University of Missouri, University of

Florida-support of primary project objective

Genetic Engineering

University of Missouri-Photobiological Production of Hydrogen

University of Florida-Genetic Engineering of Hydrogen Evolution in Blue-Green Algae

Optimum Culture Conditions

SERI-Hydrogen Production by PSB

Oak Ridge National Laboratory-Photosynthetic Water-Splitting

Task II: Cell-Free Research

Improved Materials/Efficiencies

SERI-Algal Hydrogenase

Battelle-Feasibility of Hydrogen Production by Solar Photoelectrolysis of Biomass Waste Streams

Molecular Architecture

SERI-Primary Photosynthesis Studies

Task III: Biochemical Engineering Research

Modeling and Simulation

SERI-Bacterial Hydrogen System Design and Analysis

SERI-Hydrogen Container Materials Research 
For hydrogen production by whole cells the research objective is to achieve a $10 \%$ or better solar conversion efficiency. This is to be accomplished through (1) isolation of the best hydrogen-producing microorganisms from natural habitats, (2) study of the biochemistry and biophysics of hydrogen evolution in these organisms, (3) establishment of the conditions necessary to sustain maximum rates of hydrogen production over long periods, and (4) manipulation of the genetic control of hydrogen production. The figure of $10 \%$ conversion of light to hydrogen energy was chosen as the research objective because a preliminary evaluation of the technology indicated that such a system would probably produce hydrogen at competitive prices.

The research objective for cell-free hydrogen production is to achieve a solar conversion efficiency of $25 \%$ or better. At this solar conversion efficiency, roughly $0.06 \mathrm{~m}^{3}$ ( 2 standard cubic feet) of hydrogen would be produced per square meter of surface per hour. A solar conversion efficiency of $25 \%$ or better was chosen for two reasons: (1) Since the theoretical limit for such a technology is $33 \%$ solar conversion efficiency, $25 \%$ should be an achievable performance goal. (2) At a solar conversion efficiency of $25 \%$, hydrogen will be generated at $40 \%$ of the price of electrolytic hydrogen, which is a very competitive price.

The objective of the biochemical engineering research task is to identify possible technical hurdles in these new biotechnologies for hydrogen production and to determine solutions for the problems within the technical performance and cost goals for each technology.

\subsection{STATUS}

\subsubsection{Whole-Cell Research}

The first step toward development of a hydrogen production biotechnology based on whole cells is the isolation of organisms from the natural environment that produce hydrogen at rapid rates. Several investigators in this subprogram participate full- or part-time in this activity. At the University of Miami more than 50 new strains of marine purple sulfur and nonsulfur PSB were screened for their ability to produce hydrogen at high rates from a variety of substrates (see Figure 4-2). Several strains showed high hydrogen production rates. Purple sulfur PSB can be used to produce hydrogen from, for example, pulp and paper industry waste streams in which hydrogen production from nonsulfur PSB would be shut down due to the streams' sulfur content. The salt-tolerant PSB will also be useful for producing hydrogen from organic waste streams containing salts, e.g., chemical and textile process streams. A collection of the most promising marine hydrogen-producing PSB was transferred from Miami to SERI, where they will be available for use in genetic engineering efforts, and studies of special system problems.

Researchers at SERI also isolated three new strains of Rhodopseudomonas species that tolerate at least $3 \%$ ethanol. The strains can grow in neutralized waste beer and can photoproduce hydrogen from the beer for 2-3 days. The highest alcohol tolerance previously observed for PSB was approximately $1 \%$.

The biochemistry and biophysics of hydrogen production in naturally occurring organisms must be understood in order to devise means of genetically engineering hydrogenproducing "superbugs." Such studies are being performed by investigators in this subprogram. 


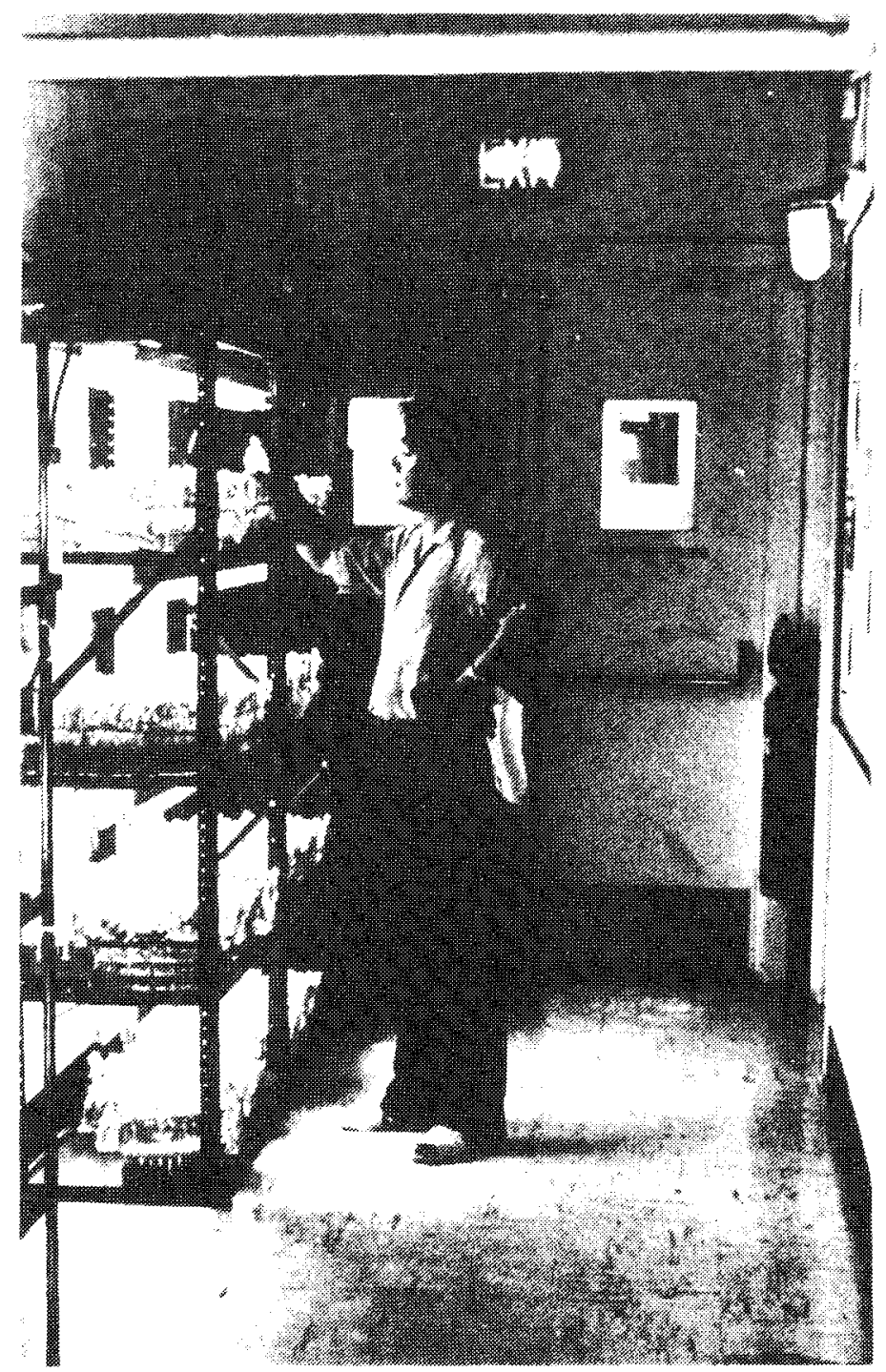

Figure 4-2. Akira Mitsui Examines Strains Isolated from Tropical Marine Environments 
For example, in FY 1983 researchers at SERI discovered that prolonged continuous illumination of photosynthetic bacteria (PSB) leads to decreased hydrogen evolution. They sought a biochemical cause for this phenomenon. A bacteriochlorophyll degradation product was found to accumulate in the culture medium as the $\mathrm{H}_{2}$ evolution rates decreased. Researchers also observed that a drop in nitrogenase activity was linked to leaching of essential periplasmic factors. (The periplasm is the space between the cell membrane and the cell wall.) That periplasmic factors are involved in nitrogenase activity is shown in Figure 4-3; much of the whole cell nitrogenase activity is restored when periplasmic factors are added to the spheroplasts prepared by removing the cell wall. Therefore, it appears that the rates of hydrogen evolution decrease because the cell wall and membrane structure begin to degenerate after prolonged continuous illumination, resulting in the loss of necessary constituents. What causes this degeneration is unknown. Information generated by these studies will permit the control or reversal of decreased hydrogen evolution.

At the University of Missouri the existence of a mechanism for transporting ammonia in the PSB Rhodopseudomonas capsulata has been verified. Nitrogen-fixing PSB scavenge their environment for traces of ammonia before they derepress synthesis of nitrogenase. Experiments showing that these bacteria possess an ammonia transport system indicate an apparent rate constant, $\mathrm{K}_{\mathrm{M}}\left(\mathrm{pH} 6.8,30^{\circ} \mathrm{C}\right)$, was $69 \mu \mathrm{M} \mathrm{NH}_{4}^{+}$and a maximum rate of uptake of $0.09 \mu \mathrm{M} / \mathrm{mg}$ protein min. These observations are significant because they suggest that regulation of the ammonia transport system may be linked genetically (or biochemically) to regulation of nitrogenase expression. Since nitrogenase is the

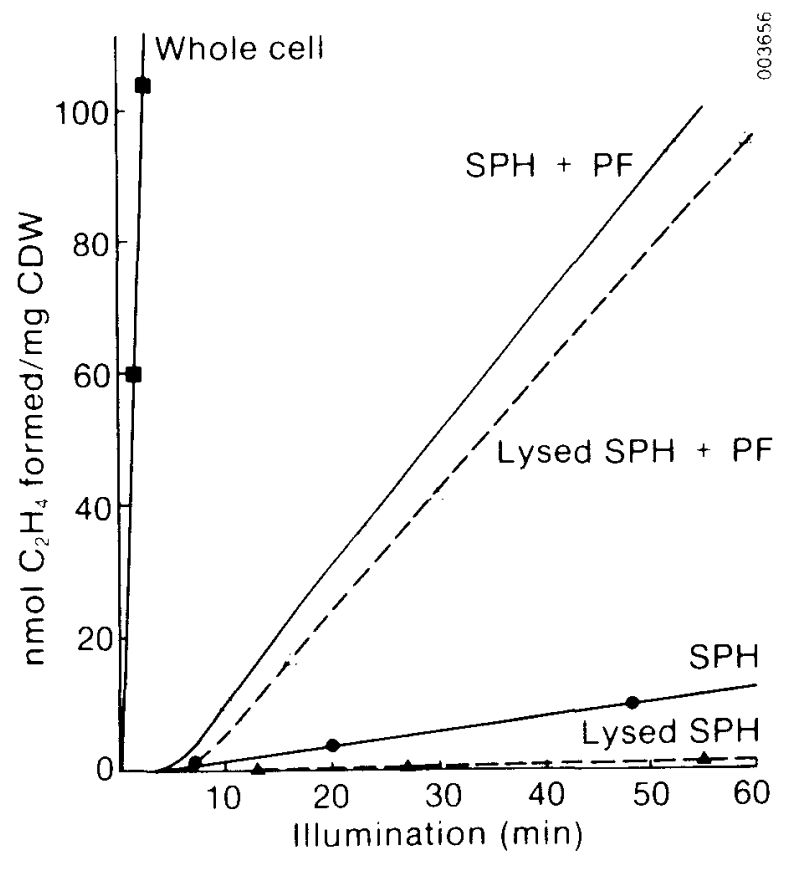

Figure 4-3. Reconstitution of Nitrogenase Activity by Periplasmic Fraction 
enzyme that produces hydrogen in $\mathrm{PSB}$, information on the regulation of production of the enzyme may suggest how regulation might be eliminated.

Hydrogen can be produced by photosynthetic bacteria either through use of the nitrogenase enzyme complex (in the absence of fixed nitrogen) or through an evolving hydrogenase enzyme. The nitrogenase enzyme is dependent on ATP. The amount of hydrogen produced by these bacteria is directly proportional to the amount of ATP synthesized. The amount of ATP synthesized correlates, in turn, with the amount of light absorbed. Therefore, the efficiency of converting solar energy into hydrogen using the nitrogenase enzyme of photosynthetic bacteria is determined by the number of molecules of ATP that are required to produce a molecule of hydrogen. In FY 1983 researchers at SERI estimated that the maximum theoretical conversion efficiency for PSB ranges between $30 \%$ and $40 \%$. Therefore, considerable improvement over the $5 \%$ conversion efficiency of light to hydrogen may be expected with improved strains of PSB. This range of efficiency indicates that hydrogen production from PSB is not limited by the normal photosynthetic efficiencies (i.e., 12\%-15\%) measured by sugar fixation.

During FY 1983 researchers at Oak Ridge National Laboratory (ORNL) performed experiments with low-chlorophyll, photosystem-II-deficient, and low-carbon-fixation green algal mutants (see Table 4-2). They showed that it is possible to achieve higher hydrogen

Table 4-2. Light-Saturated Rates of $\mathrm{H}_{2}$ and $\mathrm{O}_{2}$ Photoproduction in Selected Mutants of Chlamydomonas reinhardtii

\begin{tabular}{|c|c|c|c|c|}
\hline Strain & $\begin{array}{c}\text { Hydrogen } \\
\text { (mol/mg chl min) }\end{array}$ & $\begin{array}{c}\text { Oxygen } \\
\text { (mol/mg chl } \mathrm{min})\end{array}$ & $\underset{\text { Ratio }}{\mathrm{H}_{2}: \mathrm{O}_{2}}$ & $\begin{array}{l}\text { Chlorophyll } \\
\text { (\%) }\end{array}$ \\
\hline \multicolumn{5}{|l|}{ Wild-type } \\
\hline UTEX No. 2246 & 0.034 & 0.018 & 1.9 & 1.5 \\
\hline \multicolumn{5}{|l|}{ Low chlorophyll } \\
\hline $\begin{array}{l}C C-535 \\
C C-544 \\
C C-1006 \\
C C-1194 \\
C C-1193 \\
C C-1239 \\
C C-1369\end{array}$ & $\begin{array}{l}0.217 \\
0.099 \\
0.170 \\
0.175 \\
0.095 \\
0.266 \\
0.247\end{array}$ & $\begin{array}{l}0.098 \\
0.037 \\
0.053 \\
0.022 \\
0.009 \\
0.053 \\
0.102\end{array}$ & $\begin{array}{r}2.2 \\
2.7 \\
3.2 \\
8.1 \\
10.6 \\
5.0 \\
2.4\end{array}$ & $\begin{array}{l}1.50 \\
1.30 \\
1.10 \\
0.19 \\
0.18 \\
0.05 \\
0.86\end{array}$ \\
\hline \multicolumn{5}{|c|}{ Cytochrome 553 deficient } \\
\hline CC-939 & 0.002 & 0.003 & 0.67 & 0.47 \\
\hline \multicolumn{5}{|c|}{ Photosystem II deficient } \\
\hline $\mathrm{CC}-1222$ & none & none & - & 0.96 \\
\hline \multicolumn{5}{|c|}{ Carboxylase deficient } \\
\hline $\begin{array}{l}\mathrm{CC}-1215 \\
\text { F } 60\left(\mathrm{~N}_{2}\right) \\
\left.\text { F60 ( }{ }_{2} / \mathrm{CO}_{2}\right)\end{array}$ & $\begin{array}{l}0.457 \\
0.310 \\
0.294\end{array}$ & $\begin{array}{l}0.075 \\
0.057 \\
0.054\end{array}$ & $\begin{array}{l}6.1 \\
5.4 \\
5.4\end{array}$ & $\begin{array}{r}0.84 \\
0.65 \\
-\end{array}$ \\
\hline
\end{tabular}


production rates compared to wild type by shutting off alternate pathways for electron flow in photosynthesis. Especially encouraging was the discovery that hydrogen production could be enhanced 10-fold by blocking carbon fixation which proceeds through the carboxylase enzyme. These experiments give a first indication of which types of mutations are most effective in enhancing hydrogen evolution in green algae. These data are shown in Table 4-2.

Researchers at ORNL also discovered that when hydrogen and oxygen are simultaneously photoproduced by green algae (see Figure 4-4 for schematic of experimental apparatus), a higher level of light is required to produce hydrogen at a maximum rate. In recent experiments chemicals were used to suppress the flow of electrons from photosystem II (PS II) and inject electrons into photosystem I (PS I). The results suggest that hydrogen production in green algae is partially uncoupled from normal electron flow through the Z-scheme. This implies that hydrogen production in green algae proceeds partly from the flow of electrons from PS II to PS I, and partly by a mechanism that resembles that operative in photosynthetic bacteria. Since the process of electrons flowing to the production of hydrogen in green algae is poorly understood, this information is very important if hydrogen production from green algae is to be improved.

Genetic engineering of a hydrogen-producing "superbug" depends on the availability of a strong gene pool (from culture collections) and on the information generated by the biophysical and biochemical studies. Generation of a hydrogen "superbug" will involve manipulating the microorganisms genetically (1) to either reverse or override biochemical control of hydrogen production enzymes, and (2) to enhance hydrogen evolution by adding biochemical functions to the cell that it normally does not possess.

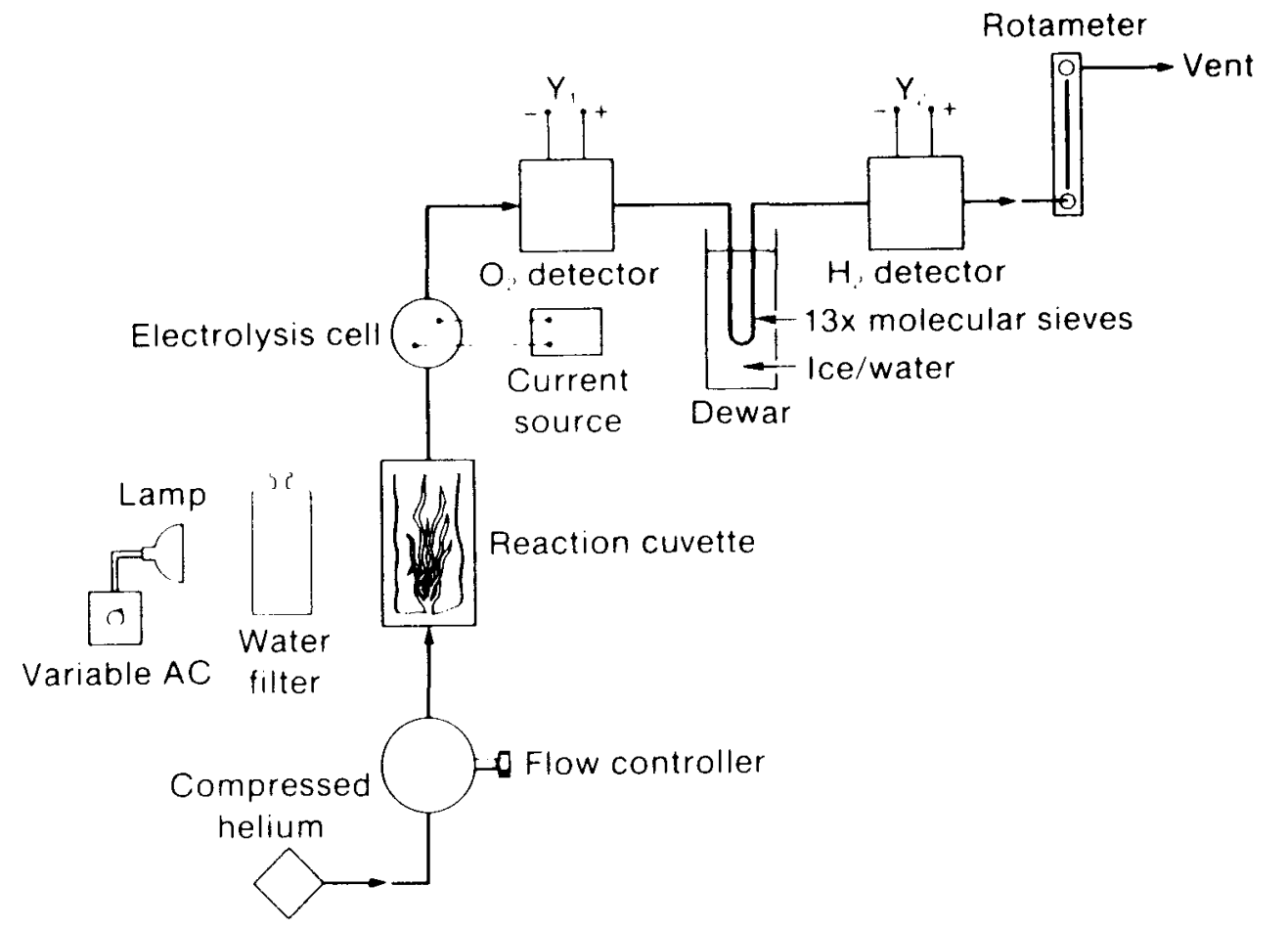

Figure 4-4. Apparatus for Simultaneous Measurement of Hydrogen and Oxygen Evolution in Algae 
One of the most straightforward genetic manipulations that can be used to isolate mutants is called selection pressure. This technique consists of applying an environmental stress, such as high salt concentration or high temperature, to a population of cells. Only cells that can tolerate the stress survive; all other cells are killed. ORNL scientists successfully used a selection procedure consisting of exposing green algal cultures to long periods of hydrogen production conditions, A culture of green algae stressed in this manner has shown initial hydrogen evolution rates 2 to 3 times higher than those observed for the same organism not exposed to the selection pressure. Organisms selected in this manner will provide a base for further biophysical and biochemical studies aimed at understanding hydrogen production in algae; they will also provide genetic engineering material for enhancement of hydrogen production.

Investigators at the University of Missouri developed a screening procedure for selecting PSB mutants deficient in nitrogenase. Complementation experiments mapping the positions of the mutations have shown that these mutations are not associated with regulation of nitrogen metabolism because they are not linked to glutamine synthetase. The hope is that these mutations might be in the promoter region for nitrogenase synthesis because reversion of such a mutation would lead to a mutant that would be unable to turn off nitrogenase (i.e., a switched-on promoter). This would result in a mutant with very high rates of hydrogen production.

Genetic engineering involves the transfer of one or more genes from one organism to another. To do this the gene must normally be cloned. In this process genes of interest are incorporated into a carrier, such as a plasmid, or virus. Scientists at the University of Missouri report progress in transforming PSB with a plasmid carrying transposon and kanamycin resistance. This result is important for two reasons: (1) normally PSB are resistant to transformation with plasmids, and (2) this transformation could lead to development of a collection of stable mutants with well-defined phenotypes (characteristic behaviors) in which mutations of interest could be easily monitored. For example, Hup ${ }^{-}$mutation confers higher hydrogen production capacity to PSB. Transposon generation of a Hup (hydrogen uptake minus) mutant from Rhodopseudomonas capsulata B100 proved difficult. However, another strain, Rsp. capsulata EY 3, was more cooperative; three new Hup mutants have apparently been generated by transposon mutagenesis in this strain. Further work is in progress to confirm that the Hup mutants observed are indeed transposon generated.

Plasmids into which genes from an organism have been integrated (clones) are especially useful in identifying and mapping regions of interest on the chromosome of the donor organism. However, for the clones to be effective genetic probes, the recipient organism needs to be what is termed a $\mathrm{Rec}^{-}$mutant. This mutation greatly reduces or eliminates the recombination events between inserted plasmids and host chromosomal material. Therefore, if a change in mutant type is observed in a $\mathrm{Rec}^{-}$background when a plasmid is inserted, it can be concluded that the gene causing the change resides on the plasmid and that the gene has been cloned. Investigators at the University of Missouri appear to have generated a $\mathrm{Rec}^{-}$mutant of Rhodopseudomonas capsulata. The evidence for the $\mathrm{Rec}^{-}$ phenotype is (1) the mutant was approximately 1000 times more sensitive to 5-s exposure to UV irradiation than the parent; (2) the mutant lacked the ability to act as recipient for gene transfer via the gene transfer agent (this agent is a phage-like particle that carries random pieces of the chromosome and is dependent on recombination for expression); (3) the mutant was inhibited by $0.02 \mu \mathrm{g} / \mathrm{mL}$ of mitomycin $\mathrm{C}$, whereas the minimum inhibitory concentration for the parent was $0.25 \mu \mathrm{g} / \mathrm{mL}$; and (4) the mutant showed growth abnormalities such as a slower growth rate than the parent and a tendency to grow in filaments rather than in the typical zigzag arrangement (see Figure 4-5). One 

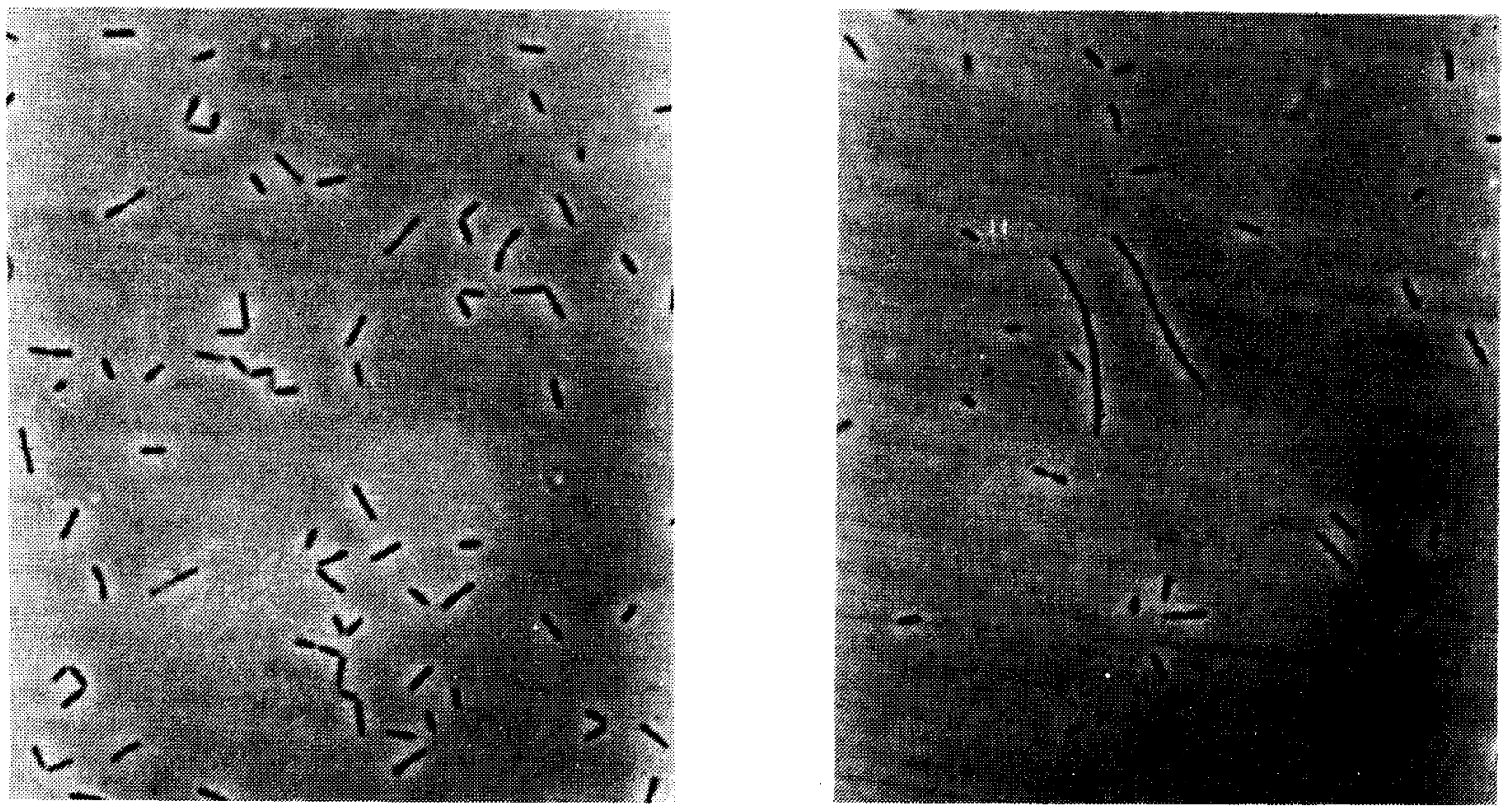

Figure 4-5. Phase-Contrast Photomicrographs. These photomicrographs show the typical zigzag appearance of the parent strain of $\mathrm{R}$. capsulata cells (left), and the tendency of mutant cells to form filaments during the stationary phase of growth (right).

aim of this project is to create a nitrogenase constitutive mutant that cannot turn off hydrogen production. Activities in pursuit of this goal have produced many mutants. Now the tool exists ( $\operatorname{Rec}^{-}$mutant) that will permit exact identification of the types and locations of the mutations produced. This development should speed progress toward the project goal of producing a hydrogen "superbug."

In another genetic engineering effort investigators at the University of Florida are mapping the location of hydrogen-producing genes on the chromosome of E. coli, an organism whose biochemistry is well known. The E. coli hydrogen-producing genes are then cloned and transferred into blue-green algae. These investigators have successfully cloned the region of DNA in E. coli containing the genes for hydrogen uptake. Two plasmids containing the genes of interest have been isolated (see Figure 4-6 for maps of the plasmids). Hydrogenase genes have never before been cloned. Work is still underway to identify genes carried on clones that are responsible for all the aspects of hydrogenase activity expression. Once all the hydrogenase genes have been cloned from $\mathrm{E}$. coli, the expression of individual genes can be studied. This will vield detailed information concerning the regulation and biochemistry of hydrogenase. These cloned genes can also be used as probes to identify the blue-green algal DNA that is responsible for hydrogenase activity. Since the blue-green algal chromosome has never been mapped, hybridization of blue-green algal DNA with E. coli hydrogenase genes is a promising method for identifying hydrogenase genes in blue-green algae. Information obtained from such studies will eventually allow genetic manipulation of hydrogenase expression.

Individual protein products from the genes responsbile for hydrogen evolution and uptake in E. coli are also being identified from the cloned genes. Ten to twelve genes appear to be involved. Of these, at least 2 genes are responsible for loss of hydrogen uptake. 

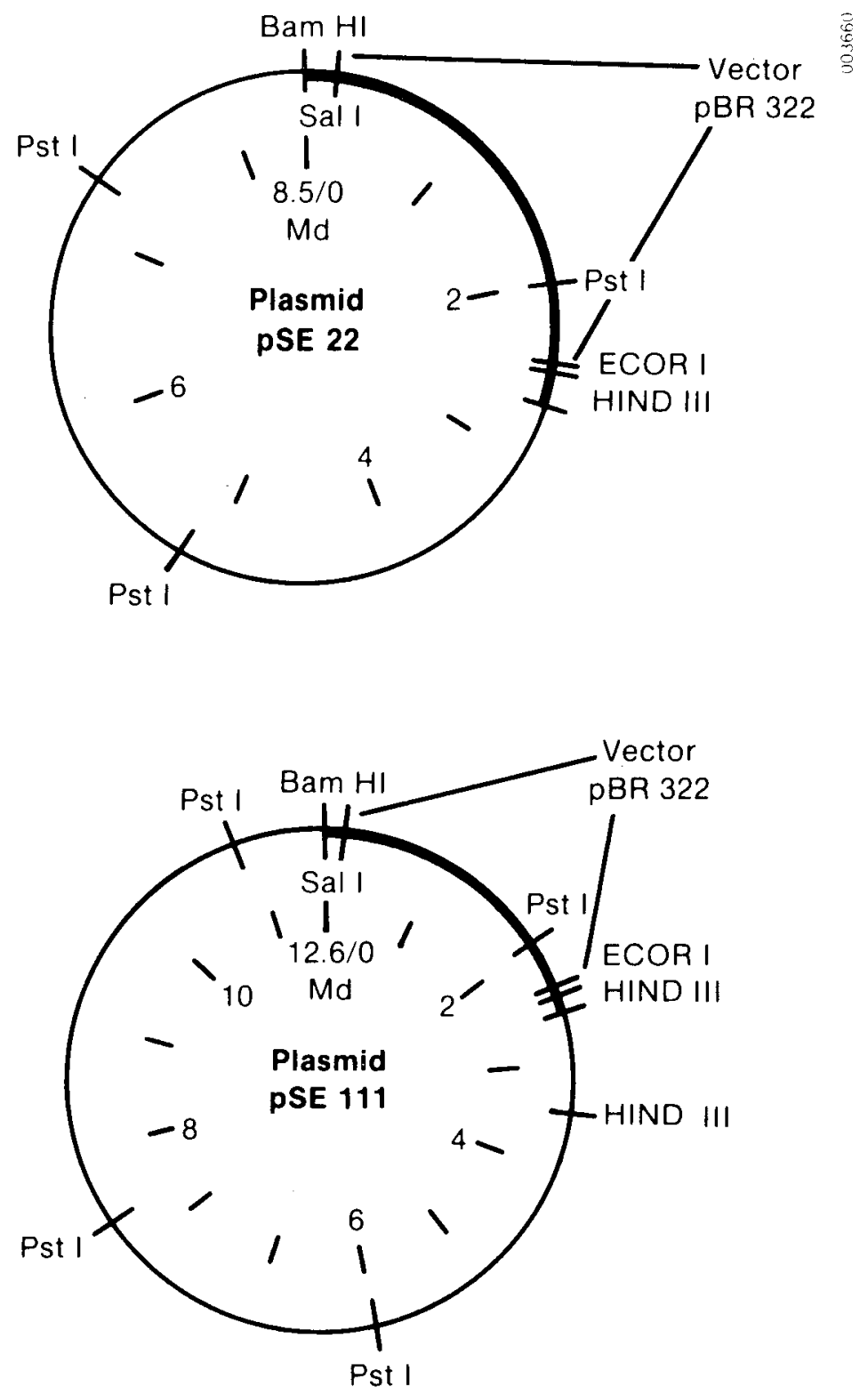

Figure 4-6. Restriction Maps (partial) for Recombinant Plasmids Containing Hydrogenase/Hydrogen Uptake Genes 
These two genes result in at least 3 types of hydrogen-uptake-minus mutants. In addition, at least two previously unknown control genes have been discovered. One gene controls expression of hydrogenase under aerobic conditions, while the other controls expression of hydrogenase under anaerobic conditions. These genes were discovered when the cloned genes were reintroduced into E. coli, followed by growth under aerobic and anaerobic conditions.

Restriction endonuclease cleavage maps of four plasmids containing hydrogenase genes have been completed (see Figure 4-7). By matching cleavage sites and fragment sizes, it is possible to tell how much overlap there is in the genes carried by each plasmid. The fragments generated by endonuclease cleavage can also be used as probes to determine the exact locations and functions of the genes carried by each plasmid. This work is now in progress at the University of Florida.

Also at the University of Florida, five new hydrogenase mutants of Anabaena variabilis (a blue-green algae) have been isolated and partially characterized. These mutants will be used to study the regulation of hydrogenase activity in blue-green algae. One of the newly isolated mutants is $\mathrm{Gln}^{-}$. Normally $\mathrm{Gln}^{-}$mutants cannot grow on ammonia, but this $\mathrm{Gln}^{-}$mutant is able to grow on low levels of ammonia and, surprisingly, can still produce heterocysts and, hence, hydrogen. Ammonia normally represses heterocyst formation and hydrogen production in blue-green algae; therefore, this result is of great interest. Further investigation of the genetic character of this mutant is underway.
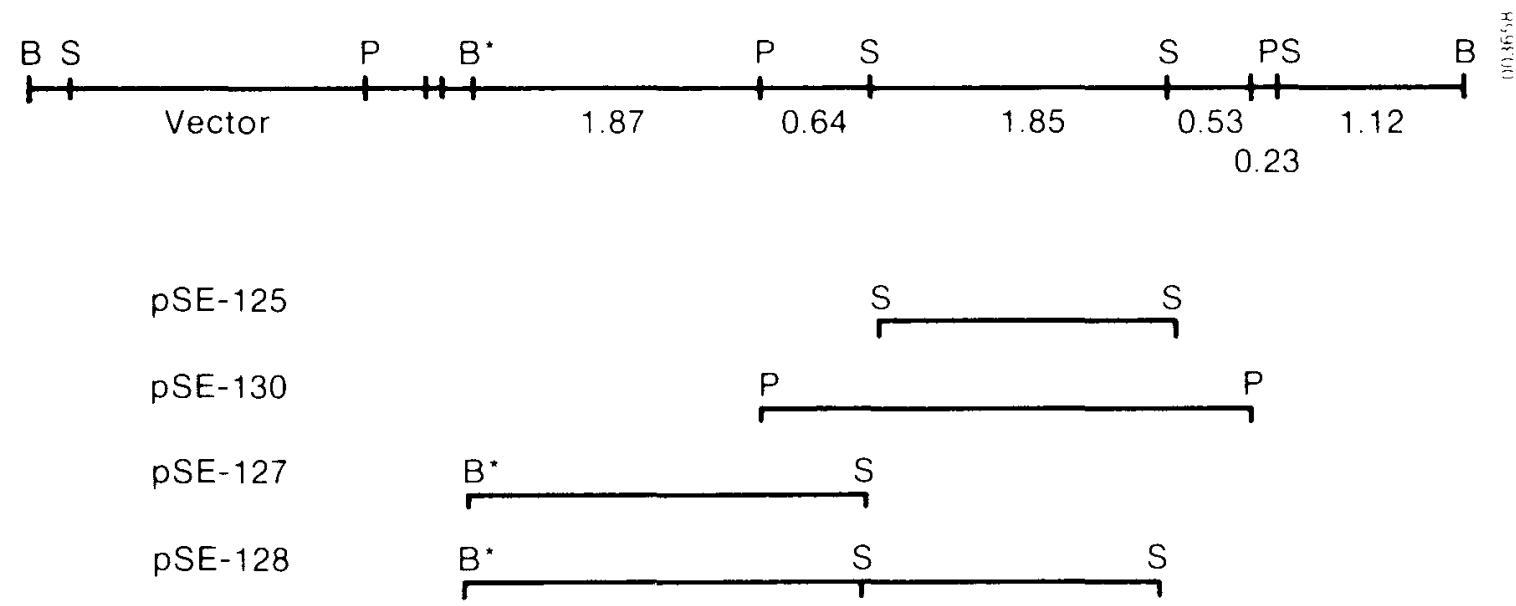

Figure 4-7. Restriction Map of E. Coli Recombinant Plasmid pSE-22 and the Subclones Derived from Plasmid pSE-22. pBR-322 is the vector; B, Bam HI; E, EcoRI; H, HindIII; P, Pst I; S, Sal I. B* represents the expected location of the Bam HI restriction site in the vector, but it is not detected in plasmid pSE-22. The numbers indicate the distances between restriction sites in megadaltons. 
The establishment of a successful hydrogen-producing biotechnology also depends on determining the culture conditions required to support maximum hydrogen evolution rates in the laboratory and then in the field. Investigators at the University of Missouri noted significant differences in the ability of PSB to remove carbon from the culture media. In batch culture, quite large amounts of substrate remain under certain conditions. Under flow-through conditions, however, virtually no carbon compounds remain in the discharged media. This is encouraging because PSB hydrogen production systems are expected to operate in the flow-through mode. Also, the efficiency of conversion of organics to hydrogen in batch culture appear to be tied to nitrogen metabolism. These results suggest that low levels of a nitrogen source could lead to complete conversion of carbon compounds to hydrogen under batch conditions.

Before photosynthetic bacteria can be considered as a practical means for the photoconversion of liquid wastes into hydrogen, it is first necessary to determine the stability of cultures during long-term incubation under hydrogen-evolving conditions. At SERI unsupplemented cultures exposed to continuous light evolved hydrogen at constant rates for up to 14 days. However, constant rates of hydrogen photoproduction can be extended by feeding with low levels of a nitrogenous compound. For example, cultures of Rps. sphaeroides SCJ fed biweekly with $8 \mathrm{mM}$ glutamate have remained in an active $\overrightarrow{\mathrm{H}}_{2}{ }^{-}$ producing mode for 18 months. Feeding cultures in the field with glutamate would not be practical, but other means of supplementing nitrogen might work under field conditions; for example, adding air to the reactor or mixing sewage or another high ammonia stream with the incoming substrate. These results are very encouraging because it indicates that reinnoculation of the hydrogen reactor would perhaps be needed only rarely.

One approach to stabilizing long-term hydrogen production is cell immobilization. The cells are concentrated (usually by dewatering) and then imbedded in some biologically innocuous polymer. At the University of Miami, immobilization of tropical marine PSB in agar sheets in an outdoor reactor resulted in a peak hydrogen production rate of $134 \mathrm{~mL} / \mathrm{g}-\mathrm{gel} \mathrm{h}$ (the average production rate over 5 days was $67 \mathrm{~mL} / \mathrm{g}-\mathrm{gel} \mathrm{h}$ ). This high hydrogen production rate is very encouraging because it is $70 \%$ of the rates achievable in the laboratory.

\subsubsection{Cell-Free Research}

Potentially practical cell-free technologies for producing hydrogen are identified through the information generated in biochemical and biophysical studies on whole cells. Successful cell-free hydrogen production will probably consist of biologically derived components, synthetic components, and carriers combined to produce a system that funnels light-generated electrons to the production of useful products, including hydrogen.

Cell-free systems for hydrogen production are expected to include photoactive watersplitting components taken from the cell, and means must be found for protecting these components from degradation. Synthetic components of potential cell-free systems undergo complex electrochemical reactions which must be understood before these components can be protected against dissolution. Research performed in FY 1983, aimed at improving both the materials available for use in cell-free systems and the efficiency of conversion of light energy to products, is described below.

As mentioned previously, hydrogenase is the hydrogen production enzyme in green algae. This year, researchers at SERI purified hydrogenase over a 1000 -fold from cellular extracts of the green algae Chlamydomonas reinhardtii. The procedure included 
an affinity chromatographic technique* in which immobilized ferredoxin molecules were the affinity ligand. Although the method yields hydrogenase of high purity, it cannot be readily scaled up for larger preparations because ferredoxin can be obtained only in limited quantitites. Furthermore, the ferredoxin-affinity gel exhibits a limited stability (half-life of about 2.5 weeks). Thus, until a cheap commercial source of pure or crude ferredoxin is located, the use of a ferredoxin-affinity column for the purification of hydrogenase will be limited to submilligram preparations. An alternative method of purification based on the commercially available protein adsorbant hydroxylapatite has been investigated. Hydroxylapatite chromatography produces a preparation of enzyme nearly as pure as that obtained from ferredoxin-affinity chromatography. This new isolation procedure will facilitate production of larger quantities of purified algal hydrogenase for use in biochemical and biophysical studies.

Studies of the detailed biochemistry of purified algal hydroganase have shown that a positively charged region exists in close proximity to the active site of the enzyme (see Figure 4-8). The pH response of the enzyme suggests that imidazole groups of histidine residues are not involved. The positive charges are most likely derived from the quaternary nitrogen atoms of lysine or arginine residues. In addition, new experimental results suggest that the cataly tic activity of algal hydrogenase requires at least one free sulfhydryl group: sulfhydryl reagents, such as dithiothreitol or 2-mercaptoethanol at concentrations ranging from $0.1 \mathrm{mM}$ to $1 \mathrm{mM}$, provide maximal protection of the catalytic activity of purified algal hydrogenase. Studies such as these will eventually provide the information necessary to modify hydrogenase stability and reactivity.

In a cell-free technology, hydrogen evolution must be balanced by oxygen evolution or some other oxidative process. In photosynthetic organisms, photosystem I normally associated with carbon fixation, can be linked to hydrogen production, and photosystem II is responsible for evolving oxygen from water.

Work at SERI this year (Figure 4-9) confirmed that isolated photosystem II preparations contain all the components normally associated with this system in intact chloroplasts. The only difference is that the rates of some of the reactions are slower in the isolated preparation. This appears to be caused by a depletion in the plastoquinone pool. SERI scientists also developed a new water-splitting photosystem II preparation having the best properties (purity and stability at room temperature) of the two literature preparations previously used. Steady-state oxygen evolution, Mehler reaction, EPR detectable Signal I, low temperature fluorescence, specific oxygen flash yield, and stability of the water-splitting apparatus at room temperature have been compared for chloroplasts, three PS II preparations reported in the literature, and the new SERI PS II preparation.

These oxygen-evolving PS II preparations are appressed (double inside-out) membranes from the grana region of the chloroplast thylakoid. At room temperature, the oxygenevolving apparatus in these detergent-fractioned preparations is 10 times more stable than in isolated chloroplasts. The basic mechanism of photosynthetic oxygen evolution is not altered by the isolation process. The isolation process does limit, however, the size of the electron acceptor pool of PS II, thus limiting the amount of water that can be split, or the amount of oxygen produced (oxygen is a convenient monitor of the system).

* Since ferredoxin is the natural cofactor for hydrogenase, its attachment to a column renders the column very selective for hydrogenase and capable of producing high purification of the enzyme. 


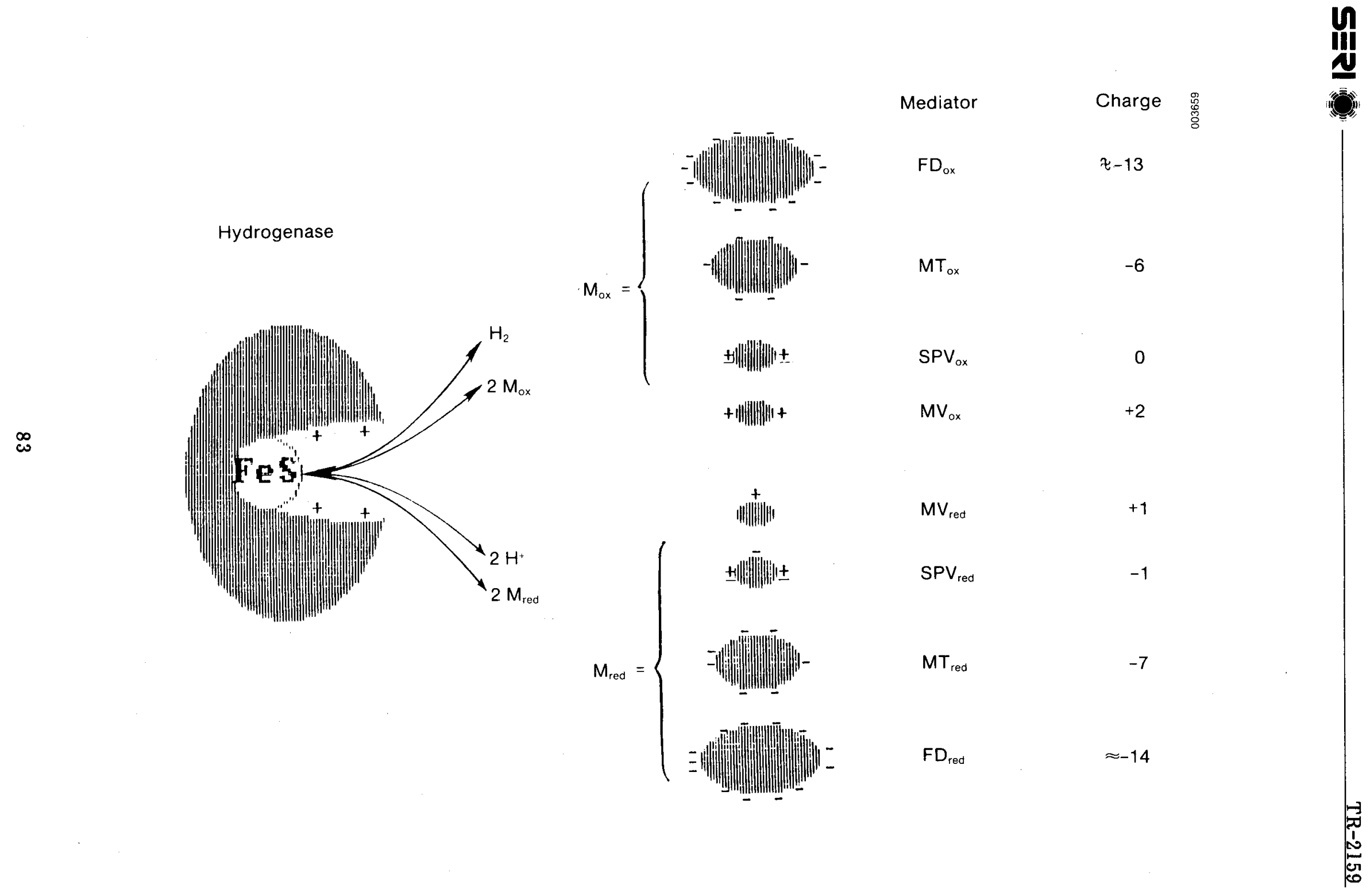

Figure 4-8. An Electrostatic Model for Hydrogenase-Mediator Interaction 


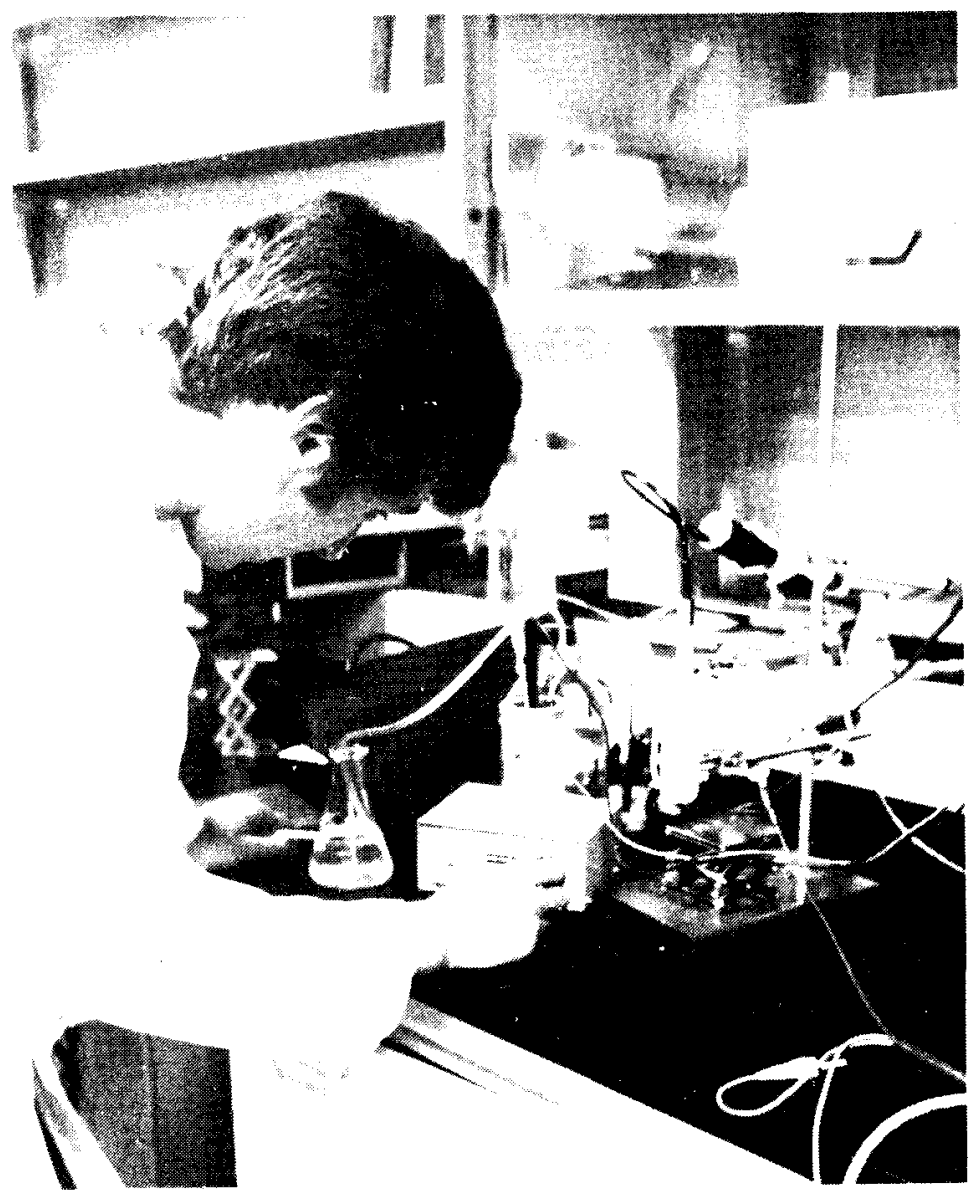

Figure 4-9. Mike Seibert Adjusts Apparatus for Measuring Oxygen Evolution from Photosystem II Preparations

In chloroplasts and algae, oxygen evolution is continuous under continuous light. In contrast patterns of oxygen emission in chloroplasts elicited by sequences of very short light flashes reach a steady-state level and thereafter continue with no change. In the case of PS II preparations, which have only limited electron acceptor capacity, the oxygen flash response* quickly goes to zero when electrons from the oxygen-evolution process saturate the acceptor pool. Chloroplast-like oxygen flash patterns have been restored by adding artificial acceptors to oxygen-evolving PS II preparations (see Figure 4-10). Not only does this demonstrate that the PS II preparation can be coupled to artificial electron transfer carriers (in the experiment shown, ferricyanide was used), but also that this can be done under conditions that do not alter the oxygen-evolution process.

The oxygen-evolving apparatus is located on the outer surface of the PS II membranes. A new project at SERI designed to sequentially remove three polypeptides $(18,23$, and $33 \mathrm{kDa}$ ) from these preparations was initiated. These polypepties (among others which will also be investigated) have been related to the oxygen-evolving enzyme complex. Preliminary results indicate that changes occur in steady-state oxygen yields, oxygen-

*Oxygen evolution in photosynthesis is a four electron process. In this experiment each flash promotes one electron, so four flashes constitute an oxygen-evolution cycle. 


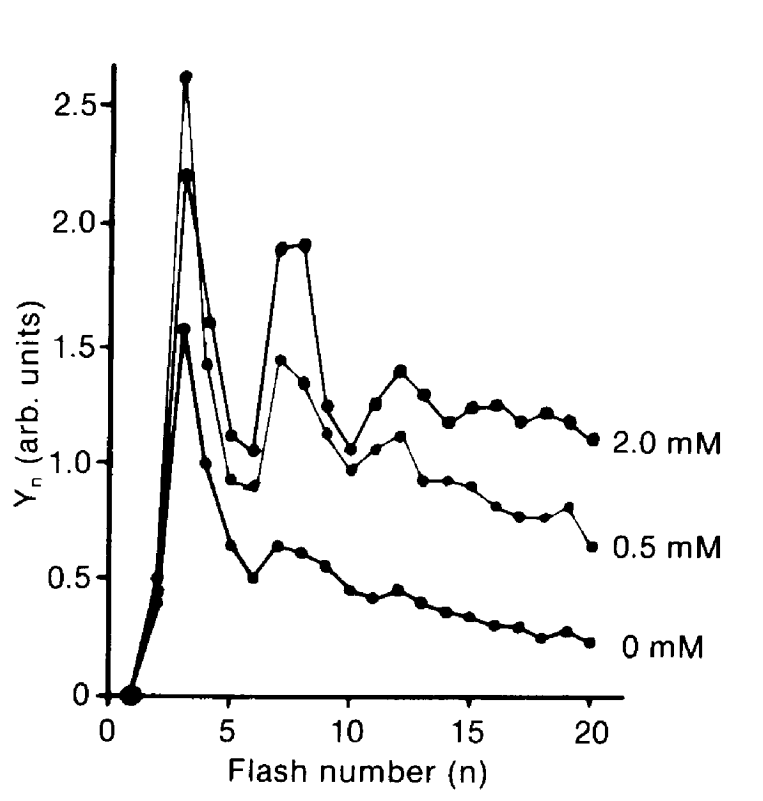

Figure 4-10. Flash Yield Sequences of an Oxygen-Evolving Preparation. A twomembrane $\mathrm{O}_{2}$-rate electrode was used. The indicated concentration of potassium ferricyanide flowed through the middle chamber.

flash-sequence patterns, fluorescence induction properties, and membrane surface characteristics as the various peptides are removed (see Figure 4-11). Understanding the functioning of the oxygen-producing portion of the photosynthetic apparatus will improve the potential for developing a successful cell-free water-splitting technology.

\subsubsection{Biochemical Engineering Research}

Totally new engineering ground will need to be broken before the practicality of hydrogen production biotechnologies can be established. Much research will therefore be needed both at the laboratory scale and in the field. Engineering research is begun for a developing solar biotechnology when laboratory experiments show sufficient progress to suggest that the system will eventually be practical. Currently, only PSB hydrogen production has reached this phase; however, information and materials generated by research performed on this system should be applicable to other hydrogen production systems under development in this subprogram.

The first activity initiated in this task is modeling and simulation. This involves gathering information from literature and industry to assess the state of the art. From this information a hypothetical system is devised, components are designed or selected, and costs for the hypothetical system are estimated. Computer programs are written to simulate component and system performance. All the research currently performed in this task is carried out at SERI.

Test runs were performed of the computer simulation (SOLBUG) of the thermal and biological characteristics of a conceptual PSB reactor. In the course of this work several 


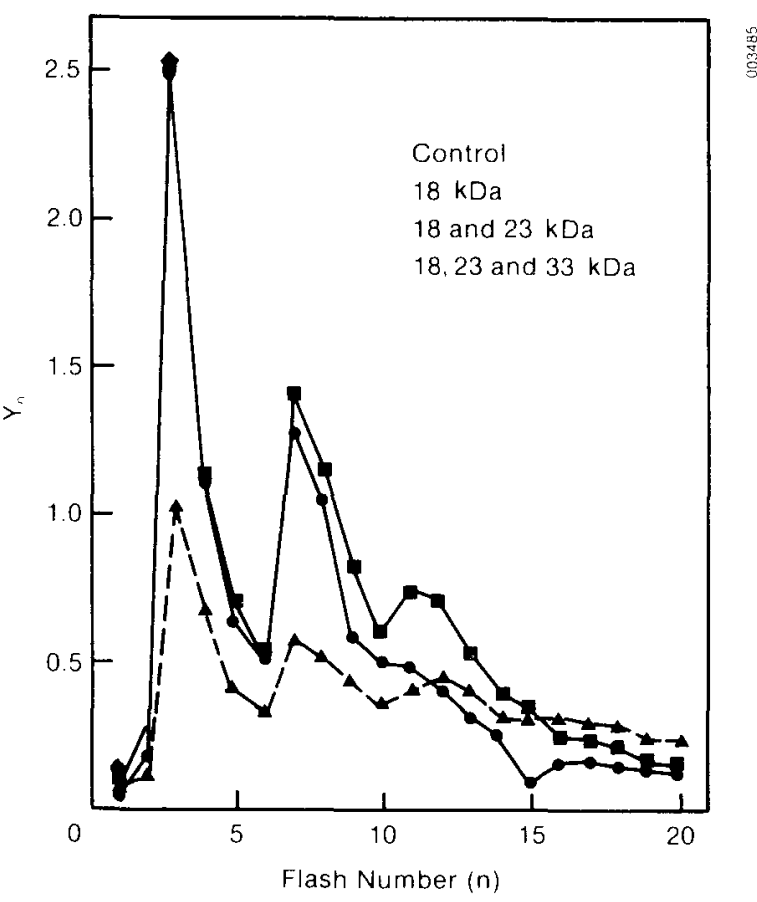

Figure 4-11. Flash-Sequence Patterns of Oxygen Evolution in Photosystem II Preparations Resulting from Sequential Removal of 3 Proteins (18, 23, and $33 \mathrm{kDa}$ ) from the Oxygen-Evolving Complex

corrections and improvements to the program were made. Plots of the results of the test runs verified that the model was behaving as expected; i.e., the data looked reasonable. This model will be used to evaluate various design parameters and improve the design of experimental reactor units. (Figure 4-12 shows a field test reactor unit.)

A survey of several candidate materials for reactors served as the basis of an analysis of hydrogen cost. Some of these materials are commercially available. SERI engineers evaluated system performance and analyzed cost using data for Tedlar and Kynar, the two lowest cost materials identified in the materials effort described below. Effects of transmittance, hydrogen permeation rate, and cost were considered. Both materials appear extremely promising. Tedlar resulted in a hydrogen cost of $\$ 89.20 / \mathrm{MWh}$; the Kynar, $\$ 81.71 / \mathrm{MWh}$ (see Table 4-3). These costs compare favorably with the $\$ 83.30 / \mathrm{MWh}$ previously predicted for the $5 \%$ efficient, $1 \times 10^{6} \mathrm{scf} /$ day plant that used a hypothetical material based on manufacturer's estimates of performance and cost.

Several runs of the SOLBUG thermal subroutine (see Figure 4-13 for a schematic of the SOLBUG thermal network) have been performed using local (Denver) weather data. The results of these runs are being used to design a test module. The test module will, in turn, be used to verify the accuracy of the thermal subroutine of SOLBUG. The test module will consist of a $1 \mathrm{~m}$ by $1 \mathrm{~m}$ by $2 \mathrm{~m}$ hole lined with vinyl and covered with plexiglass. The water in the module and the ground surrounding it will be heavily instrumented with thermistors to monitor the thermal performance.

In support of the modeling work, SERI materials researchers surveyed the literature to identify materials that might be suitable for use in proposed PSB reactors. A preliminary report identifying candidate low-cost container materials was prepared (see Table 4-4 for 


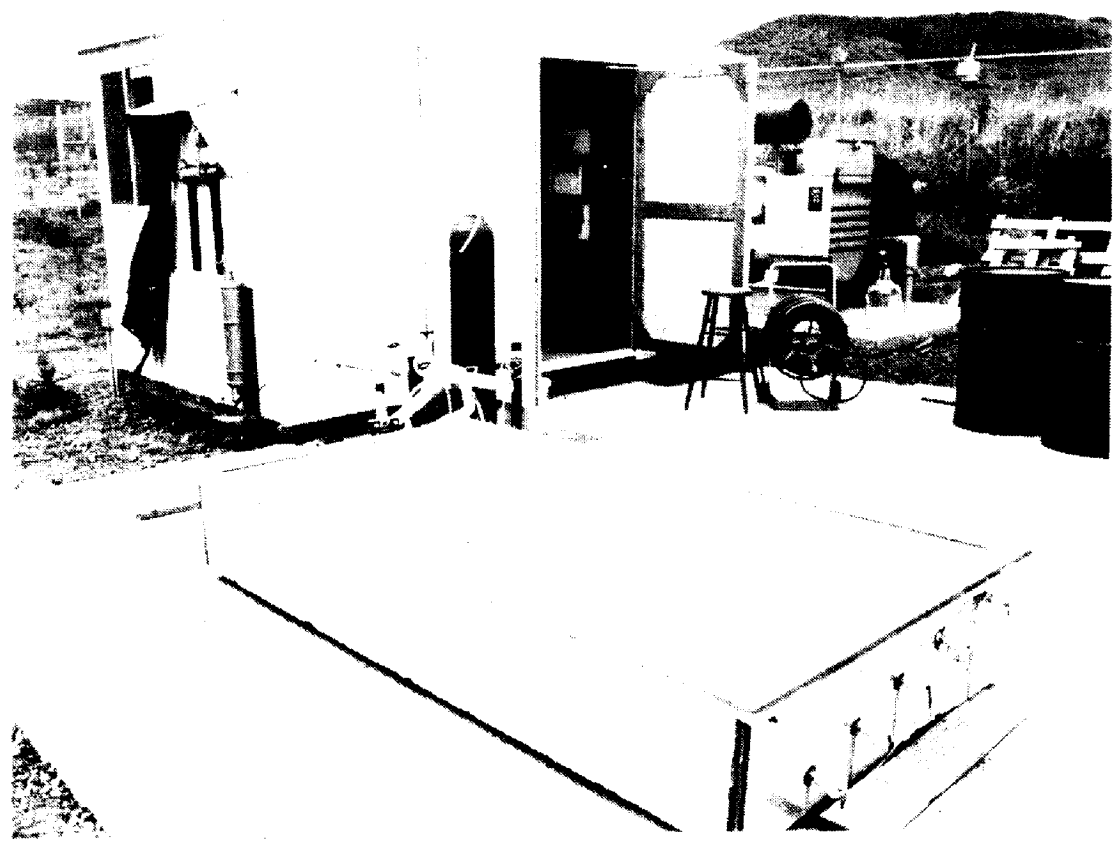

Figure 4-12. Field Test Reactor Unit

materials identified). Hydrogen permeation rates and design stresses were estimated for two of the polymer films for which cost, yield strength, and solar transmittance data were available: biaxially oriented Kynar $(2 \mathrm{mil})$ and a glass fiber-reinforced silicon $(10 \mathrm{mil})$. Cost and yield streng th data for several other polymer films showing similarly good weathering properties and low $\mathrm{H}_{2}$ permeation rates have been requested from the suppliers. The oriented Kynar film, although still experimental, looks promising because of low projected cost $\left(\$ 3.8 / \mathrm{m}^{2}\right)$, low $\mathrm{H}_{2}$ permeability $\left(6.0 \mathrm{~cm}^{3} \mathrm{H}_{2} / \mathrm{m}^{2}\right.$ day), high solar transmittance, and high tensile strength.

Hydrogen permeation rates and design stresses were estimated for two additional commercial polymer films: Tedlar $(4 \mathrm{mil})$ and Barex $(10 \mathrm{mil})$. The Tedlar film can be used in thinner sections than the Barex pecause its tensile yield strength is higher, and thus it will be less expensive $\left(\$ 4.84 / \mathrm{m}^{2}\right)$. The projected $\mathrm{H}_{2}$ permeability of the Tedlar film is

Table 4-3. Results of Materials Analysis for Photosynthetic Bacterial Reactors

\begin{tabular}{lcccccc}
\hline Material & $\begin{array}{c}\text { Permeation } \\
\text { Rate } \\
(\%)\end{array}$ & $\begin{array}{c}\text { Solar } \\
\text { Transmittance } \\
(\%)\end{array}$ & $\begin{array}{c}\text { Material } \\
\text { Cost } \\
\left(\$ / \mathrm{m}^{2}\right)\end{array}$ & $\begin{array}{c}\text { Reactor } \\
\text { Cost } \\
(\$ / \mathrm{m})\end{array}$ & $\begin{array}{c}\text { Area } \\
\text { Required } \\
\left(\mathrm{m}_{2}\right)\end{array}$ & $\begin{array}{c}\text { Cost of } \\
(\$ / \mathrm{MWh})^{\mathrm{a}}\end{array}$ \\
\hline Baseline & - & - & 4.00 & 20.5 & $2.8 \times 10^{5}$ & 83.30 \\
Tedlar & 0.16 & 90 & 4.84 & 21.4 & $3.1 \times 10^{5}$ & 89.20 \\
Kynar & 0.36 & 94 & 3.18 & 19.6 & $2.9 \times 10^{5}$ & 81.71 \\
\hline
\end{tabular}

$\left.a_{(M W h}\right)=$ megawatt hours 
Table 4-4. Possible Polymer Covers for Photosynthetic Bacterial Reactors

\begin{tabular}{|c|c|c|c|c|c|c|c|c|}
\hline Material & Manufacturer & $\begin{array}{c}\text { Service } \\
\text { Life } \\
(y r)^{\mathrm{a}}\end{array}$ & $\begin{array}{l}\text { Cost } \\
\left(\$ / m^{2}\right)\end{array}$ & $\begin{array}{l}\text { Thickness } \\
\text { (mil) }\end{array}$ & $\begin{array}{l}\text { Yield } \\
\text { Strength } \\
\text { (psi) }\end{array}$ & $\begin{array}{l}\text { Design } \\
\text { Stress } \\
\text { (psi) }\end{array}$ & $\begin{array}{c}\text { Solar } \\
\text { Trans- } \\
\text { mittance } \\
\text { (\%) }\end{array}$ & $\begin{array}{c}\mathrm{H}_{2} \text { permea- } \\
\text { fion rate } \\
\left(\mathrm{cm}^{3} / \mathrm{m}^{2} \text { day }\right)\end{array}$ \\
\hline $\begin{array}{l}\text { *Biaxially- } \\
\text { oriented Kynar }\end{array}$ & $3 \mathrm{M}$ & $15-20$ & $\$ 3.18$ & 2 & 38,000 & 18,900 & 94 & 360 \\
\hline Tedlar & Dupont & $15-20$ & $\$ 4.84$ & 4 & 12,000 & $9,45 \cap$ & 90 & 160 \\
\hline Barex & Sohio & $?$ & $\$ 1.21$ & 4 & 10,000 & 9,450 & 90 & 46 \\
\hline $\begin{array}{l}\text { Silicone } \\
\text { (glass-fiber } \\
\text { reinforced) }\end{array}$ & Dow & 20 & $\$ 13.50$ & 10 & 10,000 & 4,725 & $\begin{array}{c}80 \\
\text { (red) }\end{array}$ & 2200 \\
\hline $\begin{array}{l}\text { *Silicone } \\
\text { (glass-film } \\
\text { reinforced) }\end{array}$ & $\begin{array}{l}\text { Owens- } \\
\text { Illinois }\end{array}$ & 20 & $?$ & 10 & $?$ & $4,72.5$ & $?$ & 250 \\
\hline
\end{tabular}

Estimated by manufacturer. 


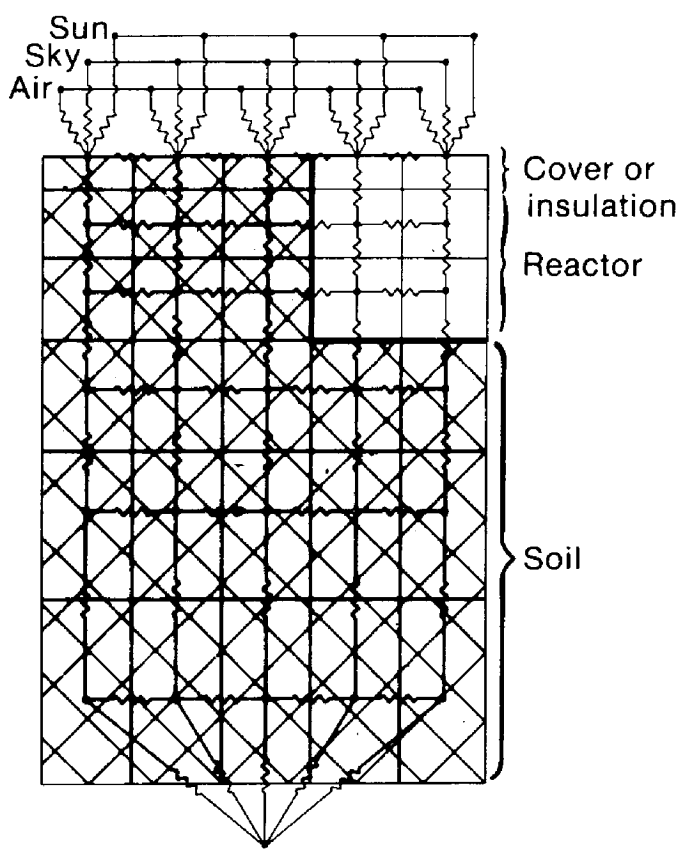

Figure 4-13. Thermal Network in SOLBUG quite low $\left(2.6 \mathrm{~cm}^{3} \mathrm{H}_{2} / \mathrm{m}^{2}\right.$ day), and it is available in commercial quantities. The material is highly transparent and has good weatherability. Samples suitable for permeability measurements have been received. The hydrogen and oxygen permeation rates of these two candidate cover materials for deep-pond PSB reactors were measured at SERI. Results are shown in Table 4-5 with manufacturers' data for comparison. Manufacturers' and SERI tests were performed using Dow permeation cells, per ASTM D-1434, at $23^{\circ}-25^{\circ} \mathrm{C}$. Manufacturers' data and SERI results agree within an order of magnitude, with the exception of the oxygen permeability of Barex 210. Variations in data from replicate measurements indicate that a statistically significant number of repeat measurements are necessary. Differences between manufacturers' data and those obtained at SERI, assuming no experimental error in either case, may indicate that gas

Table 4-5. Comparison of Gas Permeation Rates Measured at SERI with Those Obtained from Manufacturer for Two Candidate Cover Materials

\begin{tabular}{|c|c|c|c|c|}
\hline \multirow{2}{*}{ Material } & \multirow{2}{*}{ Gas } & \multirow{2}{*}{$\begin{array}{l}\text { Sample } \\
\text { Number }\end{array}$} & \multicolumn{2}{|c|}{$\begin{array}{l}\text { Gas Permeation Rate } \\
\left(\mathrm{cm}^{3} / \mathrm{m}^{2} \text { day atm }\right)\end{array}$} \\
\hline & & & SERI & Manufacturer \\
\hline $\begin{array}{l}\text { 4-mil Tedlar } \\
\text { 4-mil Tedlar } \\
\text { 4-mil Tedlar } \\
\text { 3-mil Barex } \\
\text { 3-mil Barex } \\
\text { 3-mil Barex }\end{array}$ & $\begin{array}{l}\mathrm{H}_{2} \\
\mathrm{H}_{2} \\
\mathrm{O}_{2} \\
\mathrm{H}_{2} \\
\mathrm{H}_{2} \\
\mathrm{O}_{2}\end{array}$ & $\begin{array}{c}1 \mathrm{~B} \\
1 \mathrm{~B} \\
1 \mathrm{~B} \\
1 \\
2 \\
2\end{array}$ & $\begin{array}{c}258.0 \\
363.0 \\
6.07 \\
566.0 \\
656.0 \\
45.4\end{array}$ & $\begin{array}{c}225.0 \\
225.0 \\
12.4 \\
1289.0^{\mathrm{c}} \\
1289.0^{\mathrm{c}} \\
4.13^{\mathrm{c}}\end{array}$ \\
\hline
\end{tabular}

Tedlar 400 XRS $160 \mathrm{SE}$, manufactured by Dupont, oriented polyvinyl fluoride film.

$b_{\text {Barex }} 210$ film, manufactured by Sohio, $75 \%$ acrylonitrile, $25 \%$ methyl acrylate copolymer film.

${ }^{c}$ Data for unoriented material. 
permeability is not a linear function of film thickness, as implied by manufacturer's measurements, or that the films are not uniform. The need for in-house testing of representative samples of candidate cover materials is evident.

Samples of biaxially oriented, 2-mil polyvinylidene fluoride (Kynar) film are now available and have been requested. The manufacturer, $3 \mathrm{M}$, is engaged in pilot-plant production of the material. Because of the high degree of molecular orientation, tensile strength is very high, and 2-mil films should be usable as cover materials at a considerable cost savings over thicker, weaker films. Biaxial orientation should reduce gas permeability. The manufacturer has not measured the permeability of the material (predictions have been based on data from uniaxially oriented Kynar) and is interested in the results of SERI measurements. The manufacturer will decide whether to commercialize the material in the next several months and accordingly is interested in the applications under consideration at SERI.

\subsection{SUMMARY}

The Photo/Biological Hydrogen subprogram of the Biomass Program, sponsored by the U.S. DOE Biomass Energy Technology Division, has as its goal to make possible the introduction of new solar biotechnologies that produce large volumes of hydrogen from renewable resources at reasonable prices. These biotechnologies have two bases of development: (1) the use of the biochemical/biophysical systems in living cells, and (2) the use of quasi-synthetic hydrogen production systems based on components isolated from cells.

A technology based on intact, living cells (usually microorganisms) takes advantage of biochemical and biophysical systems already in place in the cell for evolving hydrogen. Living cells use hydrogen production as a means of dumping excess reducing power; the source of this hydrogen is generally water. In cell-free technologies the aim is to mimic the mechanisms that whole cells use to produce hydrogen. These naturally occuring systems need to be enhanced if they are to provide a practical basis for commercial hydrogen production. Research has aimed, therefore, at improving the efficiency of conversion of light to hydrogen energy. In the course of this research hundreds of microorganisms have been screened for hydrogen production capacity, and a number of very promising strains have been selected. The biochemistry and biophysics of hydrogen production by these selected organisms is being studied. Detailed information concerning the biological mechanisms of hydrogen production is being used to plan and execute genetic engineering aimed at producing hydrogen-evolving "superbugs." The culture requirements for maintaining maximum hydrogen production rates are being determined both in the laboratory in the field.

Progress toward the research goal of achieving at least a $10 \%$ efficiency of conversion of light to hydrogen energy in whole-cell systems has been so encouraging (laboratory-scale experiments with photosynthetic bacteria yielded an efficiency of $5 \%-6 \%$ ) that researchers have begun devising a conceptual engineering system for hydrogen production. A preliminary system flow has been developed, and components for the system have been identified. Projected cost goals are promising. For the proposed system SERI researchers are developing a computer program to model system behavior which is now two-thirds completed.

Design of cell-free systems for producing hydrogen can be based on information gleaned from studies of the biochemistry and biophysics of hydrogen generation in living cells. 
The advantage of cell-free technologies is the potential for producing hydrogen at higher rates and with less maintenance than is considered possible for whole-cell systems. To realize this potential, much research needs to be performed to identify promising systems, stabilize system components, improve the efficiency of light-to-hydrogen conversions, and learn how to construct these systems for long life and proper function. To date most of the research in this task of the $\mathrm{P} / \mathrm{BH}$ subprogram has focused on improvement of the techniques for removing hydrogen-producing components from the cell and complete characterization of these components so that they can be successfully manipulated. Progress has been encouraging, as high conversion efficiencies of light to hydrogen energy have been demonstrated.

A goal of the Photo/Biological Hydrogen subprogram is to greatly expand research in the cell-free area in future years. A more systematic approach toward identifying promising system concepts and stabilizing and enhancing the hydrogen production efficiency of the components is especially important. 


\section{SECTION 5.0}

\section{PUBLICATIONS}

This section contains references to all publications related to work supported during the period covered by this report.

\subsection{AQUATIC PUBLICATIONS}

"Algal Mass Culture Technology: Review of Patents." Prepared for the Solar Energy Research Institute by Jaycor under Subcontract XK-Z-02123-01, November 15, 1982.

"Laboratory Selection of Microalgae for Maximum Lipid and Protein Production." Prepared for the SERI Biomass Program Principal Contractor Review Meeting, June 1982, Washington, D.C.

"Microalgae from Desert Saline Waters as Potential Biomass Producers." Received by SERI and submitted to the American Solar Abstract Energy Soc. 1983 meeting in St. Paul, Minn.

Pratt, D. C., et al. "Emergent Aquatics: Stand Establishment, Management, and Species Screening." November 1982, SERI/STR-231-1819.

"Proceedings of the SERI Biomass Program Principal Investigators' Review MeetingAquatic Species Program Reports." December 1982, SERI/CP-231-1808.

Ryther, R.H. "Cultivation of Macroscopic Marine Algae." November 1982, SERI/ STR-231-1820.

Thomas, W. H. and S. R. Gaines. "Algae from the Arid Southwestern United States: An Annotated Bibliography." Prepared under Subcontract XK-2-0270-01 for SERI by Scripps Institute of Oceanography, October 1982.

Thomas, W. H., et al. "Yields, Photosynthetic Efficiencies and Proximate Chemical Composition of Dense Cutters of Marine Microalgae." Draft final report prepared for Solar Energy Research Institute under Subcontract XK-09111-1, December 1982.

Tornabene, T. G., Ami Ben-Amotz and J. S. Hubbard. "Isolation, Analysis and Identification of Lipids." Draft final report on laboratory syllabus for Microalgae Lipid Short Course, December 1982.

Bonnewell, V., W. L. Koukkari, and D. C. Pratt. 1983. "Light, Oxygen, and Temperature Requirements for Typha latifolia L. Seed Germination." Can. J. Botany (in preparation for April 1983 publication.

Schertz, C., D. R. Dubbe, and D. C. Pratt. 1983. "Harvesting Cattail (Typha spp.) Rhizomes as an Alternative Feedstock for Alcohol Production: Modifications of Potato Harvester." Final report to U.S. Department of Energy, Alcohol Fuels Division. 19 p. 
Spencer, K., and S. Lien submitted an abstract entitled "Utilization of Stored Oil in a Strain of Chlorella" to the American Society of Plant Physiologists.

Hill, Andrew, and Bernie Neenan. "Optimizing Multi-Product Conversion Processes for Commercial Use: A Case of Microalgae Production." Submitted to ASES 1983 meeting.

Thomas, W. H. and Don Seibert, et al. "Microalgae from Desert Saline Waters as Potential Biomass Producers. Submitted to ASES 1983 meeting.

Thomas, W. N. 1983. "Development of a System for Automating the Measurement of Biomass Yields and Efficiencies of Light Utilization by Microalgae: Final Report to the Bio-Energy Council." 17 pp.

J. Connolly refereed three manuscripts and three proposals in Photophysics of Algal and Bacterial Pigments.

Debusk, T. N., and J. N. Ryther, "Effects of Seawater Exchange, pH, and Carbon Supply on the Growth of Gracilaria tikvahiae in Large-Scale Cultures," submitted to Botanica Mania in September 1983.

Seibert, D., and W. Thomas, "Computerized Non-Invasive Measurement of the Growth Response of Microalgae to Temperature and Salinity," submitted to Journal of Phycology in July 1983.

Thomas, W., D. Seibert, M. Alden, P. Eldridge, and A. Neori, Yields, Photosynthetic Efficiencies, and Proximate Chemical Composition of Dense Cultures of Marine Microalgae, SERI/STR-231-1896, Golden, CO: Solar Energy Research Institute.

Thomas, W., D. Seibert, M. Alden, P. Eldridge, and A. Neori, "Yields, Photosynthetic Efficiencies, and Proximate Composition of Dense Marine Microalgal Cultures: I. Introduction and Phaeodactylum tricornutum Experiments; II. Dunaliella primolecta and Tetraselm is suecia Experiment; III. Isochrysis spp. and Monallanthus salina Experiments; and Comparative Conclusions," submitted to Biomass in August 1983.

\subsection{ANAEROBIC DIGESTION PUBLICATIONS}

Chum, H. L., G. Gross, and C. Wallace. "Materials in Biomass Energy Systems." Submitted for publication in the Encyclopedia of Materials Sciences and Engineering, M. Beaver, editor, Pergamon Press.

Chum, H. L., M. Ratcliff, F. L. Posey, J. A. Turner, and A. J. Nozik. "Photoelectrochemistry of Levulinic Acid on Undoped Platinized nTiO 2 Powders." Submitted for publication in the Journal of Physical Chemistry.

Chum, H. L., M. Ratcliff, H. A. Schroeder, and D. W. Sopher. "Characterization, Fractionation, and Electrochemical Reduction Reactions of Ethanol-Extracted ExplosivelyDecompressed Aspen Lignin." Manuscript preparation completed.

Chum, H. L. and R. A. Osteryoung. "Survey of the Electrochemistry of Some BiomassDerived Compounds." December 1982, SERI/TR-322-417. 
Clausen, E. C., and J. L. Gaddy. "The Production of Methane by Anerobic Digestion in Large or Small-Scale Facilities." Progress in Solar Energy, 1982.

Hashimoto, A. G. "Conversion of Straw-Manure Mixtures to Methane at Mesophilic and Phermophilic Temperatures." Biotechnology and Engineering. Accepted August 4, 1982.

Hashimoto, A. G. "Thermophilic and Mesophilic Anaerobic Fermentation of Swine Manure." Agricultural Wastes. Accepted June 24, 1982.

Hashimoto, A. G. "Effect of Mixing Duration and Vacuum on Methane Production Rate from Beef Cattle Waste." Biotechnology and Bioengineering. 24:9-23, 1982.

Hashimoto, A. G. "Performance of a Pilot-Scale, Thermophilic, Anaerobic Fermenter Treating Cattle Waste." Resources and Conservation. 8:3-17, 1982.

Hashimoto, A. G. and S. A. Robinson. "Pilot-Scale Conversion of Manure-Straw Mixtures to Methane." Resources and Conservation. 8:19-28, 1982.

Kruger, H. J., B. H. Huynh, P. O. Ljungdahl, A. V. Xavier, D. V. DerVartanian, I. Moura, H. D. Peck, Jr., M. Teixeira, J. J. G. Moura, and J. LeGall. "Evidence for Nickel and a Three-Iron Center in the Hydrogenase of Desulfovibrio desulfuricans." J. Biol. Chem. In press.

Moura, I., J. J. G. Moura, H. Santos, A. V. Xavier, G. Burch, H. D. Peck, Jr., and J. LeGall. "Proteins Containing the Factor $F_{430}$ from Methanosarcina barkeri and Methanobacterium thermoautotrophicum: Isolation and Properties." Biochem. Biophys. Acta. 1982.

Moura, J. J. G., I. Moura, M. H. Santos, A. V. Xavier, M. Scandellari, and J. LeGall. "Isolation of $\mathrm{P}_{59}$ from Methanosarcina barkeri: Evidence for the Presence of Sulfite Reductase Activity." Biochem. Biophys. Res. Commun. 108:1002-1009, 1982.

Moura, J. J. G., I. Moura, B. H. Huynh, H. J. Kruger, M. Teixeria, R. C. DuVarney, D. V. DerVartanian, A. V. Xavier, H. D Peck, Jr., and J. LeGall. "Unambiguous Identification of the Nickel EPR Signal in " Ni-Enriched Desulfovibrio gigas Hydrogenase." Biochem. Biophys. Res. Commun. In press.

Prior, R. L., A. G. Hashimoto, J. D. Crouse, and M. E. Dykeman. "Nutritional Value of Anaerobically Fermented Beef Cattle Wastes as a Feed Ingredient for Livestock III. Growth and Carcass Traits of Beef Cattle and Sheep Fed Fermenter Biomass." J. Animal Science. Submitted March 9, 1982.

Prior R. L., R. A. Britton, and A. G. Hashimoto. "Nutritional Value of Anaerobically Fermented Beef Cattle Wastes as a Feed Ingredient for Livestock II. In Vitro Metabolism Studies in Beef Cattle and Sheep." J. Animal Science. Submitted March 9, 1982.

Prior, R. L., R. A. Britton, and A. G. Hashimoto. "Nutritional Value of Anaerobically Fermented Beef Cattle Wastes as a Feed Ingredient for Livestock I. Chemical Composition and In Vitro Digestibility of Fermenter Biomass." J. Animal Science. Submitted March 9, 1982.) 
Speece, R. E., G. F. Parkin, and D. Gallagher. "Nickel Stimulation of Anaerobic Digestion in Water Research." 1982.

Teixeira, M., I. Moura, A. V. Xavier, D. V. DerVartanian, J. LeGall, H. D. Peck, Jr., B. H. Huynh, and J. J. G. Moura. "Desulfovibrio gigas Hydrogenase-Redox Properties of the Nickel and Iron-Sulfur Centers." Eur. J. Biochem.

Varel, V. H. and A. G. Hashimoto. "Methane Production from Fermenter Cultures Acclimated to Waste from Cattle Fed Monensin, Lasolocid, Scalinomycin, and Avoparcin." Applied and Environmental Microbiology. 44(6):1415-1420, 1982.

Varel, V. H. and A. G. Hashimoto. "Methane Production from Fermenter Cultures Acclimated to Waste from Cattle Fed Monensin, Lasolocid, Salinomycin, or Avoparcin." Joint annual meeting of the American Society of Animal Science and Canadian Society of Animal Science. Guelph, Ontario, Canado. (Abstract)

Chum, H. L., G. Gross, and C. Wallace. "Materials in Biomass Energy Systems." Submitted for publication in the Encyclopedia of Materials Sciences and Engineering, M. Beaver, editor, Pergamon Press.

Chum, H. L., M. Ratcliff, F. L. Posey, J. A. Turner, and A. J. Nozik. "Photoelectrochemistry of Levulinic Acid on Undoped Platinized nTiO 2 Powders." Submitted for publication in the Journal of Physical Chemistry.

Chum, H. L., M. Ratcliff, H. A. Schroeder, and D. W. Sopher. "Characterization, Fractionation, and Electrochemical Reduction Reactions of Ethanol-Extracted ExplosivelyDecompressed Aspen Lignin." Manuscript preparation completed.

Clausen, E. C., and S. L. Gaddy. 1983. "Kinetic Improvements in the Biological Productin of Methane from Cellulosic Residues." Energy from Biomass and Wastes, Chicago, IL.

Clausen, E. C., and J. L. Gaddy, 1982. "The Production of Methane by Anerobic Digestion in Large or Small-Scale Facilities." Progress in Solar Energy. In press.

Hashimoto, A. G.. "Conversion of Straw Manure Mixtures to Methane at Mesophilic and Thermophilic Temperatures." Biotechnology and Bioengineering. Accepted 4 August 1982.

Kruger, H. J., B. H. Huynh, P. O. Ljungdahl, A. V. Xavier, D. V. DerVartanian, I. Moura, H. D. Peck, Jr., M. Teixeira, J. J. G. Moura, and J. LeGall. "Evidence for Nickel and a Three-Iron Center in the Hydrogenase of Desulfovibrio desulfuricans." J. Biol. Chem. In press.

Lissolo, T., M. F. Cocquempot, D. Thomas, J. LeGall, K. Schneider, and H. G. Schlegel. "Hydrogen Production Using Chloroplast Membranes without Oxygen Scavengers: An Assay with Hydrogenase from Aerobic Hydrogen-Oxidizing Bacteria and Flavodixins from Desulfovibrio sp." Eur. J. App. Biochem. Biotech. In press.

Moura, I., J. J. G. Moura, H. Santos, A. V. Xavier, G. Burch, H. D. Peck, Jr., and J. LeGall. 1982. "Proteins Containing the Factor $\mathrm{F}_{430}$ from Methanosarcina barkeri and Methanobacterium thermoautotrophicum: Isolation and Properties." Biochem. Biophvs. Actä. 
Speece, R. E., G. F. Parkin, and D. Gallagher. "Nickel Stimulation of Anaerobic Digestion in Water Research." 1982.

Teixeira, M., I. Moura, A. V. Xavier, D. V. DerVartanian, J. LeGall, H. D. Peck, Jr., B. H. Huynh, and J. J. G. Moura. "Desulfovibrio gigas Hydrogenase-Redox Properties of the Nickel and Iron-Sulfur Centers." Eur. J. Biochem. In press.

Published SERI report-the proceedings of the June 1982 Program Review held in Washington, D.C.

The manuscript, "Electrochemistry of Biomass-Derived Materials. I. Characterization, Fractionation, and Electrochemical Reduction Reactions of Ethanol-Extracted Explosively-Depressurized Aspen Lignin," by Chum, Ratcliff, Schroeder (Colorado State University), and Sopher, has been submitted for publication in the Journal of the American Chemical Society.

The manuscript, "Electrochemistry of Lignin Materials and Derived Compounds," hy Chum, Sopher, and Schroeder (CSU), has been submitted for publication in the Proceedings of the International Conference on Fundamentals of Thermochemical Riomass Conversion.

The paper, "Biomass Electrochemistry," has been submitted for the Solar and Biomass Workshop, 26-28 April 1983, Atlanta, GA.

Chum, H. L., G. Gross, and C. Wallace. "Materials in Biomass Energy Systems." Submitted for publication in the Encyclopedia of Materials Sciences and Engineering, M. Beaver, editor, Pergamon Press.

Chum, H. L., M. Ratcliff, F. L. Posey, J. A. Turner, and A. J. Nozik. "Photoelectrochemistry of Levulinic Acid on Undoped Platinized nTiO 2 Powders." Submitted for publication in the Journal of Physical Chemistry.

Chum, H. L., M. Ratcliff, H. A. Schroeder, and D. W. Sopher. "Characterization, Fractionation, and Electrochemical Reduction Reactions of Ethanol-Extracted ExplosivelyDecompressed Aspen Lignin." Manuscript preparation completed.

Clausen, E. C., and J. L. Gaddy. 1982. "The Production of Methane by Anerobic Digestion in Large or Small-Scale Facilities." Progress in Solar Energy. In press.

Kruger, H. J., B. H. Huynh, P. O. Ljungdahl, A. V. Xavier, D. V. DerVartanian, I. Moura, H. D. Peck, Jr., M. Teixeira, J. J. G. Moura, and J. LeGall. "Evidence for Nickel and a Three-Iron Center in the Hydrogenase of Desulfovibrio desulfuricans." J. Biol. Chem. In press.

Speece, R. E. 1983. "Environmental Requirements for Anaerobic Digestion of Biomass in Advances in Solar Energy - An Annual Review of Research and Development." In press.

Speece, R. E., and G. F. Parkin. 1983. "The Response of Methane Bacteria to Toxicity for Proceedings of the Third International Symposium on Anaerobic Digestion," Boston, MA, August 1983. 
Speece, R. E., G. F. Parkin, and D. Gallagher. 1982. "Nickel Stimulation of Anaerobic Digestion in Water Research." Vol. 17, No. 6, pp. 677-683.

Teixeira, M., I. Moura, A. V. Xavier, D. V. DerVartanian, J. LeGall, H. D. Peck, Jr., B. H. Huynh, and J. J. G. Moura. "Desulfovibrio gigas Hydrogenase-Redox Properties of the Nickel and Iron-Sulfur Centers." Eur.J. Biochem. In press.

All contractors and in-house researchers presented papers and talks at the 3rd Annual Solar and Biomass Workshop on April 26-28 in Atlanta, GA.

The manuscript entitled "High Performance Size Exclusion Chromatography (HPSEC) of Low Molecular Weight Lignins and Model Compounds" by Himmel, Oh (Biotechnology Branch), Sopher, and Chum was accepted for publication in the Journal of Chromatography.

The manuscript entitled "Electrochemistry of Biomass-Derived Materials. I. Characterization, Fractionation, and Electrochemical Reduction Reactions of Ethanol-Extracted Explosively-Depressurized Aspen Lignin" by Chum, Ratcliff, Schroeder (Colorado State University), and Sopher has been submitted for publication in the Journal of the American Chemical Society.

The manuscript entitled "Electrochemistry of Lignin Materials and Derived Compounds" by Chum, Sopher, and Schroeder (CSU), has been submitted for publication in the Proceedings of the International Conference on Fundamentals of Thermochemical Biomass Conversion.

Published SERI report entitled Farm and Industrial Scale Biomass Fermentation Studies. Annual Progress Report by E. C. Clausen and J. L. Gaddy. University of Arkansas (SERI/STR-231-1910).

Published SERI report-the proceedings of the December 1982 Program Review held in Golden, CO.

Bachmann, A., K. Baugh, V. Beard, P. J. Colberg, P. L. MeCarty, and L. Young, Heat

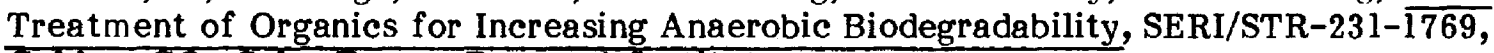
Golden, CO: Solar Energy Research Institute.

Chum, H. L., G. Gross, and C. Wallace, "Materials in Biomass Energy Systems." Submitted to Encyclopedia of Materials Sciences and Engineering, M. Beaver, editor, Pergamon Press.

Chum, H. L., M. Ratcliff, F. L. Posey, J. A. Turner, and A. J. Nozik. "Photoelectrochemistry of Levulinic Acid on Undoped Platinized nTiO 2 Powders." Submitted for publication in the Journal of Physical Chemistry.

Chum, H. L., M. Ratcliff, H. A. Schroeder, and D. W. Sopher. "Characterization, Fractionation, and Electrochemical Reduction Reactions of Ethanol-Extracted ExplosivelyDecompressed Aspen Lignin." Manuscript preparation completed.

Chum, H. L., M. Ratcliff, H. A. Schroeder, and D. W. Sopher, "Electrochemistry of Biomass-Derived Materials. I. Characterization, Fractionation, and Electrochemical Reduction Reactions of Ethanol-Extracted Explosively-Depressurized Aspen Lignin." Submitted to Journal of the Americal Chemical Society. 
Chum, H. L., D. W. Sopher, and H. A. Schroeder, "Electrochemistry of Lignin Materials and Derived Compounds," Proceedings of the International Conference on Fundamentals of Thermochemical Biomass Conversion.

Clausen, E. C., and J. L. Gaddy, 1982. "The Production of Methane by Anerobic Digestion in Large or Small-Scale Facilities." Progress in Solar Energy. In press.

Hashimoto, A. G., 1983, "Commercialization of Anaerobic Digestion in the United States," Third International Symposium on Anaerobic Digestion.

Himmel, M., Oh, D. W. Sopher, and H. L. Chum, "High Performance Size Exclusion Chromatography (HPSEC) of Low Molecular Weight Lignins and Model Compounds," submitted to Journal of Chromatography.

Kruger, H. J., B. H. Huynh, P. O. Ljungdahl, A. V. Xavier, D. V. DerVartanian, I. Moura, H. D. Peck, Jr., M. Teixeira, J. J. G. Moura, and J. LeGall. "Evidence for Nickel and a Three-Iron Center in the Hydrogenase of Desulfovibrio desulfuricans." J. Biol. Chem. In press.

Speece, R. E., 1983, "Environmental Requirements for Anaerobic Digestion of Biomass in Advances in Solar Energy-An Annual Review of Research and Development." In press.

Speece, R. E., and G. F. Parkin, 1983, "The Response of Methane Bacteria to Toxicity," Proceedings of the Third International Symposium on Anaerobic Digestion, Boston, MA, August 1983. In press.

Speece, R. E., G. F. Parkin, and D. Gallagher, 1982, "Nickel Stimulation of Anaerobic Digestion in Water Research," Vol. 17, No. 6, pp. 677-683.

Speece, R. E., and G. F. Parkin, 1983, "The Response of Methane Bacteria to Toxicity," Third International Symposium on Anaerobic Digestion.

Speece, R. E., 1983, "Anaerobic Biotechnology for Industrial Wastewater Treatment," Environmental Science and Technology. In press.

Teixeira, M., I. Moura, A. V. Xavier, D. V. DerVartanian, J. LeGall, H. D. Peck, Jr., B. H. Huynh, and J. J. G. Moura. "Desulfovibrio gigas Hydrogenase-Redox Properties of the Nickel and Iron-Sulfur Centers." Eur. J. Biochem, in press.

\subsection{PHOTO/BIOLOGICAL HYDROGEN PUBLICATIONS}

Eisenmeier, S., H. Spiller, and K. T. Shanmugam. "Enhancement of Hydrogen Production by Fructose in Anabaena variabilis: Differential Effect of $\mathrm{O}_{2}$ and Iron $\mathrm{C}_{2} \mathrm{H}_{2}$ Reduction and $\mathrm{H}_{2}$ Evolution." Env. Microbial. 1982. Submitted for publication.

"5\% Today, 10\% Some Day, at Solar Energy Research Institute." Biotechnology Newswatch. 2(21):7, 1982 .

Greenbaum, E., and J. Ramus. "Survey of Selected Seaweed for Simultaneous Production of Hydrogen and Oxygen." J. of Phycol. 1982. 
Greenbaum, E., R. L. Guillard, and W. G. Sunda. "Hydrogen and Oxygen Photoproduction by Marine Algae." Photchem. and Photobiol. 1982. Submitted for publication.

Greenbaum, E. "Application of Intact Algae to the Biophotolysis Problem." Biotechnol. and Bioeng. 1982 Submitted.

Herlevich, A. "SERI Researchers Propose Bacterial Production Plant." Review IV (4) Aug./Sept. 1982.

Kendall-Tobias, M. "A Horizontally Rotating Light-Beam Chopper." Rev. Sci. Inst. 1982.

Kendall-Tobias, M. "An Automated Langmuir Balance for Measuring Surface Pressures of Monolayers at an Air/Water Interface." 1982. Submitted to the Biophysical Society Meetings.

Odom, J. M., and J. D. Wall. "Photoproduction of Hydrogen from Cellulose by an Anaerobic Bacterial Co-Culture." Appl. and Env. Microbial. 1982. Submitted for publication.

Seibert, M., and M. Kendall-Tobias. "Photoelectrochemical Properties of Electrodes Coated with Photoactive-Membrane Vesicles Isolated from Photosynthetic Bacteria." Biochem. Biophys. Acta. 1982.

Seibert, M., G. Folger, and T. Milne. "Alcohol Co-Production from Tree Crops." Progress in Solar Energy. (K. Haggart and G. Franta, eds.). ASES Press, Boulder, $\overline{\text { CO: }}$ 1982.

Seibert, M., S. Berg, T. Goodman, and L. A. Staehelin. " $\mathrm{O}_{2}-$ Evolving PSII PreparationStructure and Function." Submitted to UCLA Symposium on Molecular and Cellular Biology. 1982.

Seibert, M., and J. Lavorel. "Oxygen-Evolution Patterns from Spinach Photosystem II Preparations." Submitted.

Vobetakis, D. G., H. J. Byker, V. E. Wood, and R. E. Schwenzel. "Alternative PhotoKolbe Reaction Pathway: Photoelectrochemical Production of Formaldehyde from Acetic Acid." J. Amer. Chem. Soc. 1982. Submitted for publication.

Vobetakis, D. G., H. J. Byker, V. E. Wood, and R. E. Schwenzel. "Surface Analysis of Photocorrosion in n-SrTiO 3 Photoanodes." J. of Electrochem. Soc. 1982. Submitted for publication.

Wall, J., and S. Takakuwa. "Hydrogen Production and Nitrogen Fixation in Rhodopseudomonas capsulata Mutant Blocked in Hydrogen Uptake Activity." Proceedings of the Inaugural Symposium of Plant Biochemistry and Physiology. 1982.

Weaver, P. F., and J.S. Schultz. "Light and Dark Production of Hydrogen by Photosynthetic Bacteria." Submitted to American Society for Microbiology for presentation at 1983 meeting.

Eisenmeier, S., H. Spiller, and K. T. Shanmugam. "Enhancement of Hydrogen Production by Fructose in Anabaena variabilis: Differential Effect of $\mathrm{O}_{2}$ and Iron $\mathrm{C}_{2} \mathrm{H}_{2}$ Reduction and $\mathrm{H}_{2}$ Evolution." Submitted for publication in Env. Microbial. 
Greenbaum, E., and J. Ramus. "Survey of Selected Seaweed for Simultaneous Production of Hydrogen and Oxygen." J. of Phycol. Vol. 19, 1982, pp. 53-57.

Greenbaum, E., R. L. Guillard, and W. G. Sunda. "Hydrogen and Oxygen Photoproduction by Marine Algae." Photchem. and Photobiol. 1981. Submitted for publication.

Greenbaum, E. Application of Intact Algae to the Biophotolysis Problem." Biotechnol. and Bioeng. 1982. Submitted for publication.

Kendall-Tobias, M. "A Horizontally Rotating Light-Beam Chopper." Rev. Sci. Inst. 1982. In press.

Odom, J. M., and J. D. Wall. "Photoproduction of Hydrogen from Cellulose by an Anaerobic Bacterial Co-Culture." Appl. and Env. Microbial. Submitted for publication. 1982 .

Olson, J. M., and J. D. Bernstein, 1982. "Solar Production of Hydrogen - A Biological Approach." I\&EC Product Res. and Dev. 21.640.

Roessler, P., and S. Lien. "The Charge Properties of Electron Mediators Affect Their Interaction with Hydrogenase from Chlamydomonas." Submitted for the American Society of Plant Physiological Meeting.

Seibert, M., and M. Kendall-Tobias. "Photoelectrochemical Properties of Electrodes Coated with Photoactive-Membrane Vesicles Isolated from Photosynthetic Bacteria." Biochem. Biophys. Acta. 1982.

Seibert, M., G. Folger, and T. Milne. "Alcohol Co-Production from Tree Crops." Progress in Solar Energy. (K. Haggart and G. Franta, eds.). ASES Press, Boulder, CO: 1982. Submitted.

Seibert, M., and J. Lavorel. "Oxygen-Evolution Patterns from Spinach Photosystem $\Pi$ Preparations." Biochem. Biophys. Acta. 1983. Accepted for publication with no changes.

Seibert, M. "Survey of Photobiological $\mathrm{H}_{2}$ Production." Written for the Program Office at the request of Dr. B. Berger.

Takakuwa, S., J. M. Odom, and J. D. Wall. "Hydrogen Uptake-Defficient Mutants of Rhodopsuedomonas capsulata." Submitted to Archives for Microbiology.

Vobetakis, D. G., H. J. Byker, V. E. Wood, and R. E. Schwenzel. "Alternative PhotoKolbe Reaction Pathway: Photoelectrochemical Production of Formaldehyde from Acetic Acid." J. Amer. Chem. Soc. 1982. Submitted for publication.

Wall, J., and S. Takakuwa. "Hydrogen Production and Nitrogen Fixation in Rhodopseudomonas capsulata Mutant Blocked in Hydrogen Uptake Activity." Proceedings of the Inaugural Symposium of Plant Biochemistry and Physiology. 1982.

Weaver, P. F., and J.S. Schultz. "Light and Dark Production of Hydrogen by Photosynthetic Bacteria." Submitted to American Society for Microbiology for presentation at 1983 meeting. 
Donahay, T. G., L. A. Staehelin, M. Seibert, P. D. Ogilvia, and S. P. Berg. "Structural, Biochemical, and Biophysical Characterization of Four $\mathrm{O}_{2}$-Evolving Photosystem II Preparations from Spinach." Submitted to Biochem. Biophy. Acta.

Eisenmeier, S., H. Spiller, and K. T. Shanmugam. 1982. "Enhancement of Hydrogen Production by Fructose in Anabaena variabilis: Differential Effect of $\mathrm{O}_{2}$ and Iron $\mathrm{C}_{2} \mathrm{H}_{2}$ Reduction and $\mathrm{H}_{2}$ Evolution." Submitted to Env. Microbial.

Greenbaum, E., and J. Ramus. 1983. "Survey of Selected Seaweed for Simultaneous Production of Hydrogen and Oxygen," J. of Phycol, Vol. 19, pp. 53-57.

Greenbaum, E., R. L. Guillard, and W. G. Sunda. 1982. "Hydrogen and Oxygen Photoproduction by Marine Algae." Submitted for publication in Photochem. and Photobiol.

Greenbaum, E. 1982. "Application of Intact Algae to the Biophotolysis Problem." Submitted for publication in Biotechnol. and Bioeng.

Kendall-Tobias, M. 1982. "A Horizontally Rotating Light-Beam Chopper." 1982. Rev. Sci. Inst. In press.

Odom, J. M., and J. D. Wall. 1982. "Photoproduction of Hydrogen from Cellulose by an Anaerobic Bacterial Co-Culture." Submitted for publication in Appl. and Env. Microbial.

Odom, J. M., and J. D. Wall. "Influence of Culture Conditions on Photoproduction of $\mathrm{H}_{2}$ by Rhodopseudomonas capsulata." Submitted for publication. Photo/Biological Hydrogen Program Principal Investigators Review. 1983 (May 20). Golden, CO. Submitted for printing.

Seibert, M., S. P. Berg, T. Goodman, and L. A. Staehelin. 1983. "O ${ }_{2}$-Evolving PS II Preparations - Structure and Function." J. Cell. Biochem. Vol. 7B, p. 326.

Seibert, M., G. Folger, and T. Milne, 1982. "Alcohol Co-Production from Tree Crops." Progress in Solar Energy. (K. Haggart and G. Franta, eds.). Boulder, CO: ASES Press. Submitted for publication.

Seibert, M., and M. Kendall-Tobias. 1982. "Photoelectrochemical Properties of Electrodes Coated with Photoactive-Membrane Vesicles Isolated from Photosynthetic Bacteria." Biochem. Biophys. Acta. In press.

Seibert, M., and J. Lavorel. 1983. "Oxygen-Evolution Patterns from Spinach Photosystem II Preparations." Biochem. Biophys. Acta. Accepted for publication with no changes.

Takakuwa, S., J. M. Odom, and J. D. Wall, "Hydrogen Uptake-Deficient Mutants of Rhodopsuedomonas capsulata." Submitted to Archives for Microbiology.

Vobetakis, D. G., H. J. Byker, V. E. Wood, and R. E. Schwenzel, 1982, "Alternative Photo-Kolbe Reaction Pathway: Photoelectrochemical Production of Formaldehyde from Acetic Acid." Submitted to J. Amer. Chem. Soc.

Donahay, T. G., L. A. Staehelin, M. Seibert, P. D. Ogilvia, and S. P. Berg. "Structural, Biochemical, and Biophysical Characterization of Four $\mathrm{O}_{2}$-Evolving Photosystem II Preparations from Spinach." Submitted to Biochem. Biophy. Acta. 
Eisenmeier, S., H. Spiller, and K. T. Shanmugam. 1982. "Enhancement of Hydrogen Production by Fructose in Anabaena variabilis: Differential Effect of $\mathrm{O}_{2}$ and Iron $\mathrm{C}_{2} \mathrm{H}_{2}$ Reduction and $\mathrm{H}_{2}$ Evolution." Submitted to Env. Microbial.

Greenbaum, E., and J. Ramus, 1983, "Survey of Selected Seaweed for Simultaneous Production of Hydrogen and Oxygen," J. of Phycol, Vol. 19, pp. 53-57.

Kendall-Tobias, M., 1982. "A Horizontally Rotating Light-Beam Chopper," Rev. Sci. Inst. In press.

Lavorel, J., M. Seibert, B. Maison-Peteri, and J. -M. Briantais, 1983, "Evaluations of the Plastoquinone Pool Size in $\mathrm{O}_{2}$-Evolving Photosystem II Preparations," Proceedings of the Sixth International Congress on Photosynthesis. In press.

Lien, S., 1983, "Biophotolysis of Water: The Light Saturation Curves." Submitted to Photochemistry and Photobiology.

Seibert, M., G. Folger, and T. Milne, 1982, "Alcohol Co-Production from Tree Crops." Submitted to Progress in Solar Energy.

Seibert, M., and J. Lavorel, 1983, "Oxygen-Evolution Patterns from Spinach Photosystem II Preparations," Biochem. Biophys. Acta. In press.

Seibert, M. and J. Connolly, "Fluorescence Properties of C-Phycocyanin Isolated from a Thermophilic Cyanobacterium." Submitted to Photochem. Photobiol.

Seibert, M., S. P. Berg, P. D. Ogilvie, T. G. Dunahay, and L. A. Staehelin, 1983, "Detergent-Extracted $\mathrm{O}_{2}$-Evolving Photosystem II Preparations Are Appressed Membranes," Proceedings of the Sixth International Congress on Photosynthesis. In press.

Takakuwa, S., J. M. Odom, and J. D. Wall, "Hydrogen Uptake-Deficient Mutants of Rhodopsuedomonas capsulata." Submitted to Archives for Microbiology.

Vobetakis, D. G., H. J. Byker, V. E. Wood, and R. E. Schwenzel, 1982, "Alternative Photo-Kolbe Reaction Pathway: Photoelectrochemical Production of Formaldehyde from Acetic Acid." Submitted to J. Amer. Chem. Soc. 


\section{SECTION 6.0}

\section{MEETTNGS AND PRESENTATTONS}

This section lists all meetings attended or planned during the period covered by this report.

\subsection{AQUATIC SPECIES PROGRAM}

"Short Course on Laboratory Procedures for Lipid Fractionation and Identification." Conducted by T. Tornabene, December 13-17, 1983, at the Georgia Institute of Technology.

Joint USA-China Biomass Conversion Technologies Symposium, Chendu, People's Republic of China, November 26-30, 1982. L. Raymond presented paper, "Aquatic Biomass: A Source of Fuels and Chemicals."

A paper, "Climate Impact on the Siting of Biomass Production Facilities," by E. Maxwell, G. Folger, and V. Szwarc was presented at the session on Climatic Aspects of Renewable Energy Alternatives of the Conference on Climate/Energy Interactions at the 63rd Annual Meeting of the American Meteorological Society, 10-13 January 1983, New Orleans, LA.

The Aquatic Species Program Principal Investigators Meeting was held in San Diego on 9-10 March. Fourteen papers were presented covering both SERI and subcontracted research.

Two papers, "Optimizing Multi-Product Conversion Processes for Commercial Use: A Case of Microalgae Production" by Andrew Hill and Bernie Neenan and "Microalgae from Desert Saline Waters as Potential Biomass Producers" by William Thomas and Don Seibert, were presented at the 1983 ASES meetings in Minneapolis in June.

K. Spencer presented a paper entitled "Utilization of Stored Oil in a Strain of Chlorella at the annual meeting of the American Society of Plant Physiologists, in Fort Collins, CO, 11 August 1983.

\subsection{ANAEROBIC DIGESTION PROGRAM}

DOE Contract Review for Dynatech, Biorefining of Industrial Wastes to Liquid Fuels and Chemicals, Boston, Mass., December 8, 1982. R. Corder attended as reviewer.

Joint USA-China Biomass Conversion Technologies Symposium, Chendu, People's Republic of China, November 26-30, 1982. A. G. Hashimoto presented paper, "Biogas Production: Large-Scale, Conventional Technology."

SERI-Sponsored Workshop, Fundamentals of Thermochemical Biomass Conversion: An International Conference, Estes Park, October 18-22, 1982. M. Lowenstein attended. H. L. Chum presented paper, "Electrochemistry of Lignin Materials and Derived Compounds." 
Southeastern Magnetic Resonance Conference, Atlanta, GA, October 1982. LeGall attended.

U.S. EPA-sponsored conference, Research Needs in Anaerobic Digestion, St. Louis, MO, October 1-2, 1982. R. E. Speece presented paper, "Nutrient Requirements in Anaerobic Digestion." R. Corder attended.

Virginia Polytechnic Institute and State University, Blacksburg, VA, December 1982. H. L. Chum presented paper, "Electrochemistry Applied to Biomass."

Presentation: "Kinetic Improvements in the Biological Production of Methane from Cellulosic Residues," presented at the IGT Energy from Biomass and Wastes VII Symposium, Lake Buena Vista, FL, January 1983, by E. C. Clausen and J. L. Gaddy.

Presentation: "Conversion of Straw-Manure Mixtures to Methane," American Society of Agricultural Engineers, Winter Meeting, Chicago, IL. 16 December 1982 by A. G. Hashimoto.

H. Chum attended the American Chemical Society Meeting, Seattle, WA. In addition to attending scientific sessions in the Chemistry of Solid Wood and Lignin session, Chum visited Prof. Sarkanen's laboratory. Important contacts with forest products and pulp and paper scientists and engineers were made.

Chum's travel to attend and present results of our lignin work at the 5th EUCHEM Conference on Organic and Organometallic Electrochemistry was approved (Ireland). Chum will also visit Dr. Utley's laboratories in London.

Dr. D. Dimmel from the Institute of Paper Chemistry, Appleton, Wisconsin visited us. We discussed our work and heard about his work in pulping reactions. We plan to do some cooperative research. Dr. Dimmel was requested by the IPC library to have copies of SERI's work (in-house and subcontracted), such as SERI reports and meetings news, sent to them, or to be put on SERI's mailing list for the Biomass and Alcohol programs so that this work can be abstracted by their excellent abstracts service.

R. Corder attended the annual ASM meeting in New Orleans on 7-9 March.

All anaerobic digestion contracts and in-house researchers presented talks at the SAEC/USDA Solar and Biomass Workshop in Atlanta, GA, April 26-28, 1983.

H. Chum attended the American Chemical Society Meeting, Seattle, WA. In addition to attending scientific sessions in the Chemistry of Solid Wood and Lignin, Chum visisted Prof. Sarkanen's laboratory. Important contacts with forest products and pulp and paper scientists and engineers were made.

Chum presented SERI's lignin results at the 5 th EUCHEM conference on Organic and Organometallic Electrochemistry in Ireland. It was very interesting to notice that the Biomass Electrochemistry field SERI started in 1979 is now attracting the interest of a large number of European investigators and governments. Great Britain, Germany and Denmark are examples of governments who are now sponsoring biomass electrochemistry research with an emphasis on lignin electrochemistry.

"The Response of Methane Bacteria to Toxicity," was presented by R. E. Speece and G. F. Parkin at the Third International Symposium on Anaerobic Digestion, 1983. 
"Commercialization of Anaerobic Digestion in the United States," was presented by A. G. Hashimoto at the Third International Symposium on Anaerobic Digestion, 1983.

Three subcontractors and the project coordinator attended the Third International Symposium on Anaerobic Digestion in Boston, MA, 14-19 August 1983.

\subsection{PHOTO/BIOLOGICAL HYDROGEN PROGRAM}

American Society for Mechanical Engineers, Phoenix, November 1982. Lindsey presented paper, "Preliminary Evaluation of PSB Hydrogen Production Systems."

5 th Miami International Conference on Alternate Energy Sources, Miami, FL, December 1982. Greenbaum chaired session entitled "Hydrogen Energy."

GRI Workshop: Production of Gaseous Fuels from Abundant Inorganic Resources, Chicago, October 1982. Greenbaum presented paper, "Simultaneous Photoproduction of Hydrogen and Oxygen in Algae."

Institute for Food and Agricultural Science, University of Florida, Gainesville, November 23, 1982. M. Seibert presented paper, "Oxygen-Evolution from PSII Preparations of Spinach."

Laboratoire du Photosynthese, CNRS, Gif-sur-Yvette, France, November 1982. M. Seibert presented paper, "Oxygen-Evolution Patterns from Spinach PSII Preparations."

Gordon Conference: Physiochemical Aspects of Photosynthesis, Ventura, CA, February 1983. Lindsey attended. Connolly chaired sessions. Seibert presented poster entitled "Comparative Analysis and Evaluation of Four $\mathrm{O}_{2}$-Evolving PS II Preparations."

Biophysical Society, San Diego, CA, February 1983. Kendall presented poster entitled "An Automated Langmuir Balance for Measurement of Surface Pressures of Monolayers at a Liquid/Air Interface.

Department of Botany, Louisiana State University, February 1983. Lien presented invited talk entitled "Isolation and Biochemical Properties of the Hydrogenase from $\underline{\mathrm{C}}$. reinhardtii."

American Society for Microbiology, New Orleans, LA, March 1983. Weaver presented talk entitled "Light and Dark Production of $\mathrm{H}_{2}$ in Photosynthetic Bacteria."

Department of Chemical Engineering, Colorado School of Mines, Golden, CO, March 1983. Lindsey presented invited talk entitled "Solar Hydrogen Biotechnologies."

Department of Biophysics and Physiology, University of Illinois, March 1983. Seibert presented talk entitled "Structural, Biochemical, and Biophysical Properties of $\mathrm{O}_{2}-$ Evolving Photosystem II Preparations from Spinach."

Lindsey attended Molecular Biology of Photosynthetic Bacteria, Madison, WI, June-July 1983. 
Seibert presented poster entitled "O- ${ }_{2}$ Evolving PS II Preparations - Structure and Function" at the UCLA Symposium on Biosynthesis of the Photosynthetic Apparatus, April 1983.

Wall presented four posters entitled "An Ultraviolet Irradiation Sensitive Mutant of Rhodopseudomonas capsulata with Possible Defects in Recombination," "Physical Analysis of Mutants in a Gene Essential for $\mathrm{H}_{2}$ Uptake by Rhodopseudomonas capsulata," "Spontaneous $\mathrm{Nif}^{-}$Mutants of Rhodopseudomonas capsulata," and "Ammonium Transport in Rhodopseudomonas capsulata" at the Molecular Biology of Photosynthetic Bacteria meeting, Madison, WI, June-July 1983.

S. Lien presented a paper entitled "Hydrogen Production by Chlamydomonas reinhardtii," at the conference on the Genetics and Molecular Biology of Chlamydomonas, at Cold Spring Harbor Laboratory, Cold Spring Harbor, NY, 26-30 June 1983. 


\begin{tabular}{|c|c|c|c|}
\hline $\begin{array}{l}\text { Document Control } \\
\text { Page }\end{array}$ & $\begin{array}{l}\text { 1. SERI Report No. } \\
\text { SFRI/TR-237-2759 }\end{array}$ & 2. NTIS Accession No. & 3. Recipient's Accession $\mathrm{N}_{\mathrm{C}}$. \\
\hline \multirow{2}{*}{\multicolumn{3}{|c|}{$\begin{array}{l}\text { 4. Title and Subtitie } \\
\text { SERI Biomass Proaram FY } 1983 \text { Annua T Report }\end{array}$}} & $\begin{array}{l}\text { 5. Publication Date } \\
\text { February } 1984\end{array}$ \\
\hline & & & 6. \\
\hline \multicolumn{3}{|c|}{$\begin{array}{l}\text { 7. Author(s) Biomass Program Office } \\
\text { (R. Corder, H. Lindsey, R. McIntosh) }\end{array}$} & 8. Performing Organization Rept. No. \\
\hline \multirow{2}{*}{\multicolumn{3}{|c|}{$\begin{array}{l}\text { 9. Performing Organization Name and Address } \\
\text { Solar Enerqy Research Institute } \\
1617 \text { Cole Boulevard } \\
\text { Golden, Colorado } 80401\end{array}$}} & \multirow{2}{*}{$\begin{array}{l}\text { 10. Project/Task/Work Unit No. } \\
1357.01 \\
11 \text {. Contract (C) or Grant (G) No. } \\
\text { (C) } \\
\text { (G) }\end{array}$} \\
\hline & & & \\
\hline \multirow{2}{*}{\multicolumn{3}{|c|}{ 12. Sponsoring Organization Name and Address }} & $\begin{array}{l}\text { 13. Type of Report \& Period Covered } \\
\text { Technical Report }\end{array}$ \\
\hline & & & 14. \\
\hline \multicolumn{4}{|l|}{ 15. Supplementary Notes } \\
\hline \multicolumn{4}{|c|}{$\begin{array}{l}\text { 16. Abstract (Limit: } 200 \text { words) Most products derived from petroleum and natural gas can be pro- } \\
\text { duced directly from biomass. The "biomass" with which this report is concerned in- } \\
\text { cludes aquatic plants, which can be converted into liquid fuels; organic wastes } \\
\text { (crop residues as well as animal and municipal wastes), from which biogas can be } \\
\text { produced via anaerobic digestion; and organic or inorganic waste streams, from which } \\
\text { hydrogen can be produced by photobiological processes. The challenge is to develop } \\
\text { technologies that will enable the production of fuels using nonrenewable resources } \\
\text { that will be competitive with existing processes. The Biomass Program office sup- } \\
\text { ports research in three areas which, although distinct, all use living organisms to } \\
\text { create the desired products. The Aquatic Species Program (ASP) sponsors research } \\
\text { on organisms that are themselves processed into the final products, while the } \\
\text { Anaerobic Digestion (ADP) and Photo/Biological Hydrogen Program (P/BHP) deal with. } \\
\text { organisms that transform waste streams into energy products. The P/BHP also sup- } \\
\text { ports investigation of systems using water as a feedstock and cell-free systems } \\
\text { that do not utilize living organisms. }\end{array}$} \\
\hline \multirow{2}{*}{\multicolumn{4}{|c|}{$\begin{array}{l}\text { 17. Document Analysis } \\
\text { a. Descriptors Agricultural Wastes ; Algae ; Anaerobic Digestion ; Bacteria ; Biomass ; } \\
\text { Electrochemistry ; Fermentation : Lipids ; Microorganisms ; Photosynthesis ; } \\
\text { Plants : Unicellular Algae } \\
\text { b. Identifiers/Open-Ended Terms }\end{array}$}} \\
\hline & & & \\
\hline \multicolumn{3}{|l|}{ 18. Availability Statement } & 19. No. of Pages \\
\hline \multirow{2}{*}{\multicolumn{3}{|c|}{$\begin{array}{l}\text { National Technical Information Service } \\
\text { U.S. Department of Commerce } \\
5285 \text { Port Royal Road } \\
\text { Sprinafield, Virainia } 22161\end{array}$}} & \\
\hline & & & $\begin{array}{r}\text { 20. Price } \\
\text { A06 }\end{array}$ \\
\hline
\end{tabular}

Form No. 0059 (3-25-82) 